\title{
Progress in Heliostat Development
}

Andreas Pfahl ${ }^{1}$, Joe Coventry ${ }^{2}$, Marc Röger ${ }^{3}$, Fabian Wolfertstetter ${ }^{3}$, Juan Felipe Vásquez-Arango ${ }^{1}$, Fabian Gross ${ }^{1}$, Maziar Arjomandi ${ }^{4}$, Peter Schwarzbözzl ${ }^{5}$, Mark Geiger ${ }^{1}$, Phillip Liedke ${ }^{1}$

${ }^{1}$ German Aerospace Center (DLR), Institute of Solar Research, Pfaffenwaldring 38-40, 70569 Stuttgart, Germany,

Phone: +49-7116862479, Fax: +49-7116862322,

E-mail: Andreas.Pfahl@dlr.de, Fabian.Gross@dlr.de, Mark.Geiger@dlr.de,Phillip.Liedke@dlr.de

${ }^{2}$ The Australian National University, Research School of Engineering, Building 35A, Canberra ACT 2601, Australia, E-mail: joe.coventry@anu.edu.au

${ }^{3}$ German Aerospace Center (DLR), Institute of Solar Research, Plataforma Solar de Almería, 04200 Tabernas, Spain, E-mail: marc.roeger@dlr.de, fabian.wolfertstetter@dlr.de

${ }^{4}$ The University of Adelaide, School of Mechanical Engineering, Adelaide SA 5005, Australia,

E-mail: maziar.arjomandi@adelaide.edu.au

${ }^{5}$ German Aerospace Center (DLR), Institute of Solar Research, Porz-Wahnheide, Linder Hoehe, 51147 Cologne, Germany, E-mail: Peter.Schwarzboezl@dlr.de

Available online at http://dx.doi.org/10.1016/j.solener.2017.03.029 0038-092X/@2017 Elsevier Ltd. All rights reserved.

(c) 2017. This manuscript version is made available under the CC-BY-NC-ND 4.0 license http://creativecommons.org/licenses/by-nc-nd/4.0/ .

\begin{abstract}
Strong efforts are being made to drive heliostat cost down. These efforts are summarised to give an update on heliostat technology comprising: determination of wind loads, heliostat dimensioning, solutions for the different sub-functions of a heliostat, a review of commercially available and prototype heliostat designs, canting, manufacturing, qualification, heliostat field layout, and mirror cleaning. There is evidence that commercial heliostat costs have dropped significantly in the past few years, with commercial suppliers of heliostat technologies now claiming heliostat field costs around $100 \mathrm{USD} / \mathrm{m}^{2}$. With new approaches even target cost of $75 \$ / \mathrm{m}^{2}$ seem to be realistic.
\end{abstract}

Keywords: heliostat, power tower, central receiver, control, wind load, qualification, cleaning, cost

\section{Introduction}

\subsection{Solar tower plants}

Concentrated solar thermal (CST) energy is a promising renewable energy technology capable of large scale electricity production and industrial process heating, usually incorporating energy storage. In a solar tower plant, moving mirrors called 'heliostats' track the sun in two axes and reflect the sun's rays onto a 'receiver' at the top of a tower (Fig. 1). The receiver absorbs the radiation and supplies thermal energy via a working fluid at a temperature of typically $300-700^{\circ} \mathrm{C}$. For power towers incorporating energy storage, the working fluid is also a heat storage medium (e.g. molten salt), and is stored in tanks to allow power generation upon demand. Alternatively, the energy received by the solar tower plant may be used for providing heat to a thermochemical process, such as the production of synthetic transport fuels. 

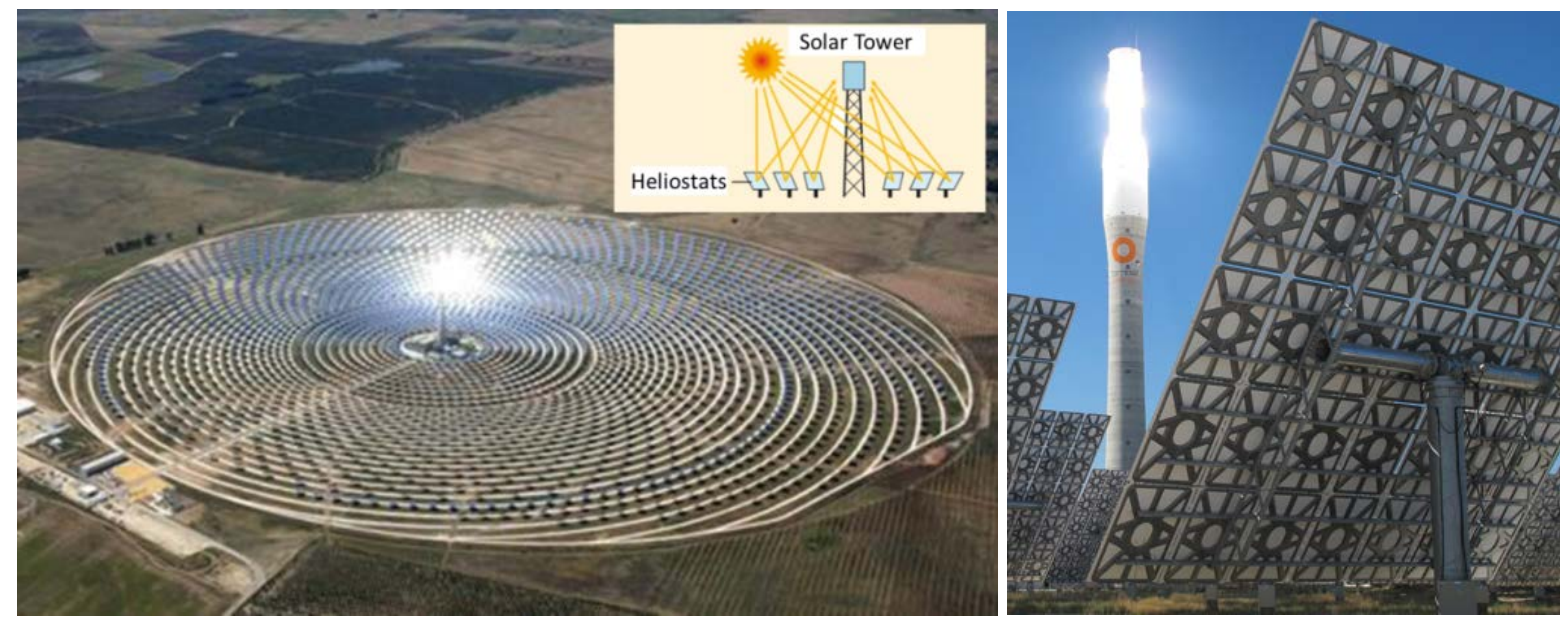

Fig. 1: First commercial power tower with storage using molten salt (Torresol Energy, 2017), (schematic by DLR)

A photovoltaic (PV) power plant currently provides electrical energy at a lower cost than a concentrating Solar Power (CSP) plant; however, storage of electrical energy is in general more expensive than storage of thermal energy. Therefore, $\mathrm{PV}$ plants are more suitable for power supply during sun hours and CSP plants during the night and in cloudy conditions. A combination of both PV and CSP is seen as a promising solution for future power supply: "The cost of solar technologies are falling so quickly that within a few years the combination of solar PV and solar towers with storage will be able to compete directly with base load fossil fuels" (Padmanathan, 2015). An important advantage of CSP compared with PV is that during construction a high fraction of labour and equipment is sourced locally, which is especially attractive for developing countries.

Examples of industrial processes that could be driven by solar tower plants are cement production (Gonzáles and Flamant, 2014) and enhanced oil recovery (CSP today, 2013b). Solar tower systems can also supply heat to thermal processes at $550^{\circ} \mathrm{C}$ or below, although $500^{\circ} \mathrm{C}$ have been achieved by some small trough demonstration projects as well. Many industrial processes are designed for higher working temperatures, which are provided by fossil fuel burners. To incorporate solar input it is sufficient to replace only the burner with a solar receiver and the rest of the plant stays almost unchanged. With further reduction of the cost of concentrated solar systems, applications for solar thermal industrial processes will become economically viable.

The heliostats represent $40-50 \%$ of the cost of a power tower plant, so they must be relatively low cost for the cost of energy from the plant to be competitive with that of fossil fuels (Mancini et al., 2000). It was shown by Gary et al. (2011) that to achieve a levelised cost of electricity (LCOE) of $0.10 \mathrm{USD} / \mathrm{kWh}$ the heliostats must cost no more than 120 $\mathrm{USD} / \mathrm{m}^{2}$. The heliostats must cost about $75 \mathrm{USD} / \mathrm{m}^{2}$ if the target LCOE is $0.06 \mathrm{USD} / \mathrm{kWh}$ (Gary et al., 2011). To achieve these targets, innovative designs and solutions regarding the complete heliostat concept and its components, are needed. Furthermore, the dimensions of heliostats must be selected to minimise manufacturing and installation costs. This requires accurate estimation of the wind loading on both operating and parked heliostats to allow structurally efficient heliostat designs to be developed with good optical performance characteristics, while avoiding structural failure. 


\subsection{Previous heliostat reviews}

Mancini et al. (2000) collected data from eight different commercial heliostats that were available on the market. They presented a general description of heliostats and their cost structure based on the information provided by the manufacturers of the heliostats.

In July 2006, a two-day workshop was held at the National Solar Thermal Test Facility (NSTTF) in Albuquerque, New Mexico, to discuss heliostat technology and to identify solutions for technology improvement. Approximately 30 heliostat experts and manufacturing companies from the United States, Europe, and Australia participated in this workshop. After the workshop a team of six experts developed a price estimate for current heliostats and evaluated the price-reduction potential solutions for the future heliostats. The results of this study were published in a SANDIA report (Kolb et al., 2007).

Pfahl (2014) presented an overview of 48 approaches for heliostat cost reduction in a tabular form and discussed their main advantages and disadvantages, giving example reference cases. The review was intended to serve as a base for the development of new low-cost heliostat concepts.

One of the objectives of the European project STAGE-STE is the development of a low cost heliostat. At the commencement of the program, the state-of-the-art of heliostat technology and the specifications were discussed and published (Téllez et al., 2014). The report presents potential solutions for cost reduction consistent with the required functional specifications, and a review of heliostat deployment worldwide.

Similarly, the Australian Solar Thermal Research Initiative (ASTRI) carried out a Heliostat Cost Down Scoping Study (Coventry et al., 2016; Coventry and Pye, 2013) as a first step in a heliostat cost-reduction project.

In the following sections, the current level of knowledge in heliostat technology about different aspects of heliostat design and manufacturing will be discussed. This review paper is arranged according to the following topics:

1. Static and dynamic wind loads

2. Heliostat dimensioning

3. Heliostat components

4. Heliostat designs

5. Canting

6. Manufacturing and assembly

7. Qualification

8. Heliostat field layout

9. Mirror cleaning

10. Cost

\section{Wind loads}

\subsection{Relevant wind properties}

Heliostats are exposed to the atmospheric conditions prevailing on the field. They experience aerodynamic forces caused by wind that can lead to a mechanical failure if they are not 
accounted for in the design. At extreme wind speeds, the loads can lead to a failure by exceeding the maximum stress that the heliostat structure is designed to sustain. In addition, fluctuating wind forces may result in fatigue failure due to flow-structure interaction and resonance.

Emes et al. (2015) showed that there is a strong dependence between the cost of the heliostat field and the design wind speed. For example, they showed that lowering the design wind speed by $9 \mathrm{~m} / \mathrm{s}$ from the maximum $22 \mathrm{~m} / \mathrm{s}$ measured wind speed at Alice Springs in Australia yields a $0.3 \%$ lower capacity factor for the solar tower power plant but it reduced the LCOE by $18 \%$. In addition they showed that with an increase in the average wind speed the heliostat size preferably should be decreased.

To determine the mean and peak loads, normalised load coefficients that depend on the shape and orientation of the heliostat structure are used. These coefficients are determined experimentally using simplified models of the heliostats at scales between 1:20 and 1:40 in wind tunnels (see Fig. 2) that reproduce the wind conditions in the lower part of the atmosphere called the "atmospheric boundary layer" (ABL). Peterka et al. (1989) presented the first set of the load coefficients for the determination of the mean and peak wind loads on heliostats.
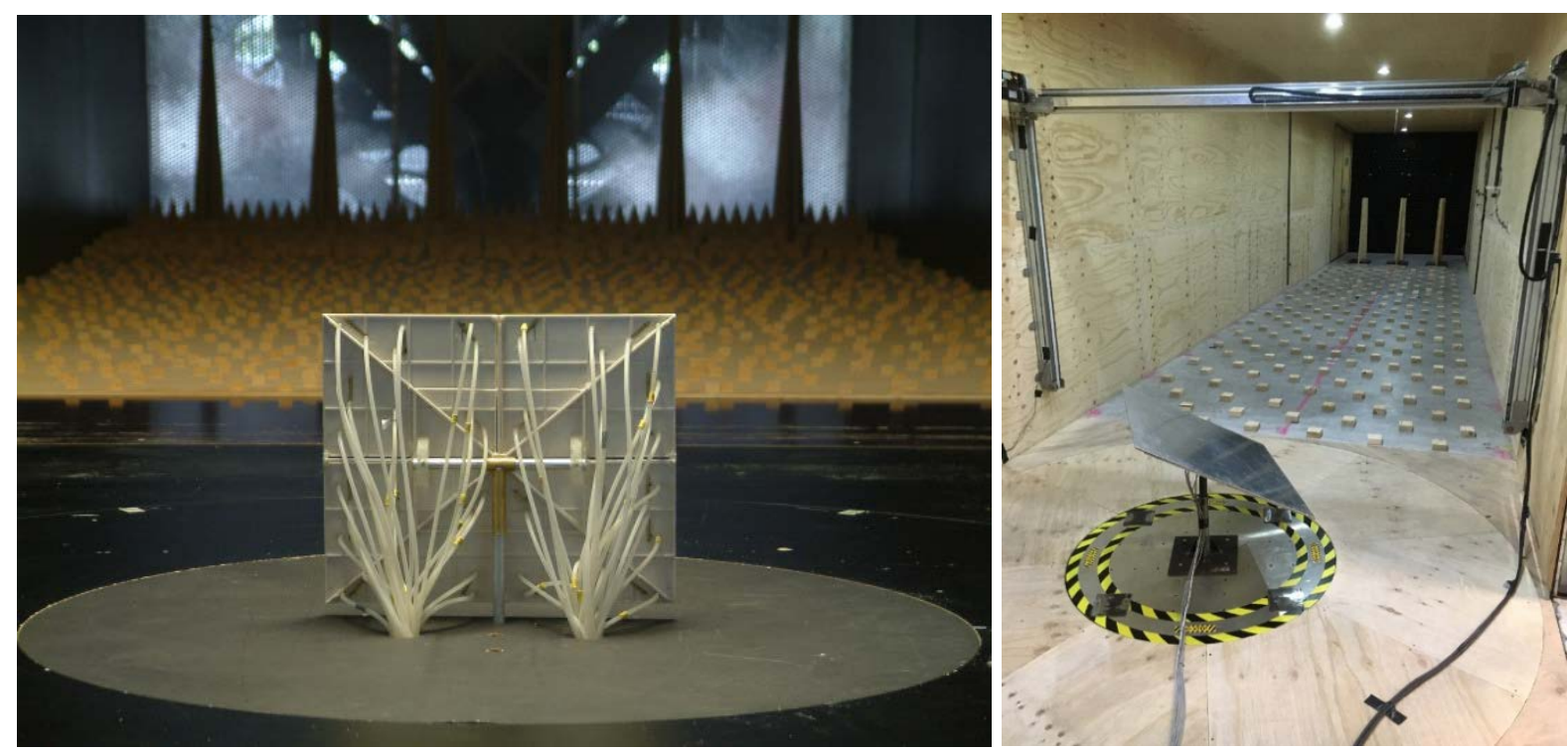

Fig. 2: Boundary layer wind tunnel. Left: Wacker Engineers; Right: The University of Adelaide

The wind conditions in the $A B L$ depend strongly on the terrain features surrounding the heliostat field. In order to determine the peak and dynamic loads accurately, the local wind conditions must be characterised. The main characteristics of the wind are described by the profile of the mean velocity and turbulence intensity, the probability distribution function (PDF) of the wind speed and direction, and the power spectral distribution (PSD) of the velocity fluctuations. The following figures showcase the main statistical quantities mentioned above to describe the wind conditions for a representative solar site located at the Plataforma Solar de Almeria (PSA) in southern Spain. To evaluate the wind speed and the prevailing wind directions at a specific site, the PDF and the wind rose are determined. These properties are shown in Fig. 3 from the wind data collected over an entire year. It can be observed that the PDF of the wind speed follows a Weibull distribution and that the majority of the values are below $10 \mathrm{~m} / \mathrm{s}$, which is the typical maximum threshold for the operation of heliostats. 

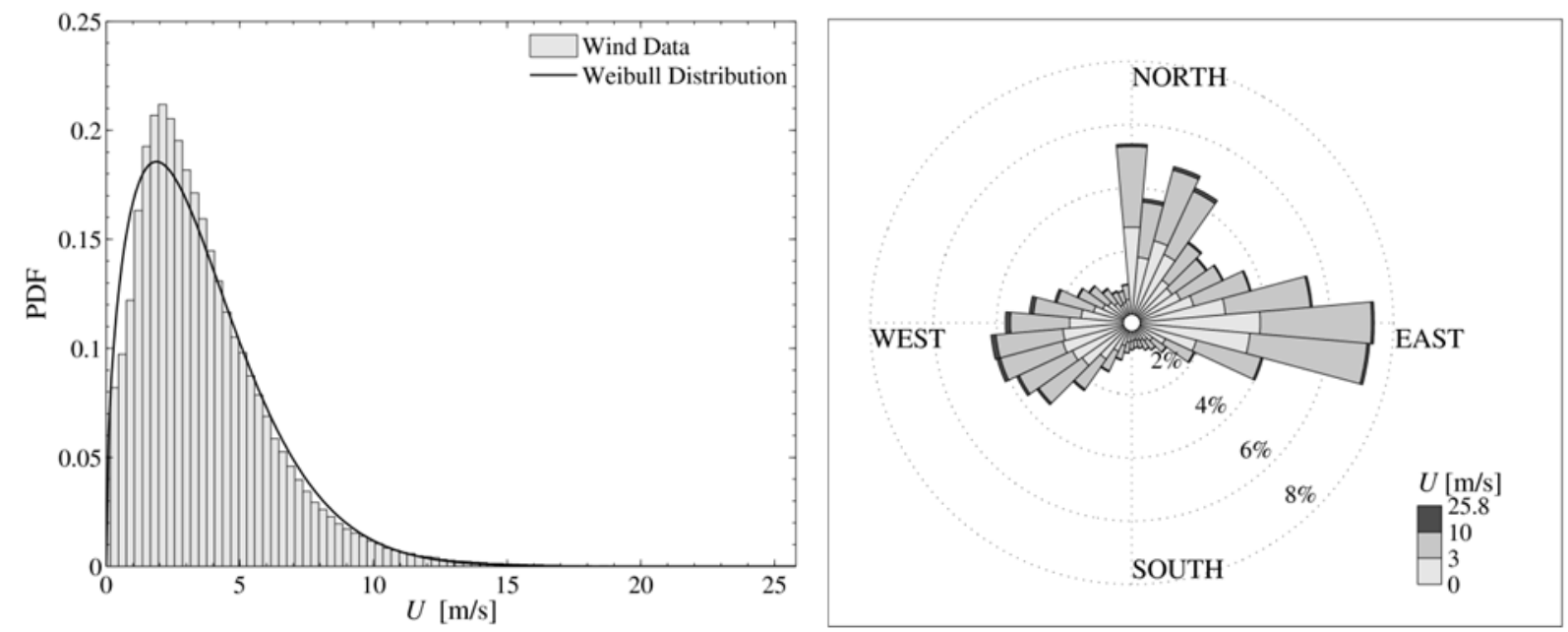

Fig. 3: Probability density function (left) and wind rose (right) (Vásquez-Arango, 2016)

In addition to the wind PDF and its prevailing direction, the wind vertical velocity distribution (velocity profile from ground level upward) and its turbulence intensity also need to be determined. Turbulence intensity relates the standard deviation of the velocity to its mean value and, since the velocity fluctuations are Gaussian, it can be used to estimate the peak wind velocity. For a given terrain, i.e. surface roughness, these values can be obtained from a logarithmic law as shown in Fig. 4. The surface roughness is obtained by fitting the log-law to experimental data for mean wind speed $U$ at different heights $z$ (see Fig. 4 left), and is then the only parameter required to compute the profile of the turbulence intensity $I_{u \text {. The }}$ calculated turbulence intensity profile is compared to a measured value, $4.5 \mathrm{~m}$ above the ground, in Fig. 4 right.
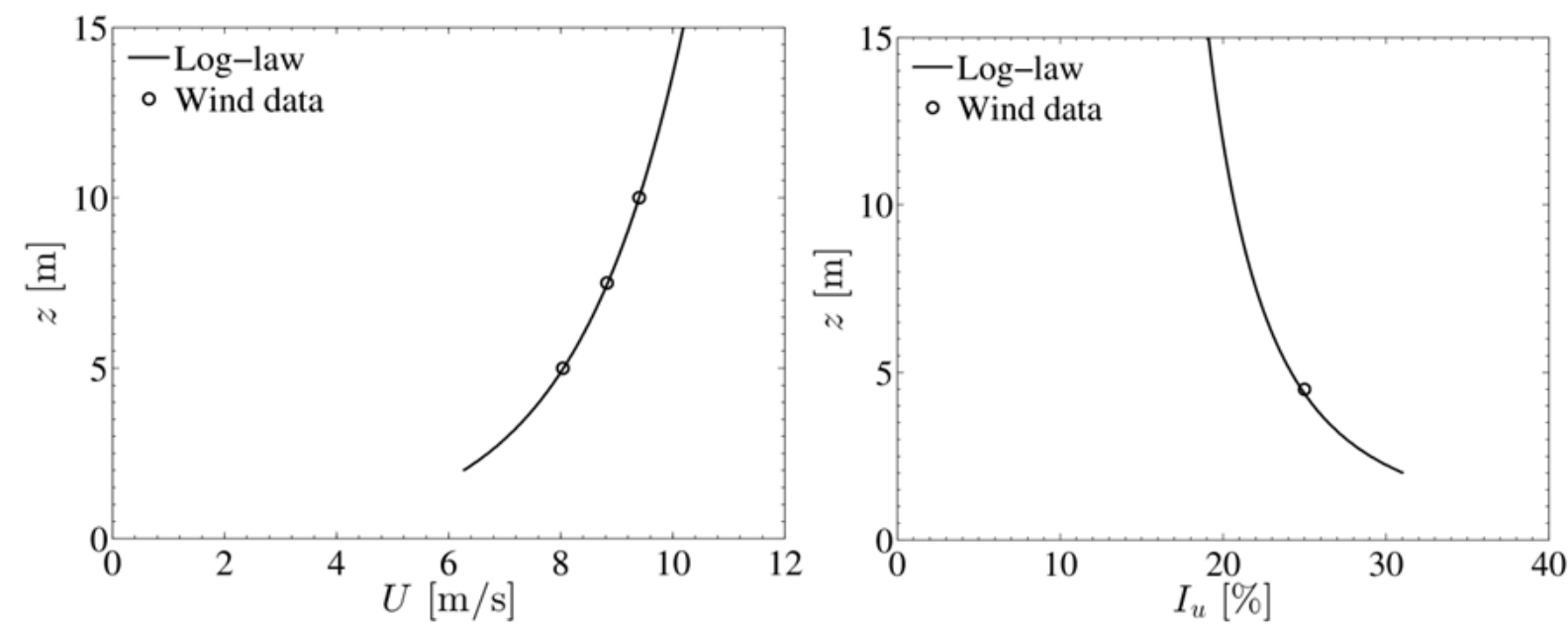

Fig. 4: Profiles of mean velocity (left) and turbulence intensity (right) (Vásquez-Arango, 2016)

Turbulence in the $A B L$ comprises velocity fluctuations at different frequencies and amplitudes. They can be viewed as a superposition of eddies of different sizes and frequencies. The contribution of the different turbulence scales to the total variance of the velocity signals is given by the power spectral density (PSD). The spectral distribution of the velocity fluctuations is important to identify resonance effects with the structure that can arise from pressure fluctuations induced by turbulence with frequencies close to the natural frequencies of the heliostat, which will be discussed in the following section. The PSD of the longitudinal (i.e. mean wind direction) and vertical velocity components are shown in Fig. 5 along with empirical formulas found in (Kaimal et al., 1972) and (Lumley and Panofsky, 1964) that can be used to approximate the spectra. 

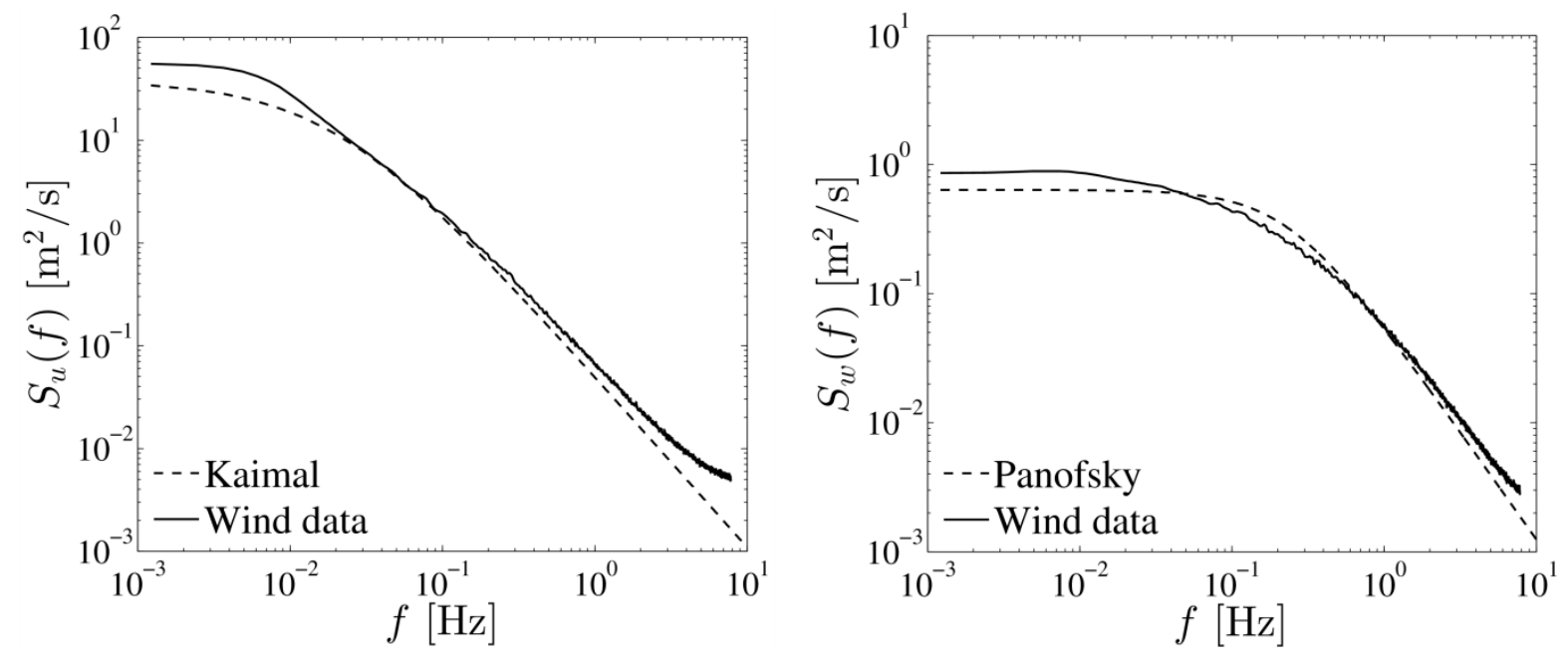

Fig. 5: Power spectral density of the longitudinal (left) and vertical (right) velocity components (VásquezArango, 2016)

To achieve a complete similarity between the real atmospheric boundary layer and the flow in wind tunnel experiment, the profiles of both mean wind and turbulence intensity, as well as the turbulent energy spectra are required to be scaled, which is not achievable in practice. Banks (2011) noted that testing of heliostats in a conventional boundary layer wind tunnel (BLWT) does not yield the expected results due to mismatch of the turbulent energy spectra because of the following reason: due to their small dimensions, the heliostats need to be modelled at larger scales (typical scales are 1:10 - 1:50) which are not in compliance with the typical wind tunnel flow scales (1:100 to 1:300). This large model scale is needed to model the details of the structure in sufficient detail and to locate the model at a height where velocity and turbulence profile are well matched in the wind tunnel. The large scale makes it impossible to correctly capture the low-frequency part of the turbulent energy spectra because the wavelength of the corresponding eddies would be far above the standard wind tunnel size (Fig. 6).

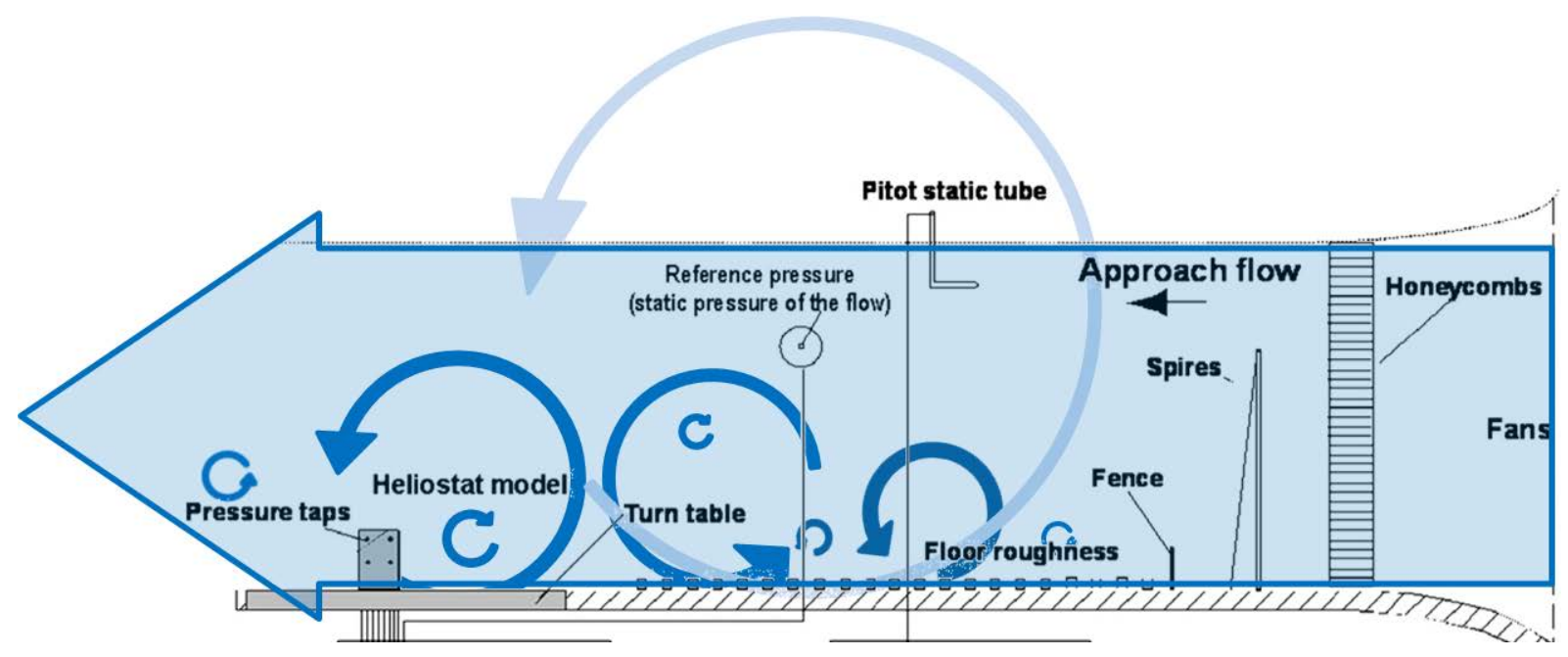

Fig. 6: Boundary layer wind tunnel dimensions limit the size of eddies which leads to too small energy in the low-frequency part of the turbulent energy spectra (Wacker Engineers, DLR)

To achieve the required turbulence intensity more energy is needed at the higher frequencies. This leads to a shift of the spectra from lower frequencies towards higher frequencies (Fig. 7). 


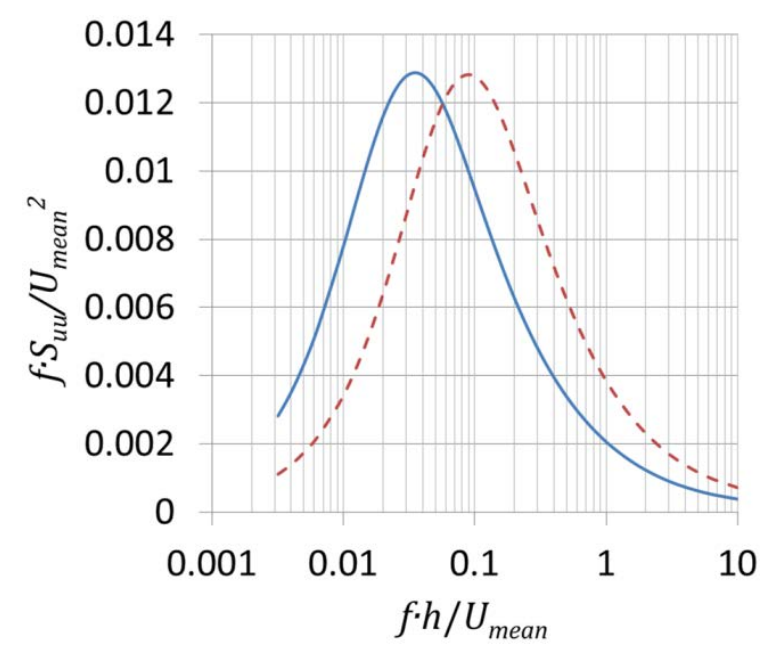

Fig. 7: Comparison of energy spectra of the longitudinal velocity component for large model scale when turbulence intensity is matched (blue solid line: full scale, red broken line: BLWT) (Dyrbye and Hansen, 1997), (DLR)

By reducing the averaging time to a value corresponding to the size of the BLWT, the frequency shift of the spectra towards higher frequencies is avoided because only turbulence structures smaller than the BLWT are required to be modelled. However, for typical roughness elements, matching either the longitudinal or the vertical turbulence intensities can be achieved (but not both simultaneously). Pfahl et al. (2017) showed that for the measurement of the peak wind load coefficients for a heliostat in stow position a match of the vertical turbulence intensity is sufficient. In previously published wind tunnel measurements of heliostats, this is usually the case. Hence, their results are valid although a significant shift of the longitudinal spectrum is given.

Wind load coefficients for heliostats are usually normalised by the mirror area, hence they are applicable to any heliostat size. However, due to the increase in turbulence intensity for lower heights, small heliostats and those with shorter pylons are attacked by a more turbulent flow and the peak load coefficients significantly increase. With a trend towards smaller heliostats in recent years, accurate estimation of the peak and mean loads has become more important. Hence, for wind tunnel investigations of heliostats the turbulence intensity must correspond to both heliostat size and the surface roughness of the surrounding terrain of a heliostat field (Pfahl et al., 2017).

\subsection{Dynamic loads}

Dynamic wind loads originate from the correlation between the temporal variation of the pressure distribution on the surface of the heliostat structure and its dynamic properties, i.e. inertia, elasticity and damping. Two main turbulence effects can cause dynamic loads: buffeting and vortex shedding. Buffeting is due to the pressure fluctuations induced by turbulence in the oncoming flow (as discussed above, \$2.1) and depends on the flow characteristics. Vortex shedding occurs in the wake of the structure due to instabilities in the shear layers. They cause periodic unsteady loads that are usually characterised by the nondimensional vortex shedding frequency, called the Strouhal number (St). The loads generated by the pressure fluctuations can induce oscillations of the structure that magnify the reacting loads when resonance takes place. In order to perform fatigue analysis of the heliostat components and evaluate design criteria regarding maximum deformations, it is necessary to determine the transient response of the structure exposed to fluctuating loads. 
In the past, most investigations of heliostats were primarily concerned with the mean and peak wind loads with less focus on dynamic loads. However, in a work by Peterka et al. (1989), the potential impact of fatigue loads was investigated experimentally. They noticed that the fluctuating loads on heliostats have very large amplitudes and can change sign. In Peterka and Derickson (1992) the following reviewer comment was cited: "I must highly emphasize to designers of large pedestal supported arrays that resonant vibrations must be considered. In our earlier designs, we experienced several drive failures in the field when only static wind loads were considered in the design. Naturally we were forced to consider dynamic effects to correct the problems."

More recently, a few studies investigated specifically the dynamic wind loads on heliostats. Huss et al. (2011) performed aeroelastic measurements of a $14.4 \mathrm{~m}^{2}$ heliostat that was used in a commercial power plant. The experiments were conducted in a wind tunnel using a 1:7 scale aeroelastic model designed to reproduce the first three modes of vibration. One subject of the investigation was the study of aerodynamic phenomena such as galloping and flutter, which are dynamic instabilities in one or two degrees of freedom, respectively. They occur when the aerodynamic forces act to reinforce motion in a dynamic mode and more energy is put into each cycle than can dissipate by structural and aerodynamic damping (Cook, 1985). For the horizontal (stow) position of the mirror frame at wind speeds of up to $40 \mathrm{~m} / \mathrm{s}$, which are typically predicted in the design, the results did not exhibit any signs of such instabilities. Aeroelastic measurements can reproduce the dynamic behaviour of the structure. However, such experiments are elaborate, especially in the fabrication of a suitable model that reproduces the geometry accurately and possesses the same dynamic properties as the fullscale structure. Furthermore, it is not possible to model all turbulence characteristics of the atmospheric boundary layer correctly in the wind tunnel as discussed in (Banks, 2011).

Griffith et al. (2011) investigated a $37 \mathrm{~m}^{2}$ U-shaped heliostat structure, and conducted numerical and experimental modal analysis to determine the dynamic properties and validate their finite element model. Later, Ho et al. (2012) carried out operational modal analysis (OMA) on the same heliostat to examine the dynamic behaviour of the structure under real operating conditions. They found that the natural frequencies determined under windy conditions were in very close agreement to the previous study, and that the aerodynamic damping is very small under these conditions.

In the work by Ghanadi et al. (2016) an unsteady computational fluid dynamic model was used to estimate the peak and mean drag coefficients for a heliostat installed perpendicular to the flow neglecting dynamic effects. As shown on Fig. 8 below, for $18 \%$ turbulence intensity the variation in amplitude of load can be already without the dynamic content equivalent to the mean load $\left(c_{d} \approx 2 \pm 2\right)$ which corresponds to the values measured by Peterka and Derickson (1992) with stiff models (i.e. also excluding the impact of dynamic properties). 


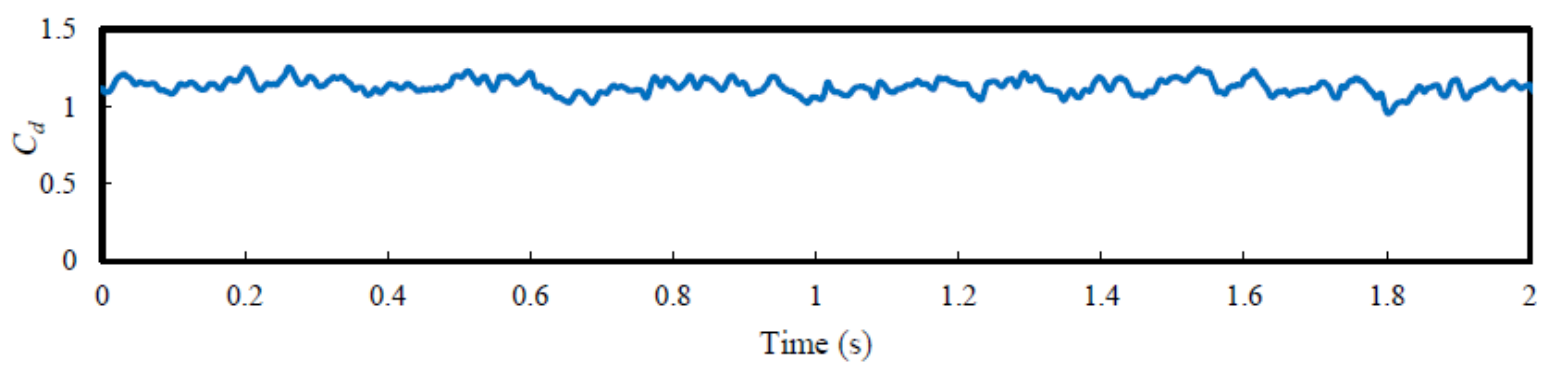

(a)

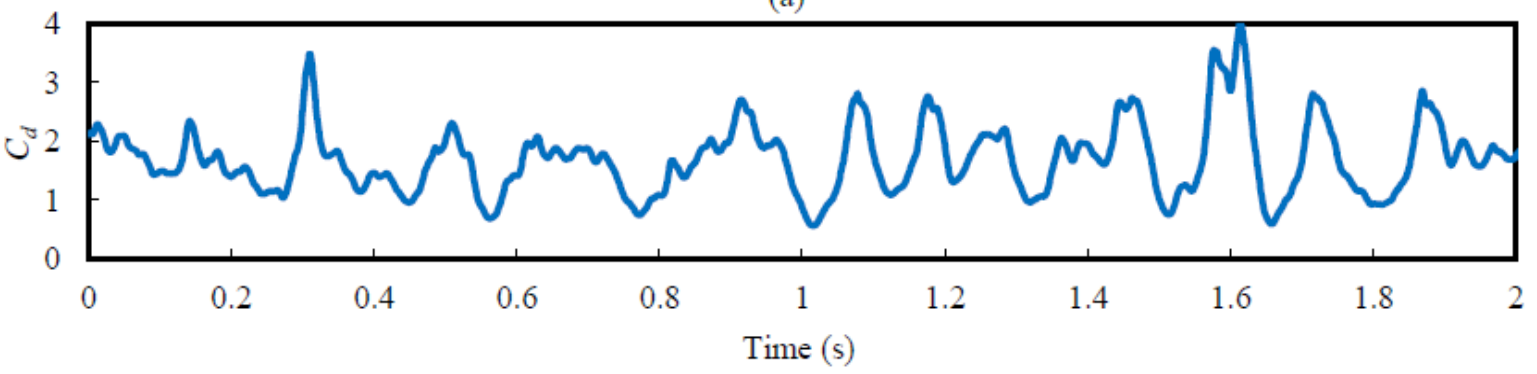

(b)

Fig. 8: Drag coefficient fluctuations of a single normal heliostat within atmospheric boundary layer when flow speed is $15 \mathrm{~m} / \mathrm{s}$ : (a) turbulence intensity $=2 \%$, (b) turbulence intensity $=18 \%$ (Ghanadi et al., 2016)

Vásquez-Arango et al. (2015) determined the dynamic properties of an $8 \mathrm{~m}^{2} \mathrm{~T}$-shaped heliostat experimentally and numerically. The results revealed the shapes of vibration that are more likely to be excited by fluctuating wind loads. They correspond to rigid body modes of the mirror frame, such as the oscillation about the elevation axis shown in Fig. 9.

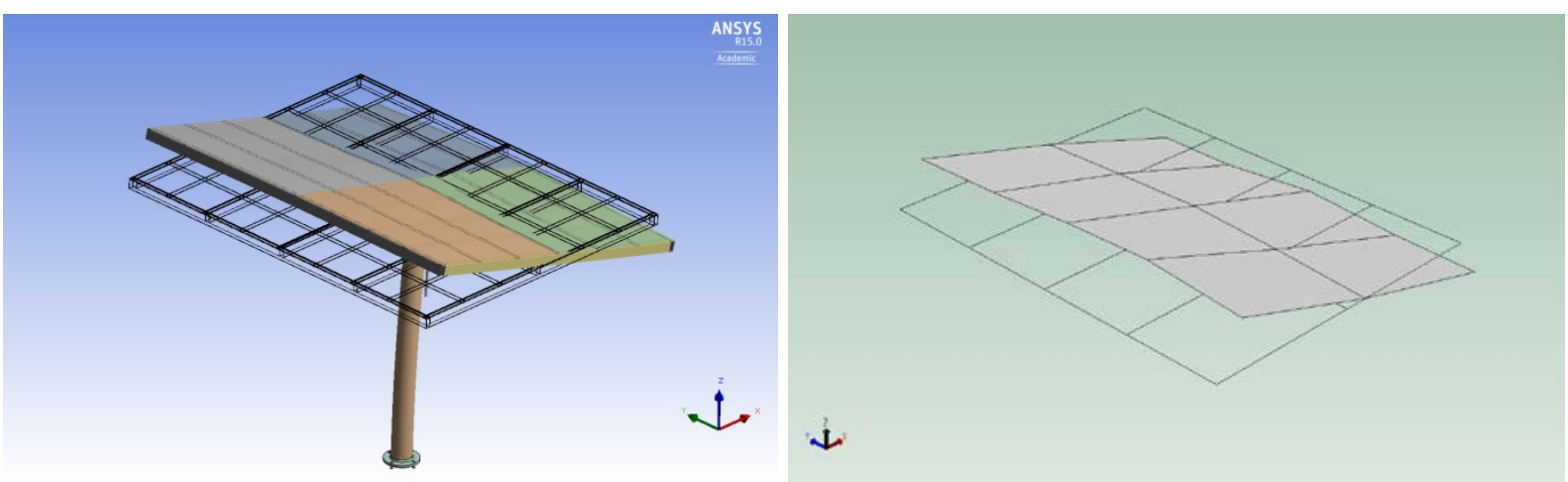

Fig. 9: Numerical (left) and experimental results (right) of the dominant mode shape (Vásquez-Arango, 2016)

The finite element (FE) model developed by Vásquez-Arango et al. (2015), and validated against experimental data, was used in combination with the damping coefficients determined experimentally to develop a dynamic FE model of a heliostat. Vásquez-Arango (2016) performed transient FE simulations that account for the inertial forces by coupling the FE model with time-dependent pressure signals obtained from large eddy simulations (LES) that included the turbulent inflow conditions similar to those of an ABL. Fig. 10 (left) shows an instantaneous snapshot of the flow field around the heliostat immersed in the ABL. On Fig. 8 (right) an overlapped sequence of snapshots from the transient FE results is displayed which describes the dominant oscillation modes of the mirror frame about its elevation axis. 


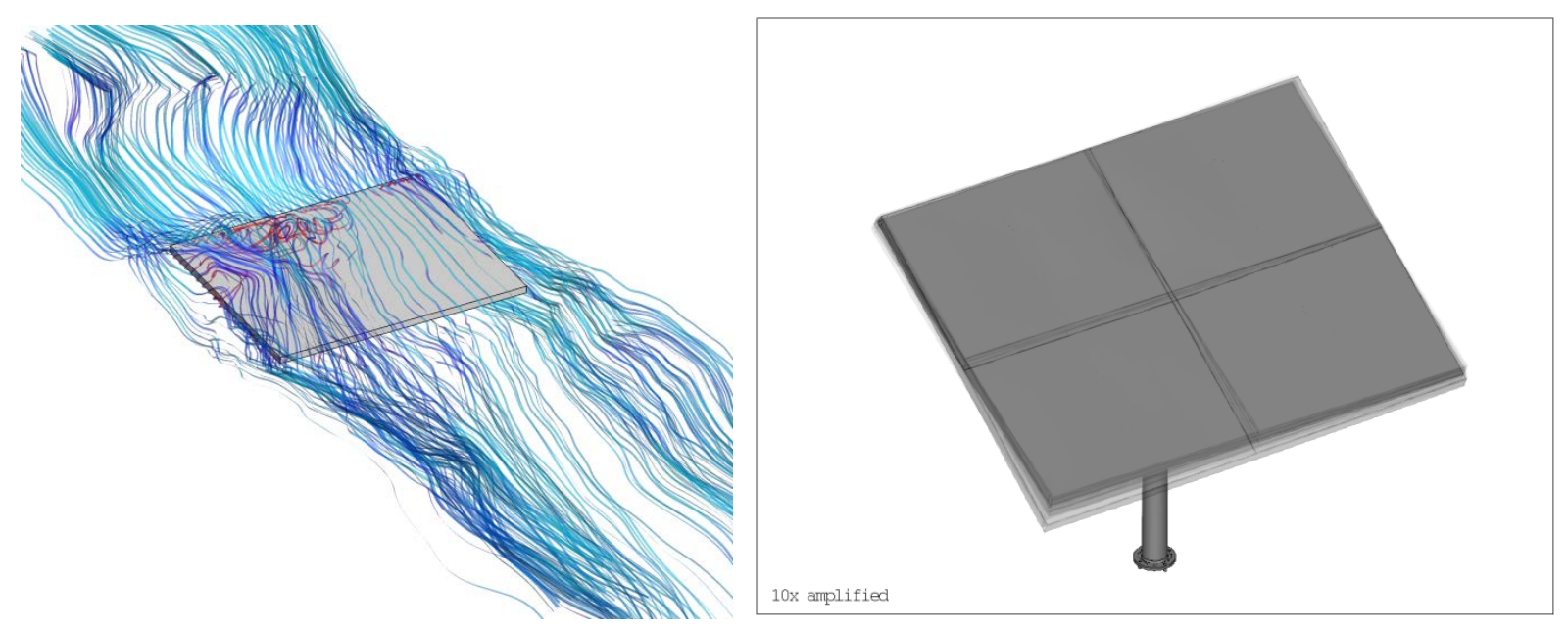

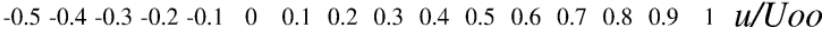

Fig. 10: Instantaneous streamlines around the heliostat (left) obtained from LES and sequence of snapshots (right) from the transient FE simulations (Vásquez-Arango, 2016)

The results from the dynamic analysis in (Vásquez-Arango, 2016) indicate a significant magnification of the peak wind loads. Fig. 11 shows a comparison between the input moment about the elevation axis $M_{y, \text { in }}$, caused by the pressure fluctuations, and the reaction (output) moment of the oscillating structure including dynamic effects caused by the inertia of the structure $M_{y, \text { out }}$, and it is observed that the amplitudes of the output moment are notably larger. The ratio of the standard deviation of the output to input moment was above 2 for all cases investigated.

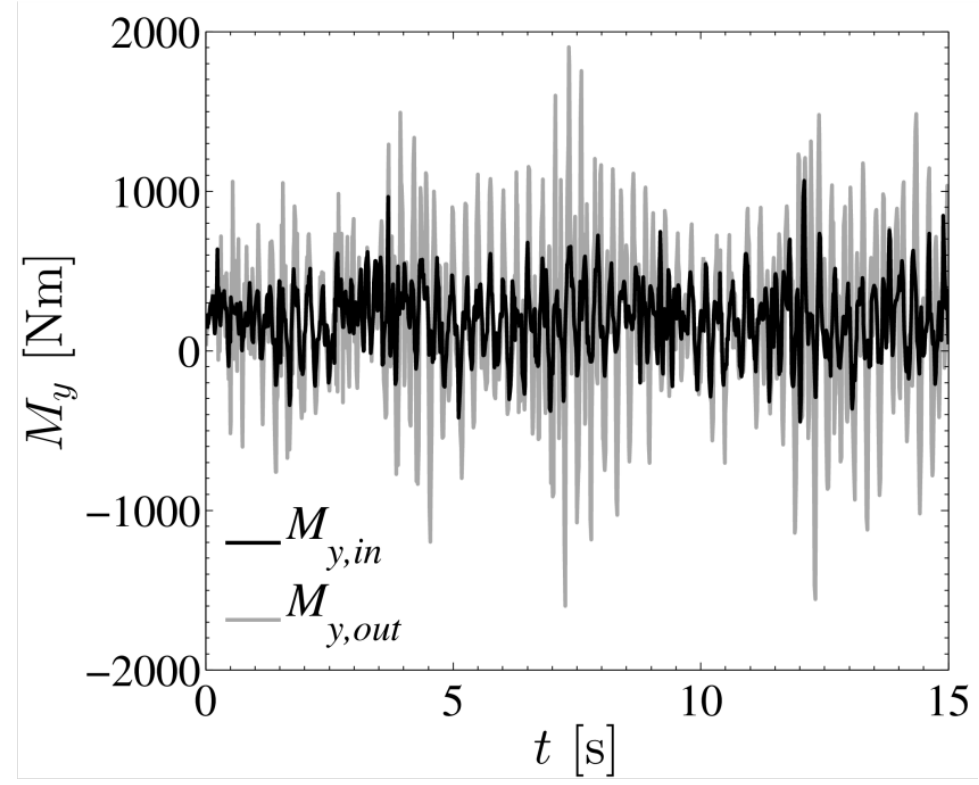

Fig. 11: Time signals of the input and output moment about the elevation axis (Vásquez-Arango, 2016)

The numerical methods used above are capable of determining dynamic wind loads on heliostats. However, despite recent advances in high-performance computing, the computational effort is still very high, especially for LES. An alternative to performing dynamic analysis on heliostats is to couple the transient FE simulations with experimental data from wind tunnel measurements or full-scale measurements as in (Gong et al., 2013). 


\section{Heliostat dimensioning}

In the following, the main decisive aspects for heliostat dimensioning considering wind loads are discussed:

1. Heliostat size

2. Tracking accuracy

3. Deformations during operation

4. Storm wind loads

\subsection{Heliostat size}

"What's the cost-optimum size of a heliostat?" is a widely discussed, but still open question. An analysis of the impact of the heliostat size on the cost is given by Jones (Kolb et al., 2007, Appendix A.8), who plotted specific cost against heliostat area for a small $\left(25 \mathrm{~m}^{2}\right)$ and a large $\left(150 \mathrm{~m}^{2}\right)$ heliostat design (Fig. 12). Not included is a cost curve of a very small $\left(2-15 \mathrm{~m}^{2}\right)$ heliostat. However, the key trends are that the slope of the curve becomes steep as the heliostat size tends towards zero, and conversely, that the slope of the curve is gentler as the heliostat size becomes large. Therefore, the optimum size spans a broad region and depends strongly on the specific conditions. Hence, no generally valid answer can be given.

Optics-Adjusted Life-Cycle Heliostat Cost for $\sim 235,000$ sq. $m$ Build

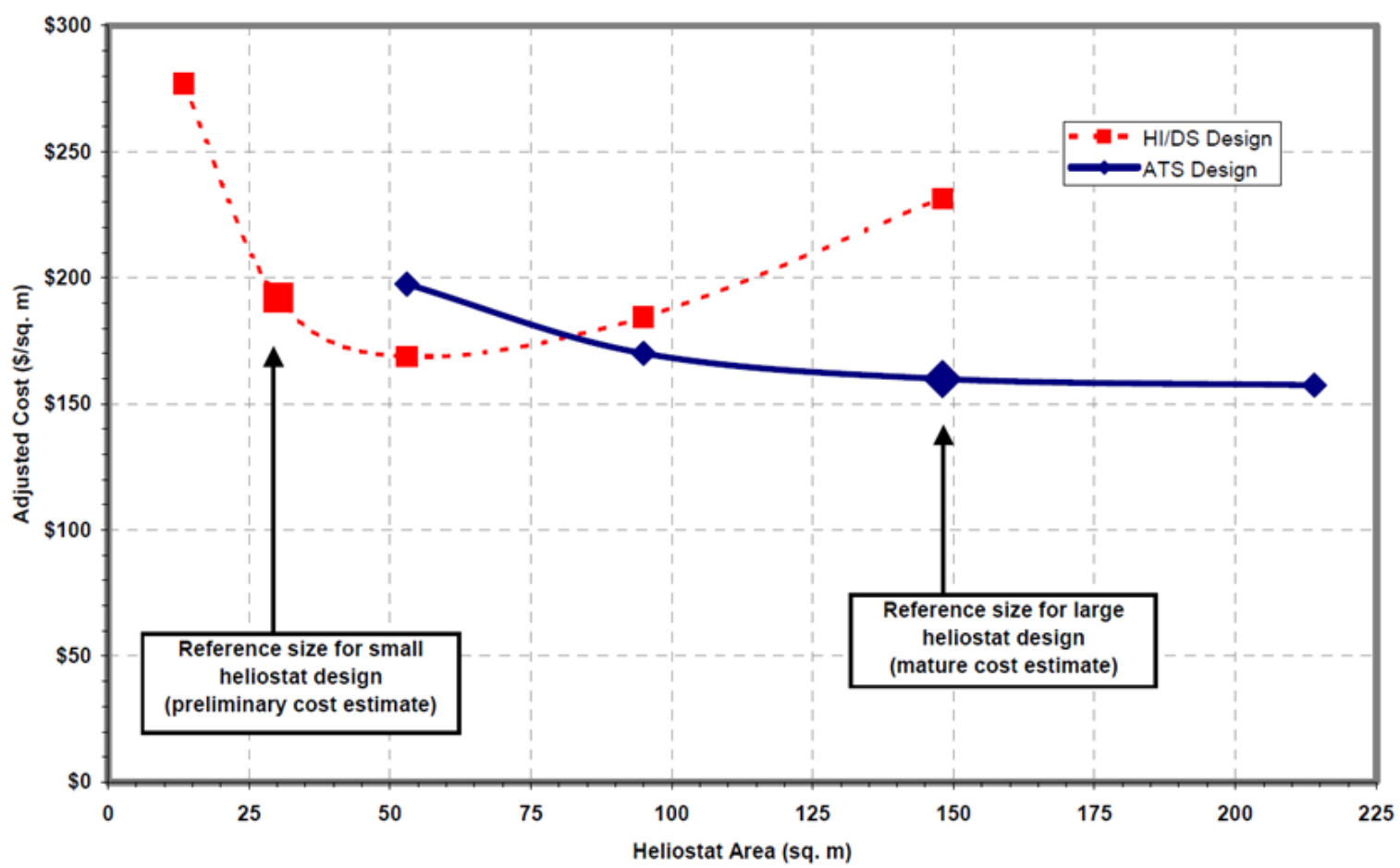

Fig. 12: Specific heliostat cost versus heliostat area for two different heliostat designs (Kolb et al., 2007)

The main advantage of big heliostats is that fewer parts and foundations are needed for an equivalent mirror area. The main advantage of small heliostats is that wind speeds are lower because of the low height and that their weight per mirror area can be smaller.

The reasons for the lower specific weight are as follows. By increasing the chord length of the mirror panel the mirror area increases to the power of two. All other dimensions of the heliostat must be increased according to the chord length to avoid an increase of the stress caused by the peak wind loads. Therefore, the volume and the mass of the heliostat increase with the chord length to the power of three or with the mirror area to the power of 1.5 
respectively (compare Kolb et al., 2007, A.3) (dependency of the wind speed with height neglected). Because the weight is a measure for the cost, especially for high production rates, small mirror support structures are advantageous due to their lower specific weight. Accordingly, for some heliostat concepts very small heliostat sizes were chosen (in particular, $2 \mathrm{~m}^{2}$ size in (Ricklin et al., 2014).

However, also huge heliostats are realised (e.g. Titan-tracker) at comparably low weight and cost. The reason is that for larger heliostats more complex structures with low specific weight like frame work cantilever arms can be realized.

Coventry et al. (2016, paragraph 8) see advantages when size is reduced to a scale equivalent to other volume manufactured commodity items regarding the following aspects:

1. Production volume

2. Use of common-off-the-shelf (COTS) components

3. Use of low-cost manufacturing processes

4. Use of standard assembly processes

5. Transport and logistics

Coventry et al. (2016) argued that based on the trends in Fig. 12, very small heliostats (less than about $10 \mathrm{~m}^{2}$ ) appear difficult to justify, and that looking for opportunities to increase size should be a design principle. However, they argued an equally important design principle is compatibility with the volume manufacturing, which will have the tendency to reduce heliostat size. Blackmon (in Stein and Lovegrove, 2012, p.574) followed a similar size optimisation method to Jones, and noted the influence fixed costs items have on optimal size. He observed reducing the cost of these items, e.g. position sensors and controllers, will favour smaller heliostats. The optimum size depends upon the costs of commercially available motors, drives and sensors etc. These devices do not scale in a smooth linear fashion.

For the heliostat design of HelioTower (\$5.2.4) a cost optimum size of about $50 \mathrm{~m}^{2}$ was determined by Cordes et al. (2012) (Fig. 13). Larger heliostats lead to significant investment in the support structure, while for smaller devices the drives and the cabling and control becomes significant. Von Reeken et al. (2015) also determined a cost optimum size of about $50 \mathrm{~m}^{2}$ for the Stellio heliostat (§ 5.1.8).

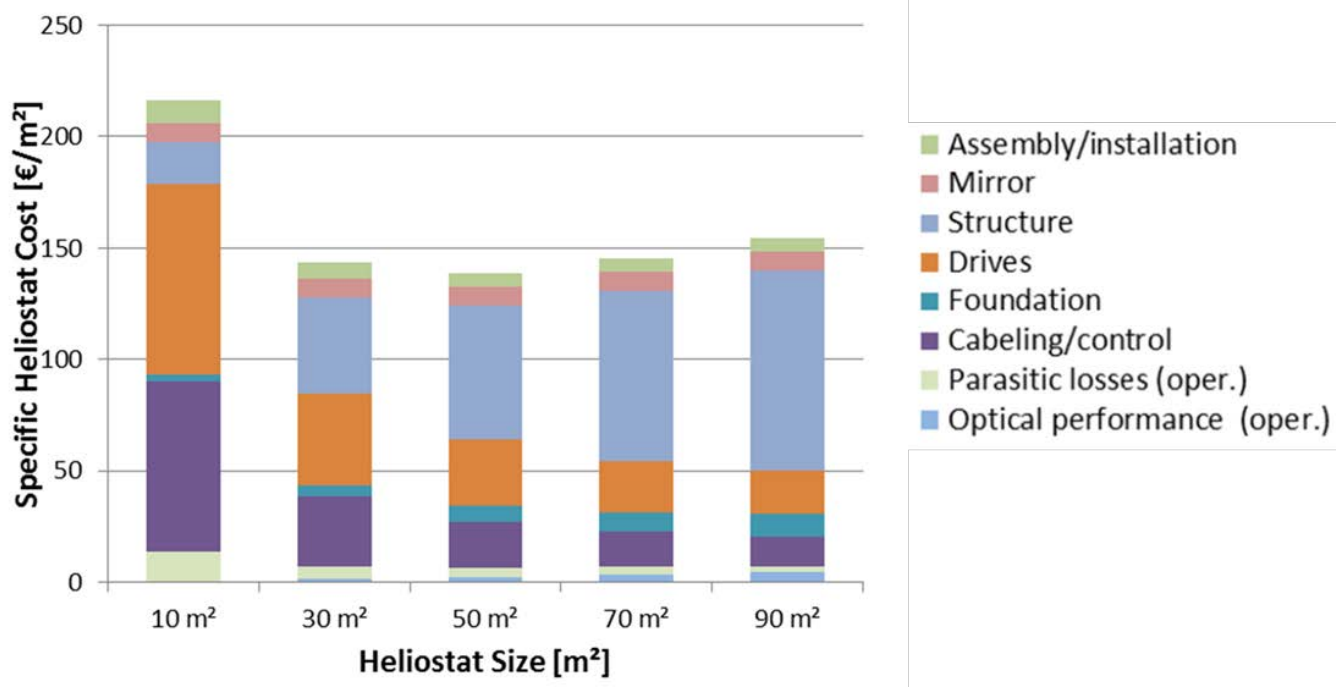

Fig. 13: Impact of size on HelioTower's heliostat cost (Cordes et al., 2012)

Pidaparthi and Hoffmann (2016) investigated the effects of heliostat size on the levelised cost of electricity (LCOE) for a power tower with a net capacity of 100 MWe, 8 hours of 
thermal energy storage and a solar multiple of 1.8 in Upington, South Africa. Large, medium and small size heliostats with total areas of $115.56 \mathrm{~m}^{2}, 43.3 \mathrm{~m}^{2}$ and $15.67 \mathrm{~m}^{2}$ respectively were considered for comparison. The results, which include the economic and the optical performance along with the annual O\&M costs, indicated that lowest LCOE values are achieved by the medium size heliostat with an area of $43.3 \mathrm{~m}^{2}$. However, it is concluded that the heliostat 'cost per unit area' should not be taken as the sole figure of merit, but rather as a guideline while comparing heliostats of different sizes. Heliostat scaling effects, learning curve benefits, the price index and the optical performance of the heliostat field layout should be considered to choose the best suitable heliostat size.

A review about the size development of heliostats, and an overview of the advantages of small and large heliostats is given by Téllez et al. (2014, begin of paragraph 2).

For the dimensioning of heliostat not only the size but also the aspect ratio of the concentrator is relevant. Its impact on the wind loading was investigated by Pfahl et al. (2011a).

\subsection{Tracking accuracy}

The tracking error is usually defined as the standard deviation of the error between the actual and ideal orientation of the optical axis of the heliostat across a year. Partly, the deviation can be caused by systematic errors like imperfect orientation of the rotation axes or errors in the calculation of the sun position. Systematic errors can be calibrated and corrected by aiming the focal spot to an extra target which is seen by a camera. The centre of the focal spot is determined and the deviation from the given aim point is calculated. This deviation is determined for several incident angles of the sun. With the deviations for different incident angles the single errors can be calculated and corrected (Berenguel et al., 2004) (compare §8.5).

The error caused by backlash of the drives cannot be corrected in this way. Backlash in combination with (turbulent) wind causes fluctuations of the position of the focal spot. If the drives are pre-tensioned no fluctuation occurs and backlash has no impact. For the elevation axis, pre-tensioning can be realised by unbalancing the mirror panel. However, for the vertical axes, pre-tensioning by gravity is not possible. Fig. 14 shows a heliostat with pretensioning of the azimuth drive by spring elements. Usually, for the azimuth drive expensive high precision gears with low backlash are needed. 


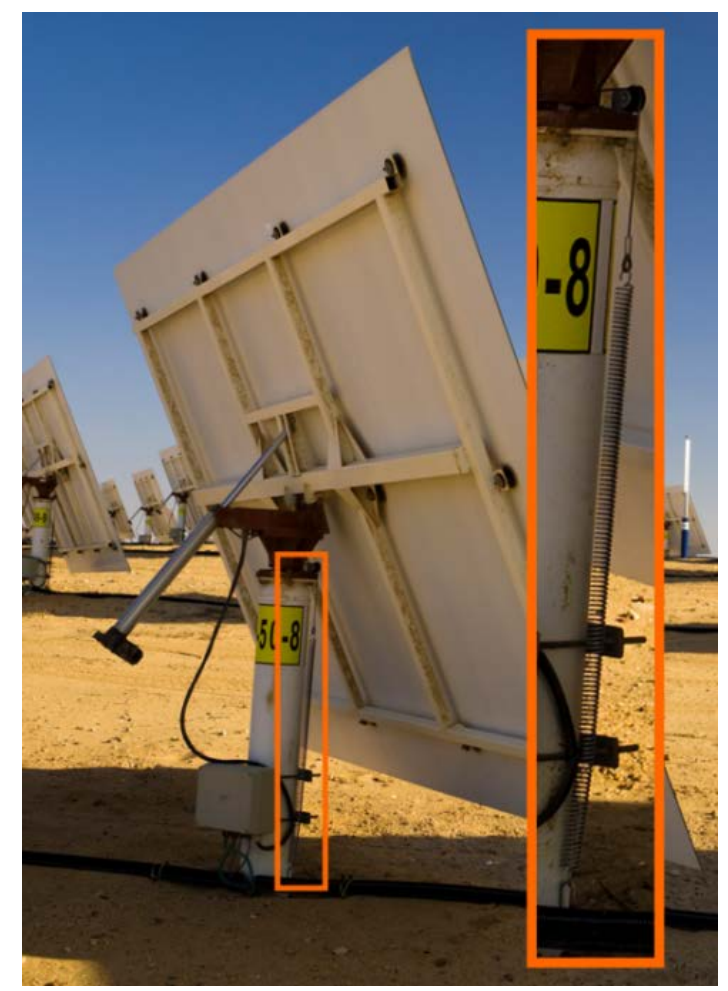

Fig. 14: Heliostat with a pre-tensioned azimuth drive via a spring (Brightsource Energy, 2012)

It's not trivial to calculate the standard deviation caused by a certain backlash because the influence of fluctuating wind conditions throughout the year and the breakaway torque have to be considered. Teufel et al. (2008) describe a method to calculate the impact of the backlash on the annual energy yield of a plant. However, this method is yet to be validated.

\subsection{Deformation by gravity and wind during operation}

The heliostat structure must be rigid enough to avoid significant deformation due to changes of the mirror orientation. A deformation of the torque tube would lead to a misalignment of the mirror facets (Fig. 15, left).
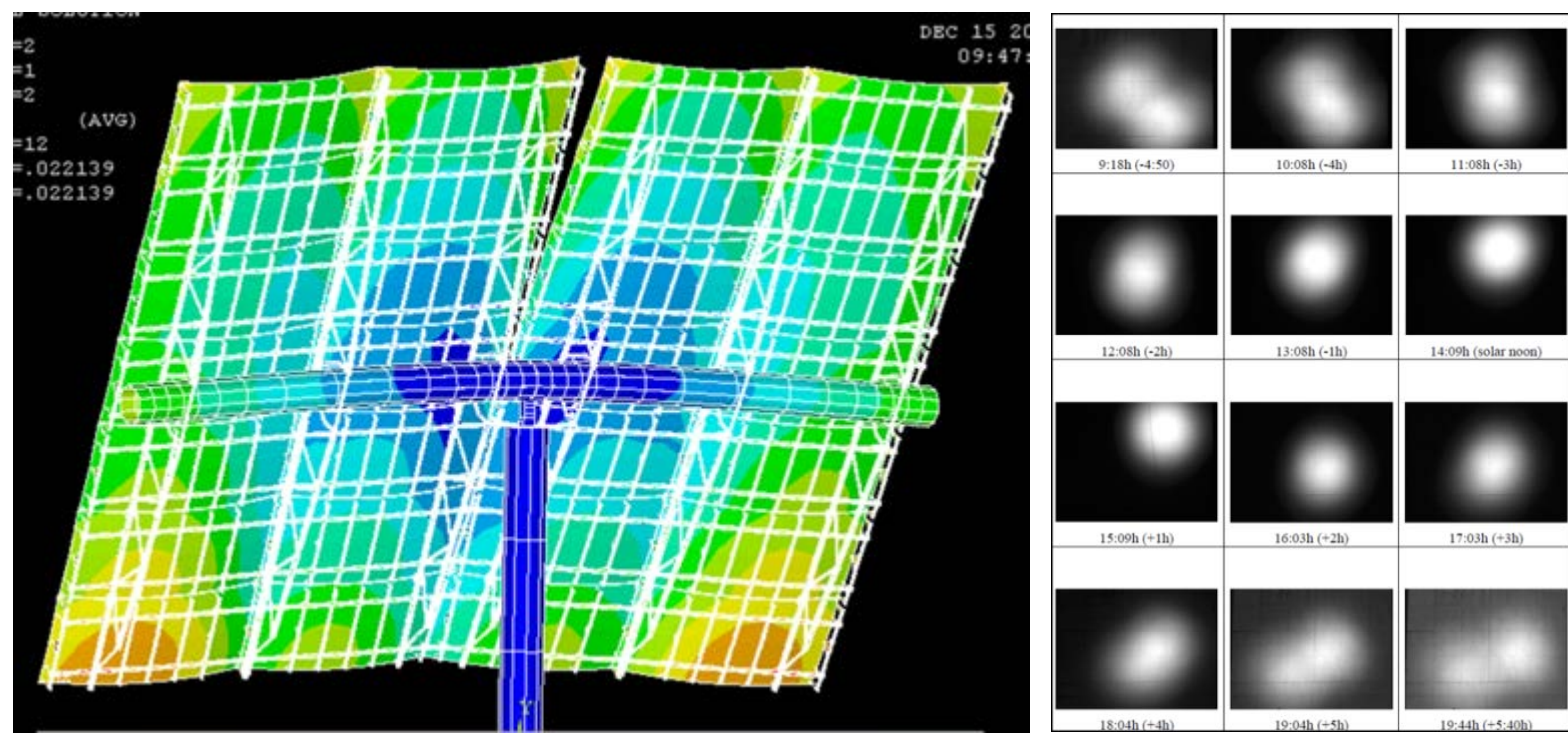

Fig. 15: Left: Deformation of torque tube due to gravity and resulting misalignment of the mirror facets (DLR); Right: Split up of focal spot due to gravity for early morning and late afternoon for canting at solar noon caused by an under-designed torque tube (Ulmer, 1998) 
Fig. 15 (right) shows how the focal spot splits up for a heliostat with an under-designed torque tube. The facets are canted to achieve a small focal spot at solar noon. In early morning and late afternoon the mirror panels and the torque tube are oriented differently which leads to a different deformation of the torque tube and a different angle of the facets relative to the torque tube, resulting in a significant slope error of the mirror panel.

Teufel et al. (2008) investigated the impact of gravity and wind loads on the annual energy yield. It was found that gravity can have a significant impact on optical losses, while wind during operation can usually be neglected. The reasons for the low impact of wind on the optical losses are the following:

- In operation, only the heliostats at the section of the field perimeter facing the wind (which is a very small portion of the total heliostat field) see significant wind loads while the others are in the wind shadow of the heliostats in front of them.

- The maximum loads occur only at certain angles of attack while for other combinations of wind direction and elevation angle the loads are much lower.

- The maximum wind speeds for operation occur quite rarely.

- When heliostats are attacked with significant wind speeds the focal spot will oscillate about a mean position. This will cause only small losses of energy while most of the energy will still hit the receiver. The reason is that the flux intensity is low at the edge of the focal spot. For vibrating heliostats near the tower it is possible no optical loss at all may occur, because their focal spot is small compared to the size of the receiver.

- Heliostats must be designed rigid enough to be able to withstand storms in stow position and to have only low deformation due to gravity during operation. Hence, their deformation in the comparably low wind loads during operation is small.

Therefore, usually the impact of the wind loads on performance during operation can be neglected (for conventional heliostats with sufficient stiffness for all mirror orientations) which simplifies the design process significantly. However, the impact of wind loads on backlash during operation has to be taken into account (§3.2).

\subsection{Survival during operation and storm}

The peak wind load coefficients are lowest for the heliostat in stow position (i.e a horizontal mirror panel). But these have to be combined with the highest wind speeds occurring during storms. Whether the different wind load components reach their highest values during operation or during storm in stow position depends on the maximum operational wind speed, the highest assumed storm wind speed and their corresponding wind load coefficients.

By strategic orientation of the mirror panels considering the wind conditions, the wind loads can be reduced with almost no additional cost. For example, the heliostat can be tilted about the elevation axis to a favourable orientation with respect to the wind direction during stow and storms (Gong et al., 2012) (if the weather conditions allow prediction of the wind direction). Alternatively, heliostats oriented in a position with a high wind load coefficient could go to stow position at lower wind speeds, or move to a slightly tilted orientation to protect other heliostats still in operation.

Partly, wind loads can be reduced by wind fences around the heliostat field. Whether they are worth the effort is discussed by Pfahl et al. (2011). A further measure to reduce wind loads for stow position are spoilers made by fence-like structures around the heliostat panels 
(Pfahl et al., 2014). However, such structures lead to additional blocking and shading, to increased wind loading during operation, and to additional cost.

\section{Heliostat components}

In this section, the main heliostat sub-functions and their related components are described (Pfahl, 2014).

1. Reflecting sunlight:

2. Fixing mirror shape:

3. Ground connection:

4. Offset determination:

5. Rotation of mirror panel: mirrors

mirror support structure

pylon and foundation

control

drives

\subsection{Mirrors (reflecting sunlight)}

A detailed overview of mirrors for heliostats is given by Coventry et al. (2016, paragraph 10) in a 2013 ASTRI study. It is concluded that "mirrored glass and reflective film are the most suitable current (or near-term) options for heliostat reflectors. Polished metal and plastic mirrors both do not currently have adequate reflectance. There are around six suppliers [in 2013] of standard 3-4 mm low-iron mirrored glass for solar applications. Three of these can also supply thin mirrored glass $(-1 \mathrm{~mm})$. Glass mirrors should be considered the default reflector, as they are relatively inexpensive, durable, have high reflectance and are accepted by industry. There are around four suppliers of reflective film. Reflective film technology is still evolving and continuing to improve, particularly via an active research program by $3 \mathrm{M}$ [although it was suspended in 2014 pending improved market conditions (O'Neill, 2014)], and encouraging durability results."

\subsection{Mirror support structure (fixing mirror shape)}

\subsubsection{Connection of glass mirrors to steel frames}

State-of-the-art power tower plants mostly use T-type heliostats with steel structure and glass-facets. The steel mirror support structure often consists of several cross beams which are mounted to a horizontal torque tube. The torque tube and the pylon together form a " $\mathrm{T}$ " and are connected to each other by the drive system for azimuth and elevation movement (Fig. 1, right).

Glass and steel have different thermal expansion ratios. Therefore, the mirrors are often connected to the support structure via pins which are flexible in both directions of the mirror plane. In the example shown in Fig. 16, steel stripes are used which are flexible in one direction, and which are connected to the cross beams by rivet joints, which allows rotation in the other direction. Only the central pins (above the torque tube) hold the gravity load of the mirrors for upright orientations and are fixed by two rivet joints to the cross beams. The pins are glued to the mirrors by pads, which increase the area of force application and which are rotatable to avoid high stress in the glass.

The height of the pads normal to the mirror plane defines the shape of the mirror panels. The number of pads is defined by the wind loads and by the required accuracy of the mirror panel's parabolic curvature. At stow position with horizontal orientation, highest pressure occurs at the edges of the panels (Pfahl et al., 2011a), caused by eddies which break there. 
Therefore, the outer pads must be located relatively close to the edges (Fig. 16) to avoid stress due to long lever arms between the loaded edges and the supporting pads.

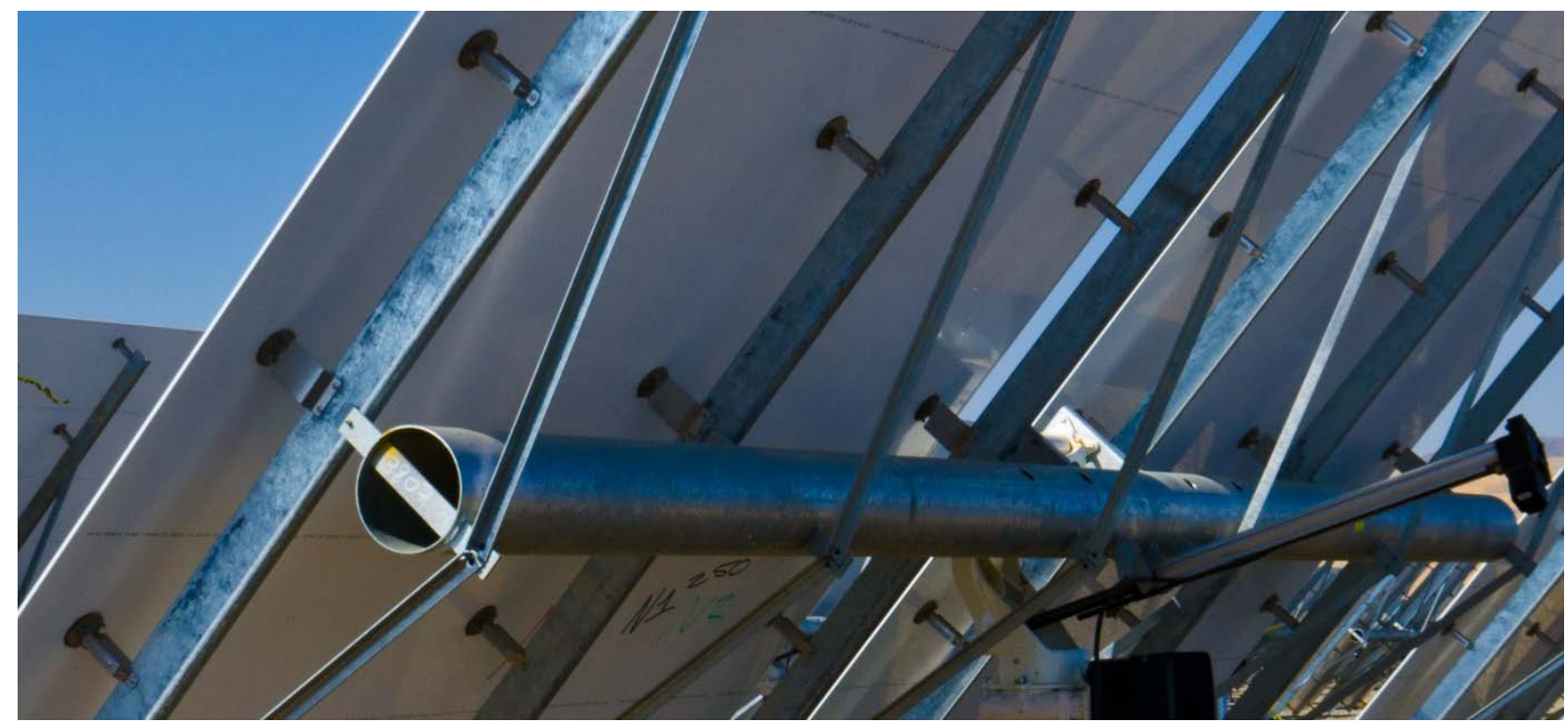

Fig. 16: Connection of glass mirrors and steel support structure via flexible pins (for compensation of different thermal expansion) and pads (for high area of force application to avoid high stress in the glass), Photo: (Brightsource Energy, 2012)

For small facets with sufficient adhesive thickness, the flexibility of the adhesive is able to compensate for the differences in thermal expansion of steel and glass and no pins are required (Fig. 17).
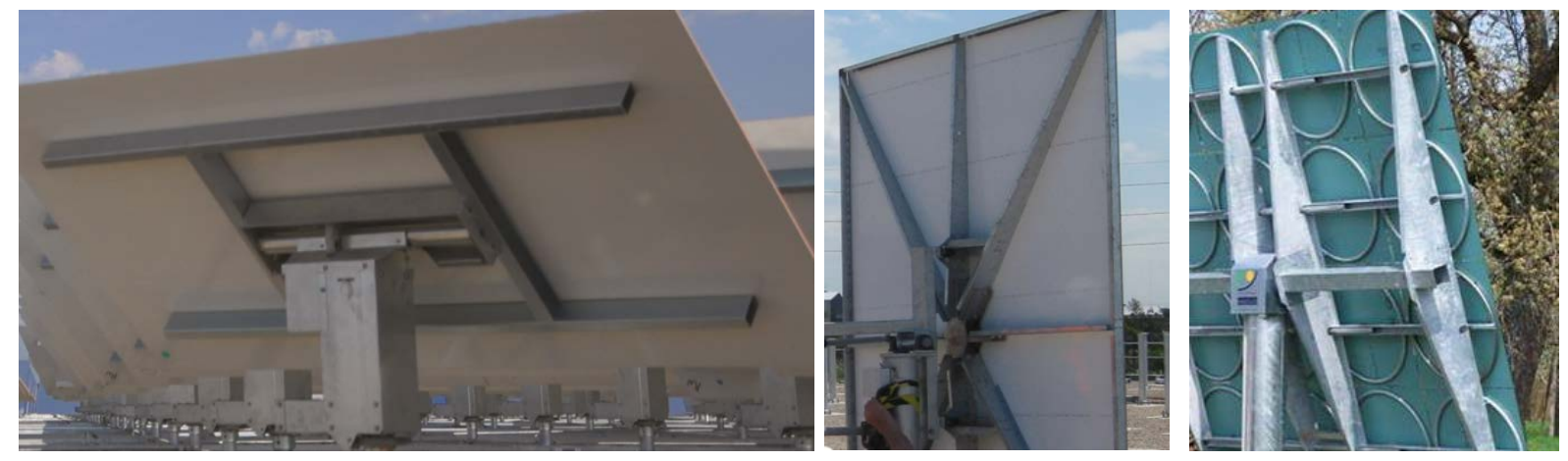

Fig. 17: Mirror facets glued directly to steel support structure (Ricklin et al., 2014), (CSIRO, 2012), SOLTEC)

\subsubsection{Stamped mirror facet support structure}

Glass mirrors reinforced by stamped support structures (compare Fig. 1, right) offer increased stiffness. Thus, thinner glass mirrors can be used. Openings in the metal sheet reduce weight. The adhesive's flexibility compensates the differences in thermal expansion of glass and steel. However, temperature changes lead to geometry changes which impact the beam quality. By optimising the geometry set at the moment of bonding, this effect can be minimised with respect to the annual energy yield (Lata et al., 2010).

Advantages of the facets are (Lata Pérez, 2010):

- $1 \%$ higher reflectivity due to $3 \mathrm{~mm}$ instead of $4 \mathrm{~mm}$ thick glass mirrors

- Less parts and lower weight of the support structure

- Mounting simplified because of better handling of the facets

- Fabrication can be highly automated 


\subsubsection{Sandwich panel mirror facets}

Coventry et al. (2016, paragraph 10.6) give an overview of sandwich panel mirror developments for heliostats. Summarised, it is reported that there is a renewal of development of mirror facets based on sandwich panel type constructions. Two companies offer foam cored sandwich panels commercially. Sandia has carried out significant work on sandwich panel mirror development for CSP in the past (Diver and Grossmann, 1998) and completed a new study with US manufacturers recently (Yellowhair and Andraka, 2013). ANU continues to develop sandwich mirror facets in the ASTRI program. Sandwich panel constructions have the following key advantages: very good optical performance compared to alternatives (Andraka, 2008); use of thin glass is feasible, hence improved reflectance; and sandwich panels are very strong and rigid, and with good design can lower the mirror support costs.

\subsection{Pylon and foundations (ground connection)}

Coventry et al. (2016, paragraph 15) and Téllez et al. (2014, paragraph 2.3) give some information about different kinds of foundations: steel reinforced concrete piers, pile driving, ground anchor, and ballast type foundations.

\subsection{Control (offset determination)}

The heliostat's purpose is to reflect sunlight onto a predetermined target. Therefore, the heliostat control needs to know the mirror's orientation to determine deviations and precisely control its actuators to minimise the offsets. The conventional approach uses calibration measurements and open loop control, whilst modern solutions use sensors for feedback and closed-loop control. The prerequisite for open loop control is a very low statistical error or back lash and a stable, predictable systematic behaviour. The calibration effort (see next §4.4.1) can be large in error prone systems. In addition, the heliostat geometry model must be suitable to describe the actual imperfections that can change with heliostat model. Closed loop systems are only limited by play, the measurement accuracy of the feedback sensor, and motor control. Difficult influences like deformation under gravity, wind and temperature can be compensated as long as the sensor-heliostat calibration stays intact. The tracking accuracy can be better in closed loop systems which reduce spillage and allow better control of the whole field of heliostats to achieve a certain overall flux distribution.

\subsubsection{Calibration}

The very precise and established state-of-the-art method of calibration is to measure the flux profile from a single heliostat on a calibration target (Berenguel et al., 2004). The irradiance distribution allows determination of heliostat orientation and mirror quality. The method needs only a white (flat) target and a camera, see Fig. 18. 

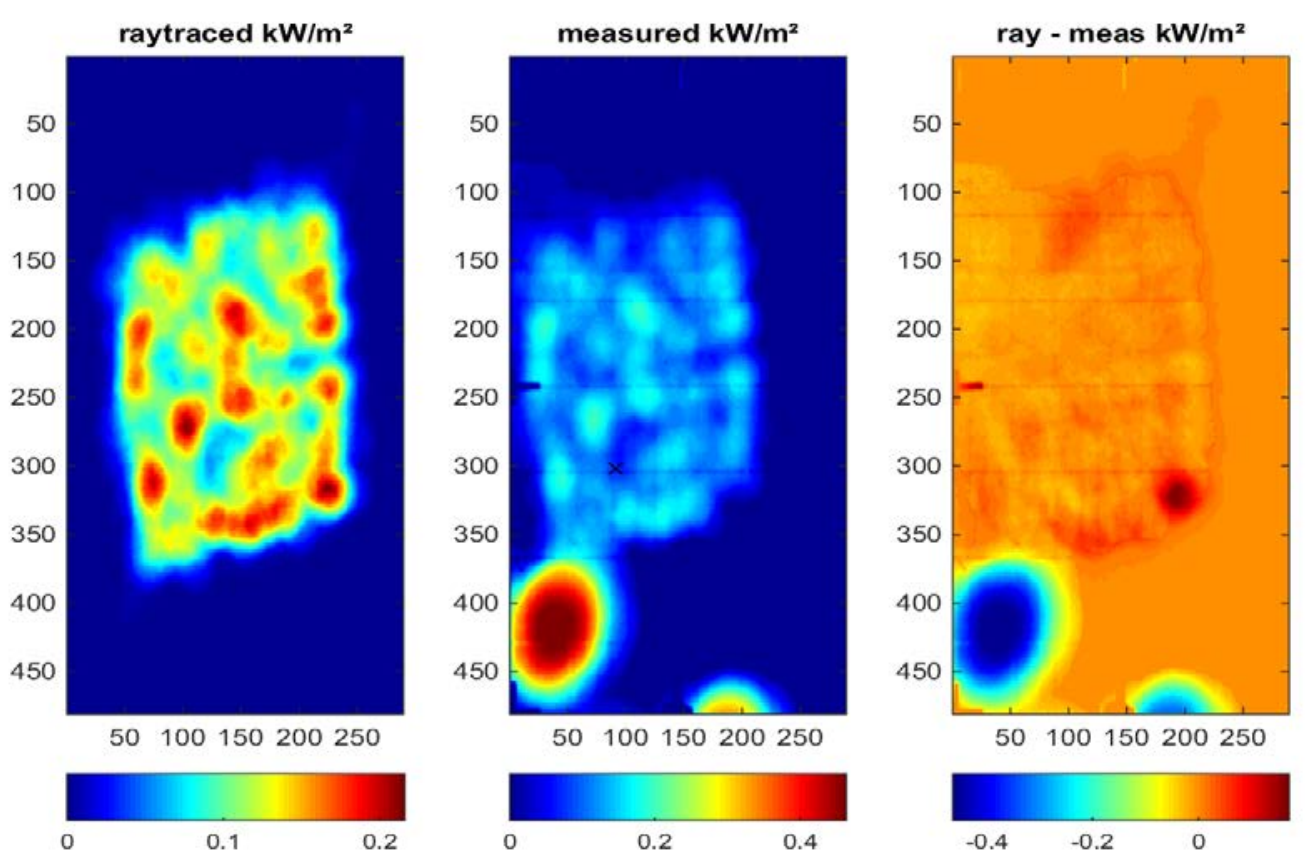

Fig. 18: Flux densities for a prototype heliostat whose focal length is about a third of the distance to the calibration target. Left: predicted flux density based on deflectometry data; centre: measured flux density; right: difference between ray traced prediction and measurement. The $x / y$ coordinates are pixels in the orthoimages whilst the flux density is shown as $\mathrm{kW} / \mathrm{m}^{2}$ (DLR)

Zavodny et al. (2015) use artificial light sources and multiple cameras to determine the heliostat orientation in positions predefined by source and camera location. This can be done at night and collects information about a lot of heliostats in parallel.

An advanced version is proposed by Bern et al. (2016) where a well-defined oscillation is imposed on a heliostat and a frequency analysis of a time series of images of the receiver extracts the contribution of the heliostat in question.

Backward gazing cameras mounted on the tower and directly observing the heliostats are used to characterize the flux distribution by Kribus et al. (2004) and Coquand et al. (2016). Röger et al. (2012) determined the heliostat orientation by detecting the contour of the heliostat. The scanner proposed by Collins (2016) consists of an array of cameras that pass through the concentrated radiation in front of the receiver. As it measures the light field (intensity and direction of light) it can characterise each heliostat's flux spot and give feedback for closed-loop control.

\subsubsection{Optical sensor}

In addition to the cameras installed on the tower or special masts in the field, one can use sensors which are mounted directly on the heliostat to measure the orientation, either for calibration (Burisch et al., 2016a) or as feedback for closed-loop control (Pfahl et al., 2008), (Harper et al., 2016).

For closed loop control, the optical sensor detects the position of the sun and of the receiver by image processing. For a fully aligned camera, the heliostat is moved such that the image centre - also representing the normal vector of the mirror $(N)$ - coincides with the centre point between Sun (S) and receiver (R) (Fig. 19, right). For a general camera, an initial calibration of the camera with respect to the mirror is necessary. In Fig. 19 (left), the normal vector of the mirror panel is cantered between the vector to the sun and the vector to the receiver so that the rays from the sun hit the receiver. The optical sensor can be a 
commodity-type smart phone camera chip with a small standard fish eye lens which will not cause significant extra cost. Such a system is under development at DLR.
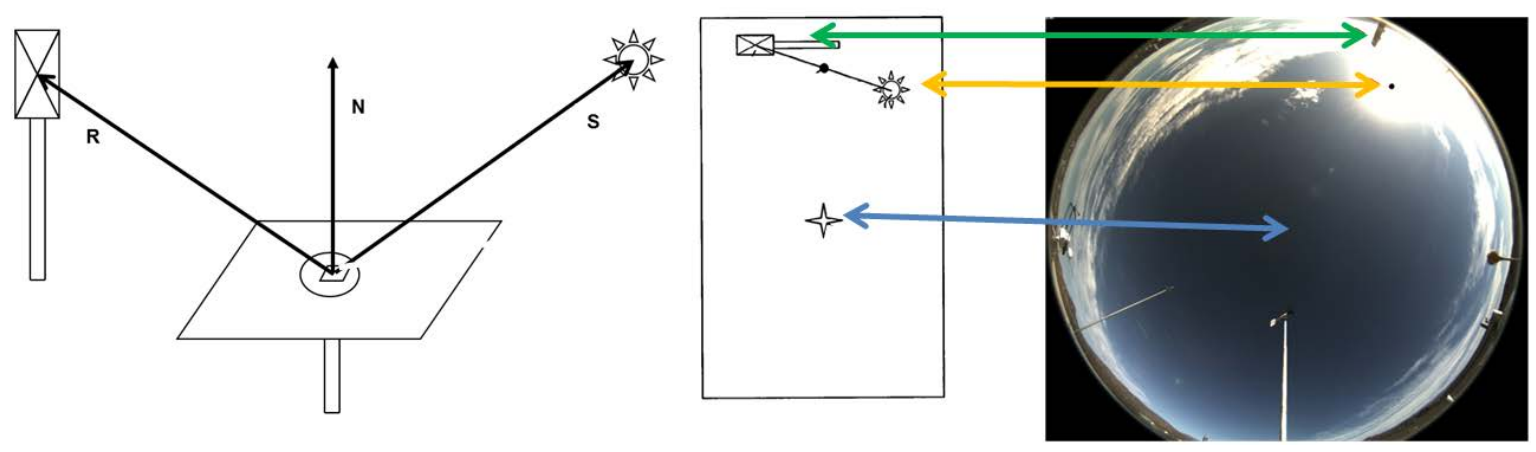

Fig. 19: Optical sensor control principle (left), image on sensor (right) (Pfahl et al., 2008), (DLR)

\subsubsection{Network: wired or wireless}

Kubisch et al. (2011) investigated the use of wireless communication devices to control heliostat fields. A heliostat field often consists of many thousand heliostats, which represent about $40 \%$ of the cost of the entire solar power plant. Around $7 \%$ of the heliostat field investment costs are generated by the power and control wiring of heliostats (CSP today, 2013a). Although additional wireless equipment is necessary, there is a cost saving potential by using wireless communication techniques combined with local power supply.

Due to additional requirements to the local heliostat electronics for wireless communication, wired heliostat fields have been the state-of-the-art in past years. However, with the rise of cheap, reliable and high performance microcontrollers, wireless communication for heliostat fields is employed for large towers such as Ashalim (BrightSource, 2016).

However, there are some trade-offs when using wireless communication. Due to the limited bandwidth it is difficult to directly control the motor positions of each single heliostat with a high update rate. Furthermore, the error probability is much higher. This is why each heliostat requires a more intelligent local control which takes aim points and sun position to calculate the necessary motor position. The local intelligence reduces network traffic and can do some error correction. Wireless heliostat fields have substantial cost saving potential.

\subsubsection{Heliostat field control}

As the heliostats collect and concentrate the sunlight, the temperature on the receiver and the flux distribution needs to be controlled. Due to changing environmental conditions, the control system has to continuously adapt the heliostat aim points, to achieve a desired and efficient flux distribution and, hence, temperature profile on the receiver. Depending on the heliostat type and the plant setup, the system has to coordinate the heliostat calibration and take care of the heliostat monitoring. At Solar Two, a dynamic aim point system (DAPS) using computer codes developed by the University of Houston changed aim points throughout the day. This minimized spillage and kept the peak flux below the specified receiver flux limit. Sandia's DELSOL code also has this capability (Zavoico, 2001), (Kolb, 2017). DLR is currently developing a universal heliostat control system (Gross et al., 2016) which can handle the mentioned tasks for various different heliostat and receiver types.

Fig. 20 shows the success of the temperature control for the simulated open volumetric receiver and simulated 2153 heliostats. The actual output temperature follows closely the set value through ramp up operation, although the synthetic DNI shows sudden changes from "clouds". Temperature deviations happen when the available power is insufficient to meet the 
demand - either because of initial movement from stow to track or lack of DNI. The figure also visualizes the number of sent heliostat commands. In case of sudden DNI changes the system has to actively adapt the number of tracking heliostats. In case of a wireless connected heliostat field, the control system should try to minimize the number of sent commands.
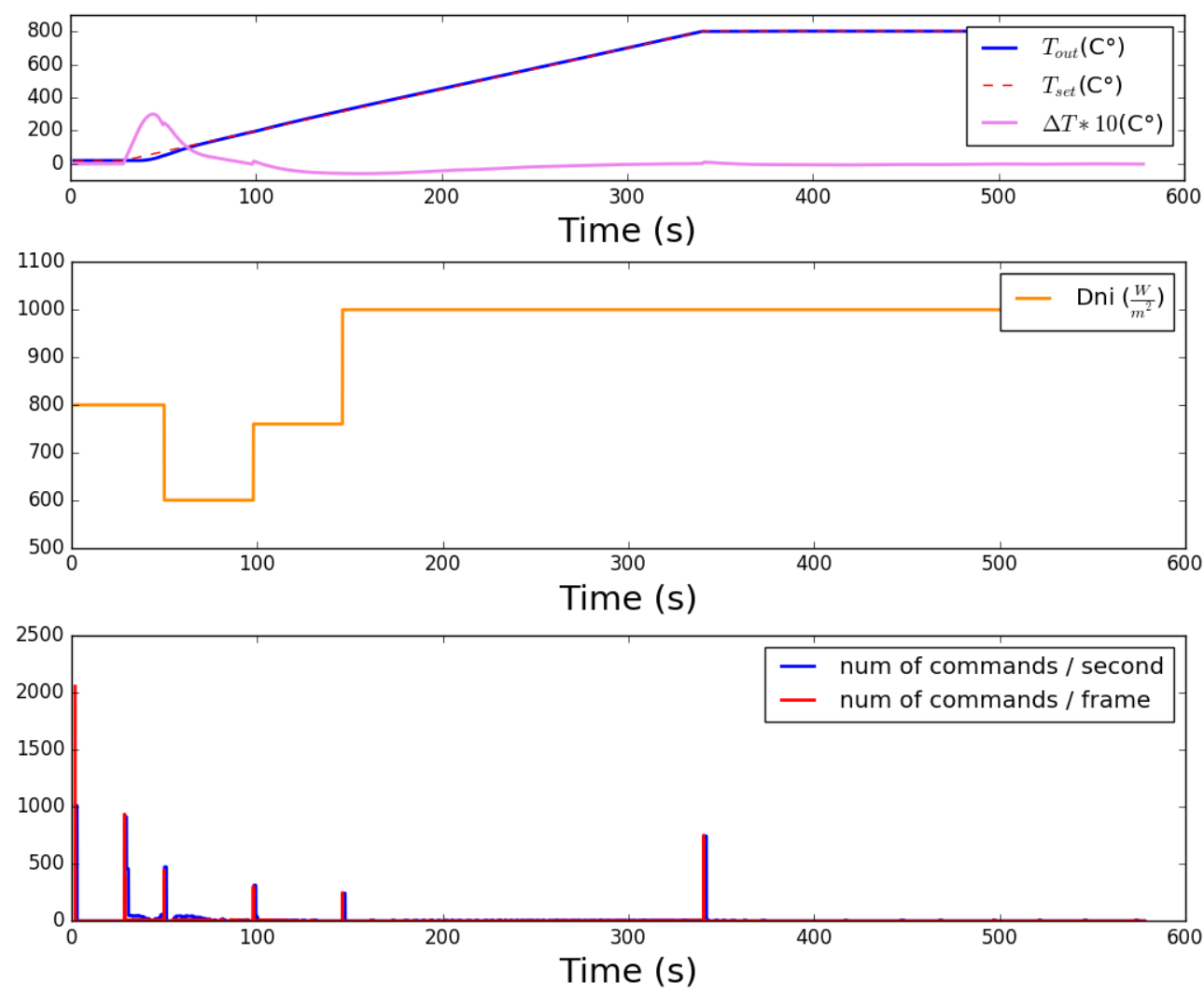

Fig. 20: Simulation of an open volumetric receiver heating up $\left(2.5^{\circ} \mathrm{C} / \mathrm{s}\right)$. The upper graph shows the "actual" ( $T_{\text {out }}$ ) and "set" ( $T_{\text {set }}$ ) temperature and their difference (multiplied by 10), the middle diagram shows the DNI perturbation and the lower diagram shows the number of commands to the heliostat field sent by the control system (DLR)

Fig. 21 shows the result of a simulation of a dynamic aim point distribution, controlled by the DLR control system. The system tries to continuously adapt the aim points of the heliostats, to never exceed given flux limits on the target surface. Additionally, the system tries to maximise the overall efficiency (i.e. reduce beam spillage) of the field by keeping the aim points close to the middle of the target. 


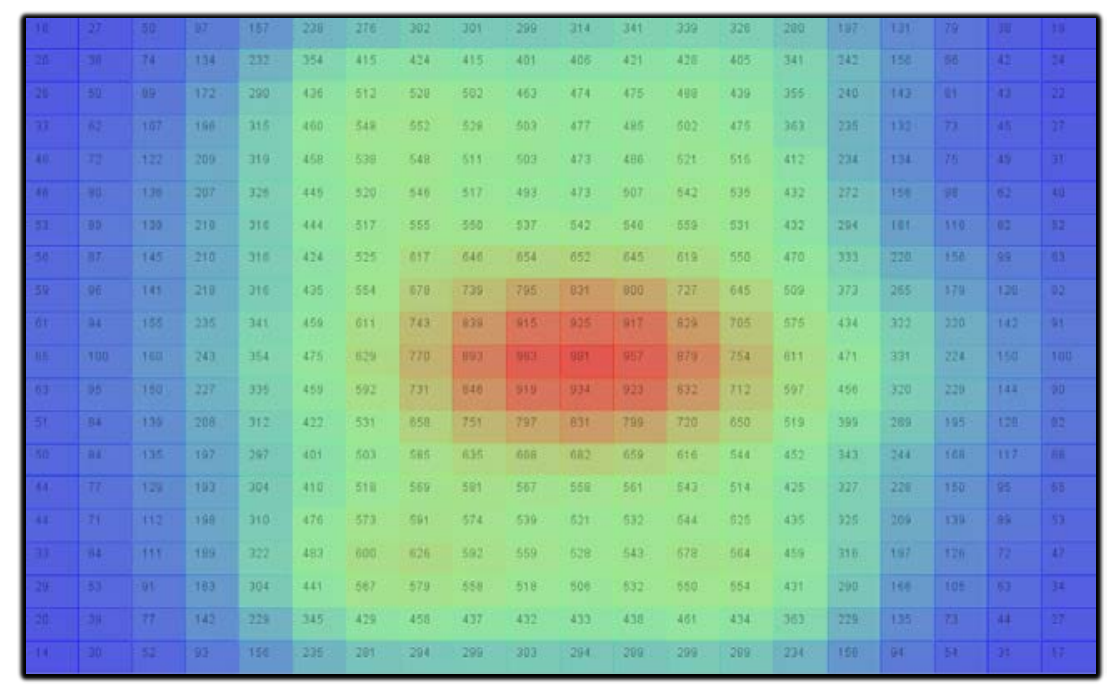

Fig. 21: Simulation of a dynamic flux distribution on an open volumetric receiver (DLR)

Other types of receivers like direct steam or molten salt receivers do have other local constraints on allowable flux and temperature, but the overall task remains the same. Ramping up and down, and safe reaction time, are also technology dependent.

\subsection{Drives (rotation of mirror panel)}

Coventry et al. (2016, paragraph 14) give an overview of the main heliostat drive systems. Summarised, it is stated that "actuation systems have long been one of the key cost drivers for heliostats. The pedestal mounted azimuth drive system has been one of the main drivers to larger size heliostats. However, some technology developers believe linear drive systems are cheaper, and can completely replace azimuth drives. Alternative drive systems, such as rim drives with cables, have been proposed to avoid the cost of pedestal mounted systems. Hydraulic drive systems have been used cost effectively on large heliostats."

Téllez et al. (2014, paragraph 2.5) list and describe two kinds of power sources of the drives - rotary electromagnetic motors and hydraulic actuators - and different kinds of mechanical transmission from the power source to the rotary axes - worm gear, spur gear, spindle, chain gear, harmonic drive, capstan drive, planocentric drive, rack and pinion and friction wheels.

\section{Heliostat designs}

Different combinations of single heliostat sub-functions describe a complete heliostat design. In the following section, current heliostat designs known to the authors are presented with focus on the special design features of each heliostat. The designs are divided into two groups: commercial heliostats and possible next generation heliostats. The amount of details given differs and depends on the information that was available to the authors.

\subsection{Commercial heliostats}

\subsubsection{Abengoa (ASUP 140)}

Abengoa has developed a $138.7 \mathrm{~m}^{2}$ hydraulic heliostat with sandwich facets (Abengoa, 2017), (Fig. 22). By the patented hydraulic drive mechanism (Ceron Garcia, 2013) complete azimuth rotation is possible. The bearings of the elevation axis are below the continuous torque tube to avoid large size of the bearings. The elevation axis is shifted from the centre 
of gravity to achieve pre-tensioning of the elevation drive to eliminate back lash (compare §3.2.).
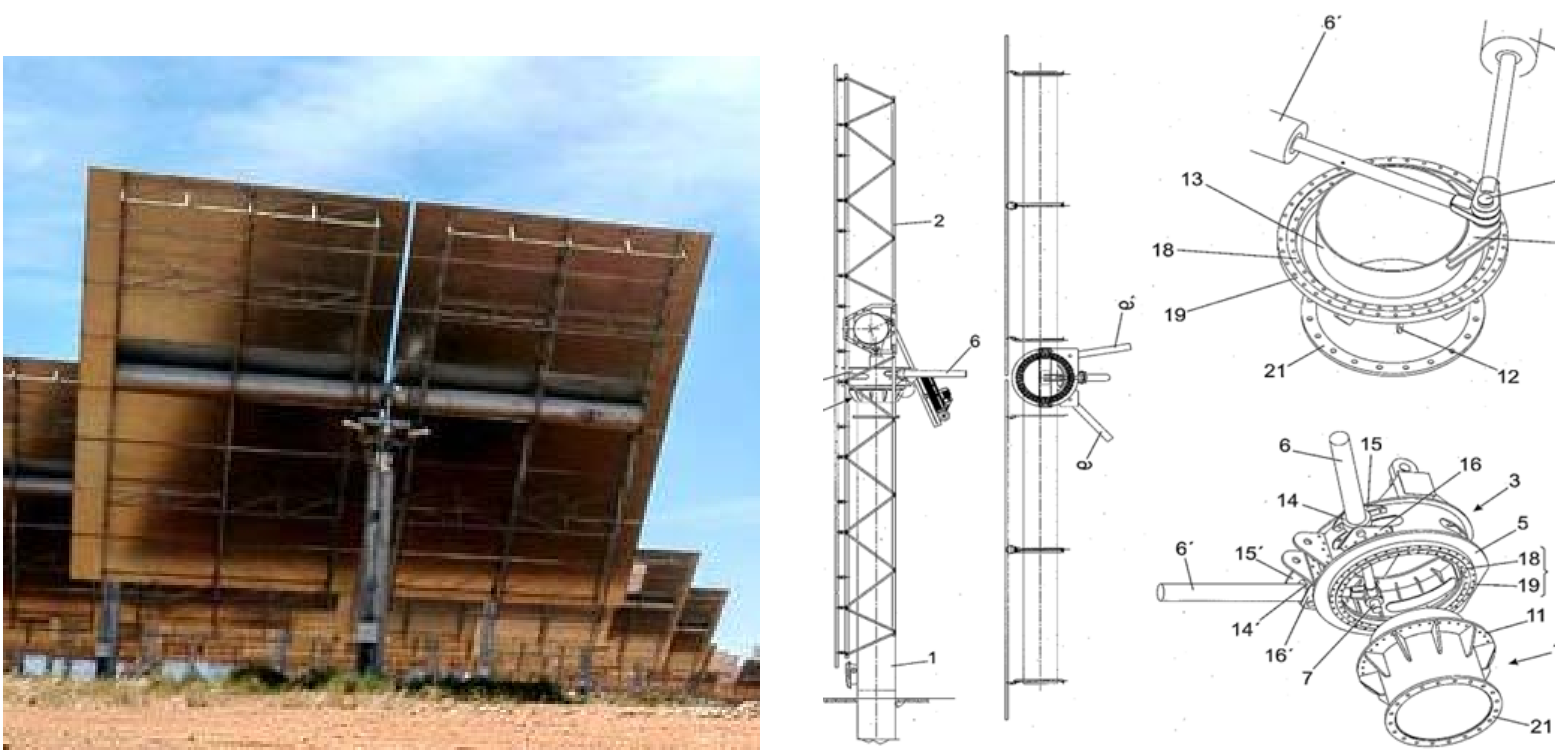

Fig. 22: Abengoa's $180 \mathrm{~m}^{2}$ hydraulic heliostat with sandwich facets (Silva, 2017) (Ceron Garcia, 2013)

\subsubsection{AORA Solar}

AORA Solar's heliostat has a dual-layer grid structure formed from metal sheets as mirror support structure, a square torque tube and an unusually long linear actuator for elevation (Fig. 23).
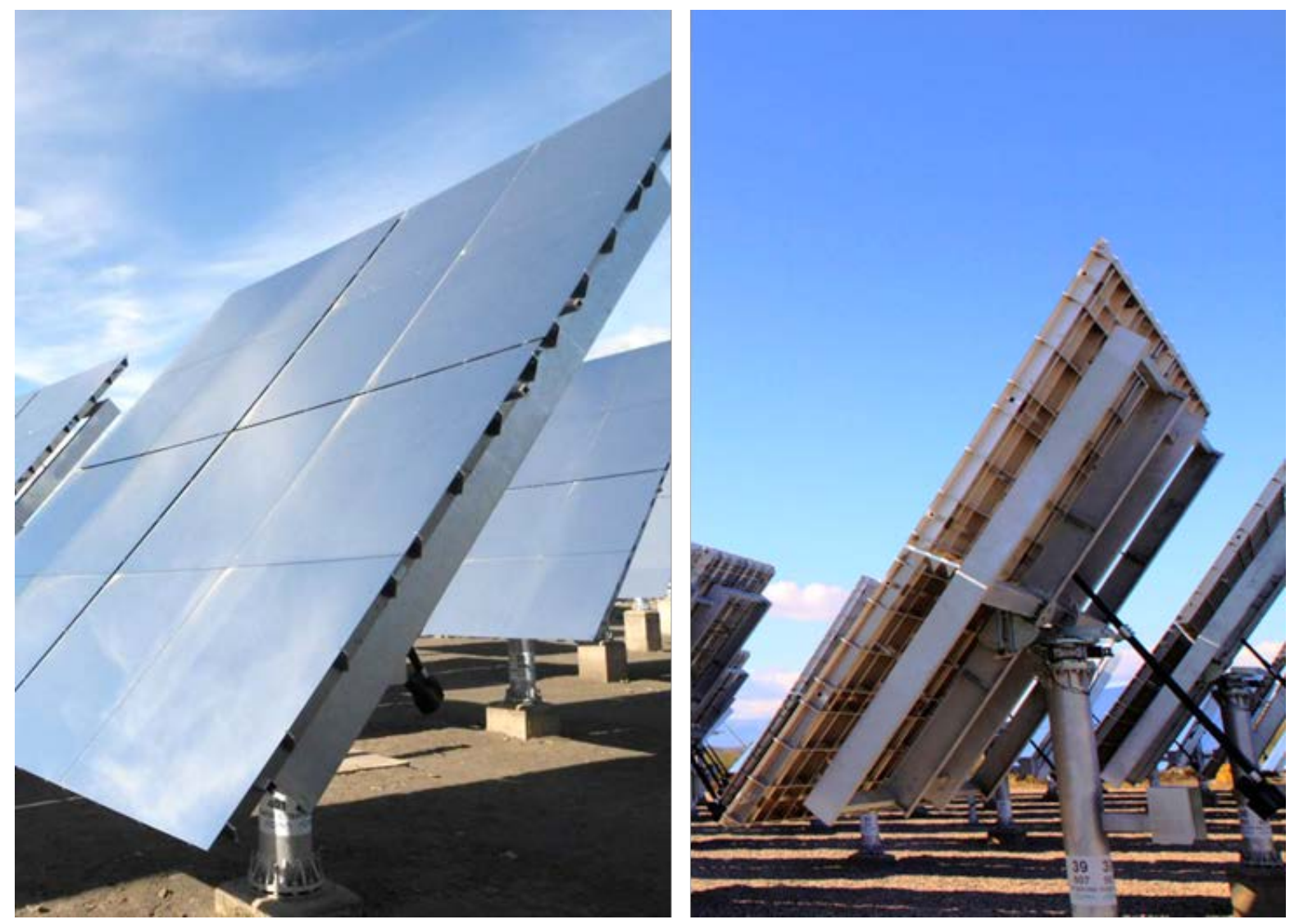

Fig. 23: AORA Solar's heliostat with grid support structure and square torque tube (AORA, 2017a, 2017b) 


\subsubsection{BrightSource Energy (LH 2.2 and LH 2.3)}

A central component of the BrightSource heliostat (Fig. 24, left) is the cast bearing support (Fig. 24, right). It is formed in a way that the bearing is above the torque tube for better weight balancing and that a continuous torque tube can be realized without the need for big bearings surrounding it.
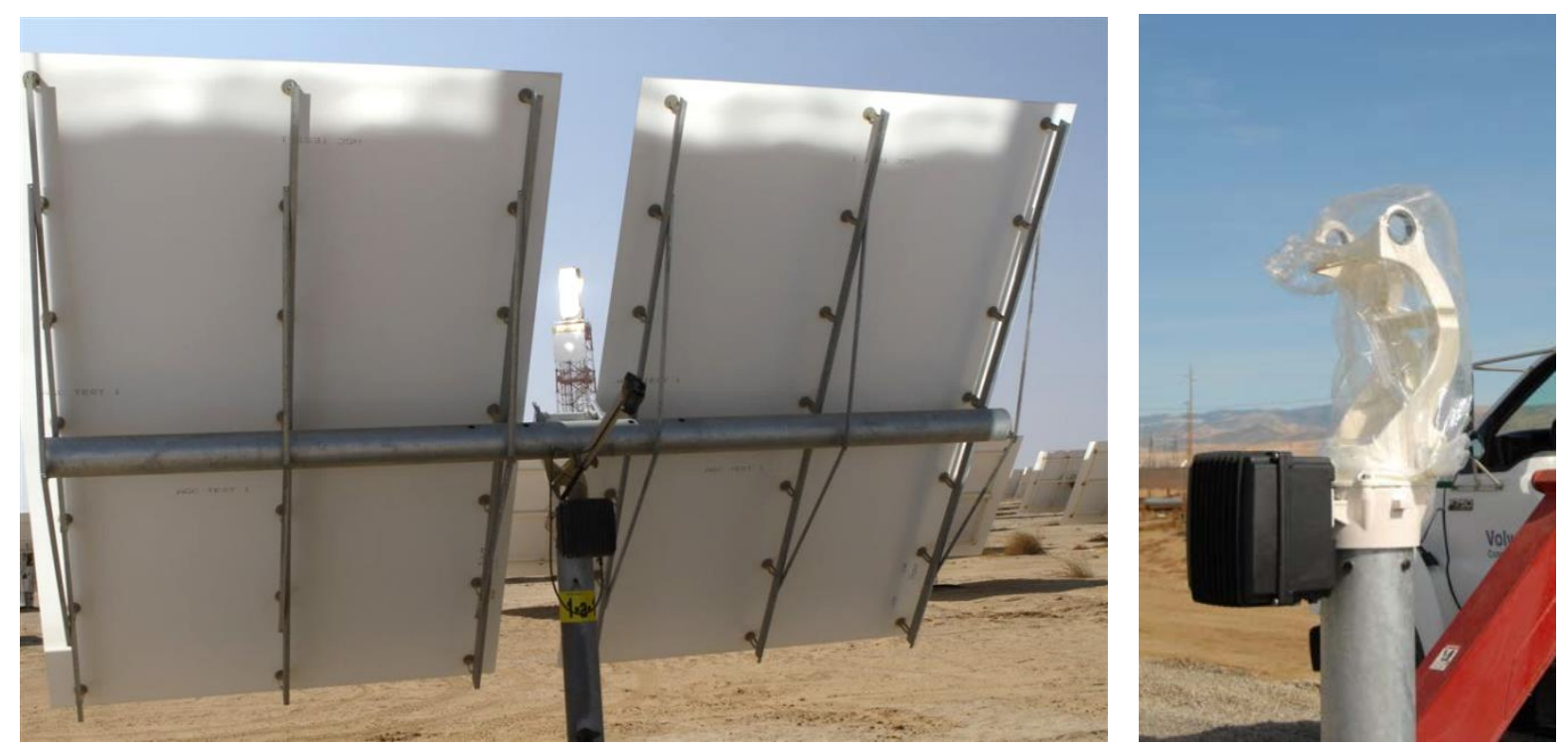

Fig. 24: Left: BrightSource's 15.2m² LH 2.2 heliostat at Ivanpah; Right: cast central bearing support (BrightSource Energy, 2010)

For the new design, the facets are not glued to the support structure by pins and pads (Fig. 16) but with linear contact (Fig. 25). The new LH2.3 collector at the Ashalim plant has an increased mirror area of $20.8 \mathrm{~m}^{2}$ (NREL, 2017).

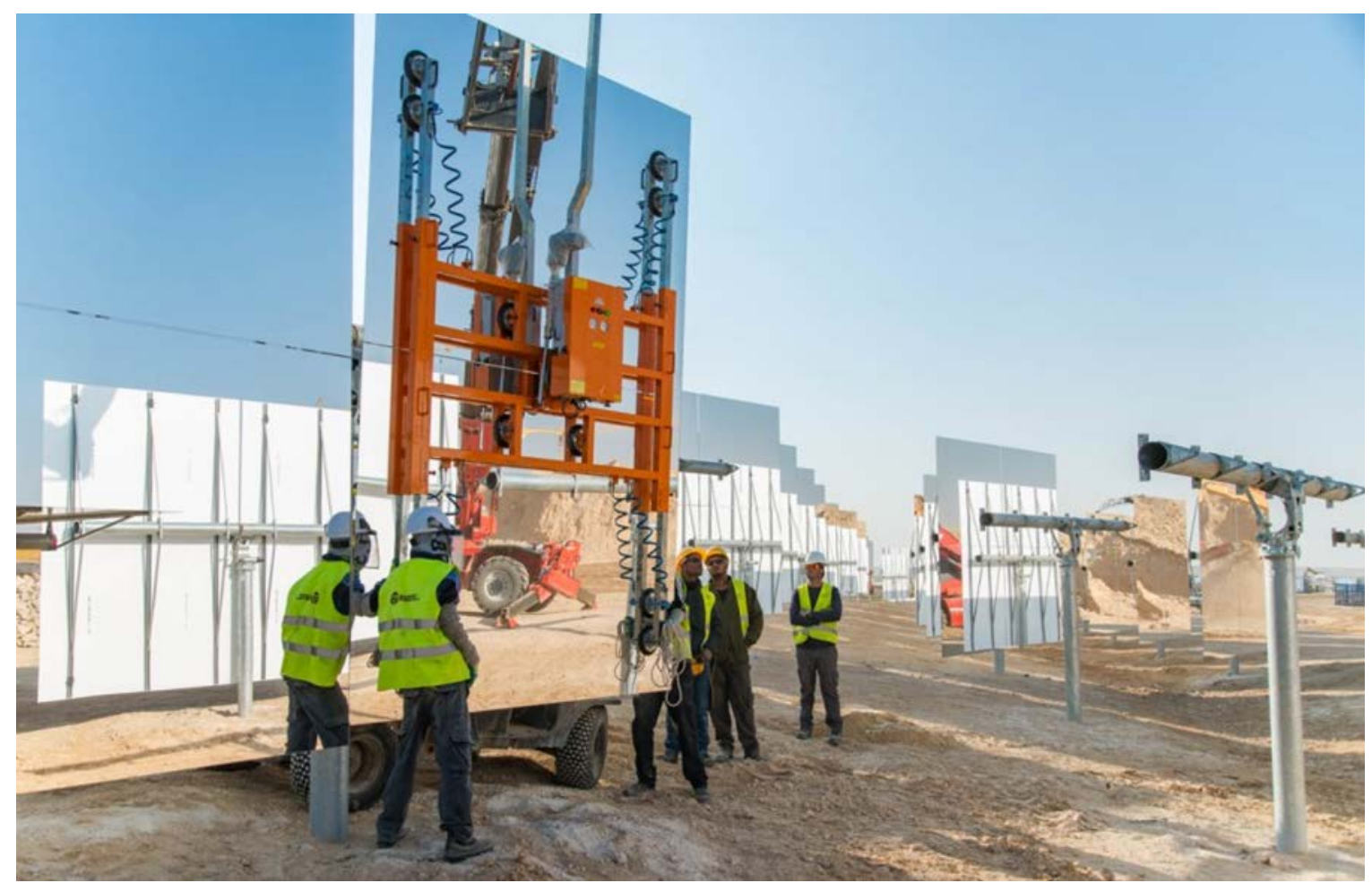

Fig. 25: BrightSource heliostat with linear bonding of the facets (Brightsource Energy, 2015) 


\subsubsection{CSIRO}

The heliostat of CSIRO is based on a single facet and two linear actuators (Fig. 26). The original size of the CSIRO heliostat was $4.5 \mathrm{~m}^{2}(2.44 \mathrm{~m} \times 1.84 \mathrm{~m})$ but today can be up to $7.22 \mathrm{~m}^{2}$ size, representing the largest manufactured sheet of glass that is still transportable by shipping container, but flexible to supplier options. The maximum design wind speed is $40 \mathrm{~m} / \mathrm{s}$, and operating wind speed $15 \mathrm{~m} / \mathrm{s}$ (Coventry et al., 2016). The first axis of rotation is horizontal to achieve a required angle range of less than $120^{\circ}$. Hence, for this heliostat type cost effective linear drives can be used for both axes (compare (Mancini et al., 2000, pp. 12f)).
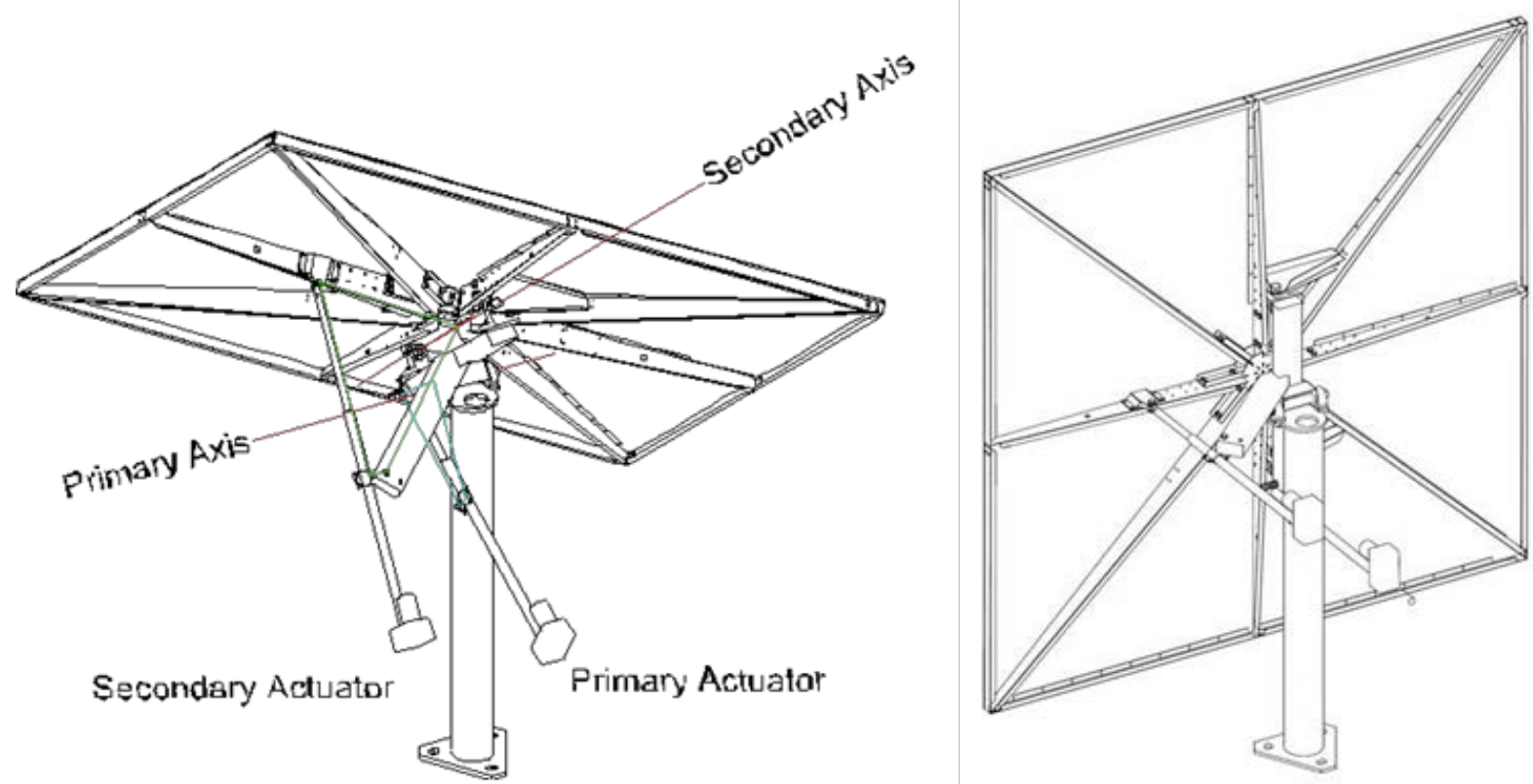

Fig. 26: CSIRO heliostat with single facet and horizontal primary axis which enables the usage of linear actuators for both axes (CSIRO)

A further advantage is the higher field density (Schramek et al., 2004, 2008, 2009). The heliostats do not rotate about the vertical axis. Hence, the heliostats of each row can be positioned closer to each other which leads to higher field efficiencies (Fig. 27).
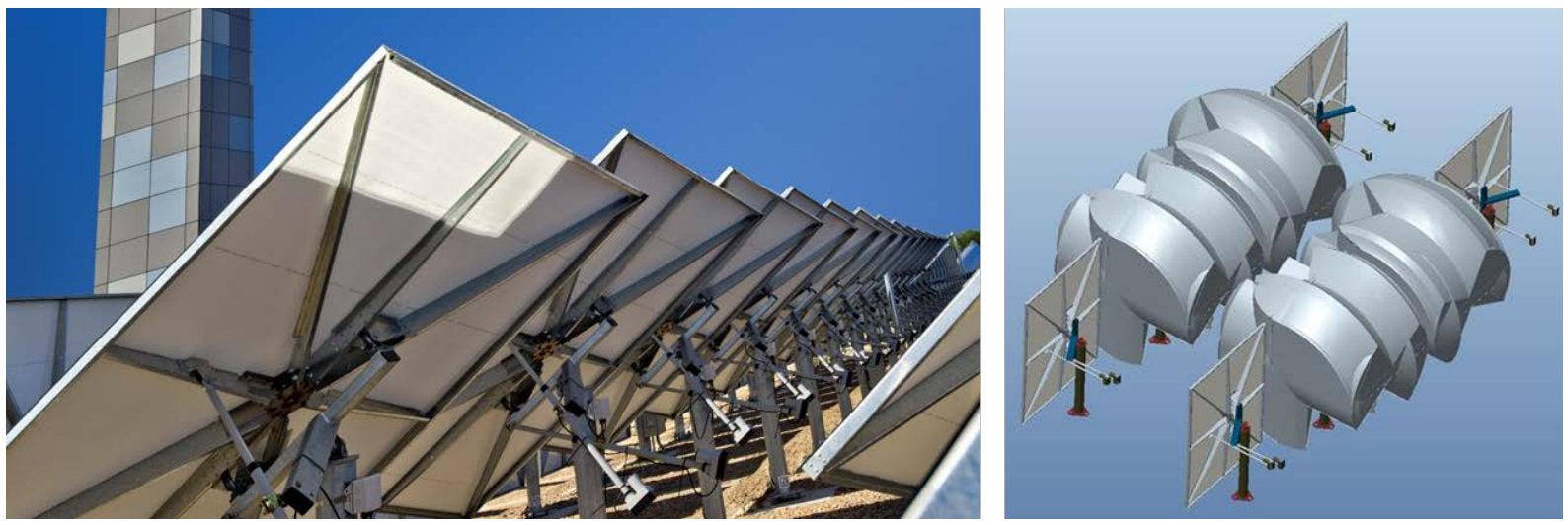

Fig. 27: Axis orientation lead to high field density (left) due to reduced required space for rotation (right) (CSIRO)

The height of the elevation axis is increased by less than $20 \%$ compared to azimuthelevation tracking because it is defined by the diagonal of the mirror panel and not only by the chord length. The increased height leads to somewhat increased wind loads, especially at the pylon base compared to an azimuth-elevation heliostat of the same area. However, the 
general benefits of small heliostats and lower wind loads still remain. Pre-tensioning of the drives by gravity is possible for most, but not all, of the range of movement in both axes, i.e. away from the well-balanced position (compare §3.2).

The "star" arrangement of the structural members that comprise the back structure (Fig. 26) is highly efficient (compare Fig. 32). Unfavourable is that the distance between the bearings of the elevation axis must be short to exclude collision with the mirror facet, though some optimization can occur by increasing the offset between primary and secondary axes. Because of the reduced mechanical advantage, the bearings must be relatively strong to be able to resist the wind loads.

\subsection{5 eSolar}

Details of eSolar's $2 m^{2}$ tripod heliostat (Fig. 28) were presented by Ricklin et al. (2014). The weight (excluding foundation) is $20 \mathrm{~kg} / \mathrm{m}^{2}$. The panels are made from simple steel frames and flat glass (compare §4.2.1). Maximum wind speed for stow is $49 \mathrm{~m} / \mathrm{s}$, and for operation $16 \mathrm{~m} / \mathrm{s}$. The stiff framework structure of the tripod reduces the loads on the pylons and foundation.

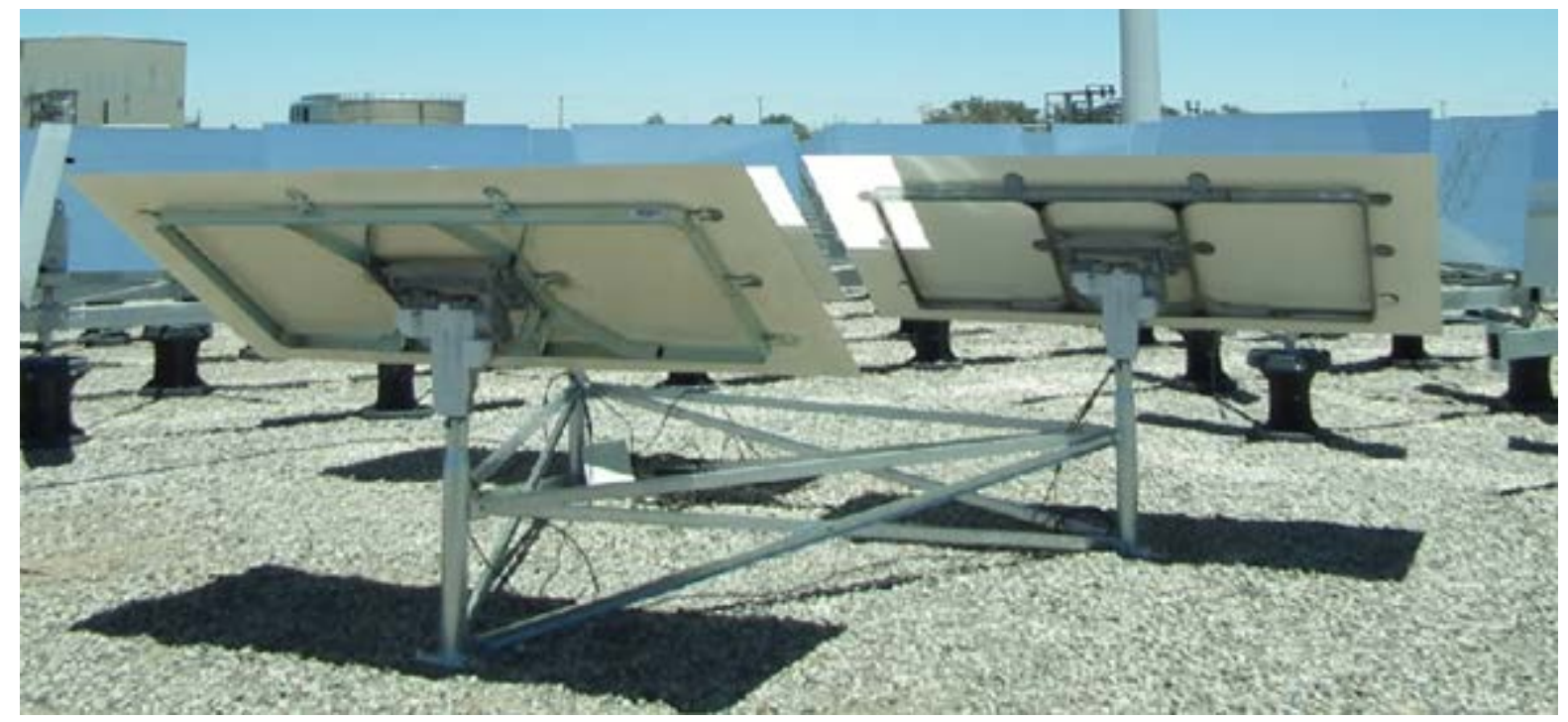

Fig. 28: eSolar's $2 \mathrm{~m}^{2}$ tripod heliostat (Ricklin et al., 2014)

\subsubsection{Heliosystems (PATH)}

Heliosystems has built 8 target aligned heliostats of $12 \mathrm{~m}^{2}$ (PATH03). The current design was developed in 2015 (Fig. 29). A former version (PATH01) was developed in 2011 and tested with over 650 heliostats. 

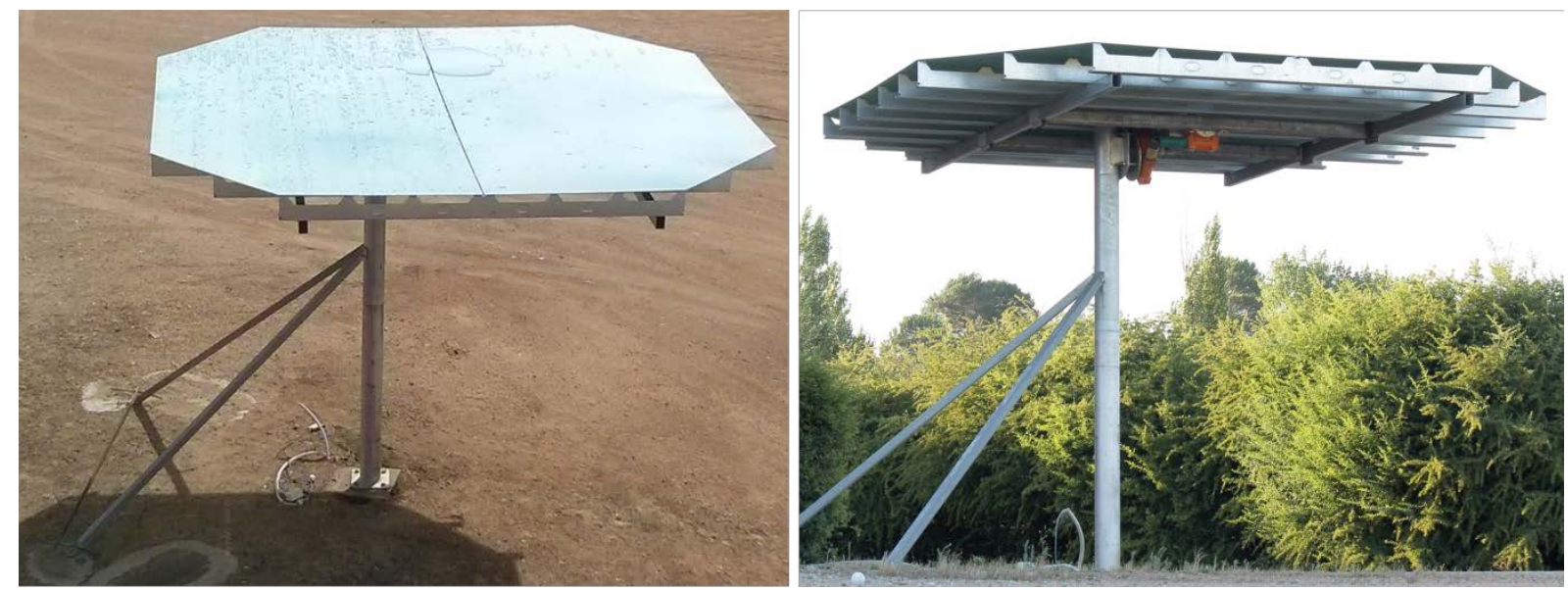

Fig. 29: Target aligned $12 \mathrm{~m}^{2}$ heliostat of Heliosystems (Heliosystems)

The reason for building target aligned heliostats is that parabolic shapes reflect rays to a small focal point - but only if the rays are parallel to their optical axis. For other directions the focal spot is widened. This optical error, called "astigmatism", can be reduced by an optimised canting of the mirror facets for all heliostat types, and especially for target aligned heliostats (Zaibel et al., 1995) where incoming and reflected rays are always in a plane fixed relative to the mirror plane (Buck and Teufel, 2009). The bigger the ratio of mirror area to distance to the receiver, the higher the achievable improvement in interception at the target.

Target aligned heliostats are of interest especially for applications requiring high concentration ratios. For the Heliosystems' heliostat, the astigmatism correction is achieved by changes to the mirror shape during operation with independent curvature in sagittal and tangential directions. The shape change is made passively without actuators or extra drive systems by making use of the elevation rotation and gravitational sag (Lehmann and Allenspach, 2012), (Lehmann et al., 2012). The heliostat's weight is $290 \mathrm{~kg}$. Slewing drives powered by 24V PMDC or BLDC gear-motors and proximity sensors are used. The design is adapted to the maximum expected wind speed which can be up to $50 \mathrm{~m} / \mathrm{s}$. For the foundations, a concrete pier, precast slab or linked ground-screws are used. Two light stays increase stability and improve tracking accuracy under windy conditions (Lehmann, 2017).

\subsubsection{Kraftanlagen München}

The heliostat of Kraftanlagen München (KAM) has a size of $14 \mathrm{~m}^{2}$. The mirror facets are connected to the cross beams by pins and pads (compare §4.2.1). 28 prototypes were built in 2016 and are in operation (Fig. 30). 


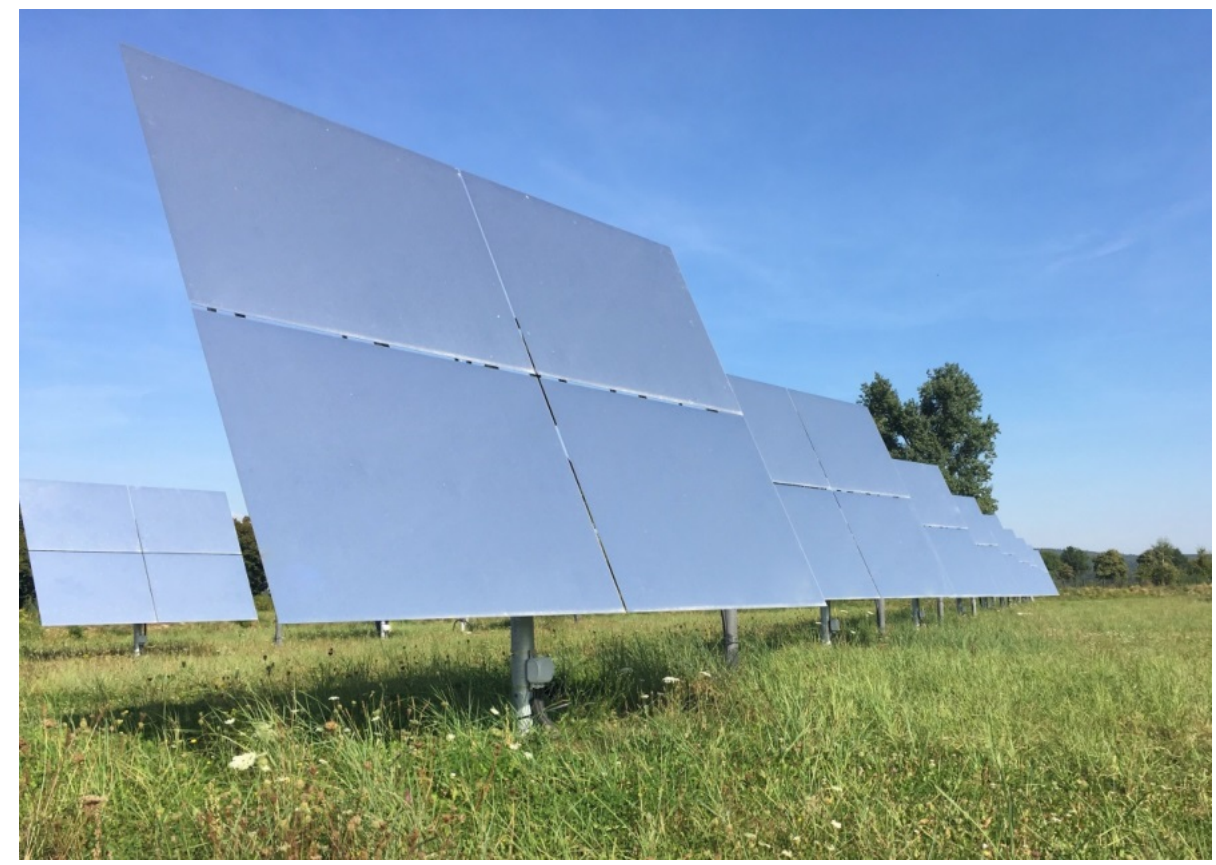

Fig. 30: 14m² heliostat of Kraftanlagen München at the Solar Tower Jülich (KAM)

\subsection{8 schlaich bergermann partner (Stellio)}

The new $48 \mathrm{~m}^{2}$ heliostat "Stellio" of schlaich bergermann partner (sbp) was presented by Balz et al. (2015) (Fig. 31, left). Usage of linear drives for both axes is enabled by a special axes arrangement reducing the required angular ranges for both axes (Haberstroh et al., 2015). The kinematics is selected in such a way that the linear drives are mostly tensile-loaded. Hence, buckling is not a problem, and cost-efficient drives can be used which are a tailored commodity product. The concentrator is pentagonal, as more closely approximating a round shape helps reduce shading and blocking, and allows for a compact field layout. High optical precision at low cost is achieved by a jig-based easy assembly method (Fig. 31, right). Measurements have confirmed high optical accuracy of the mirrors.
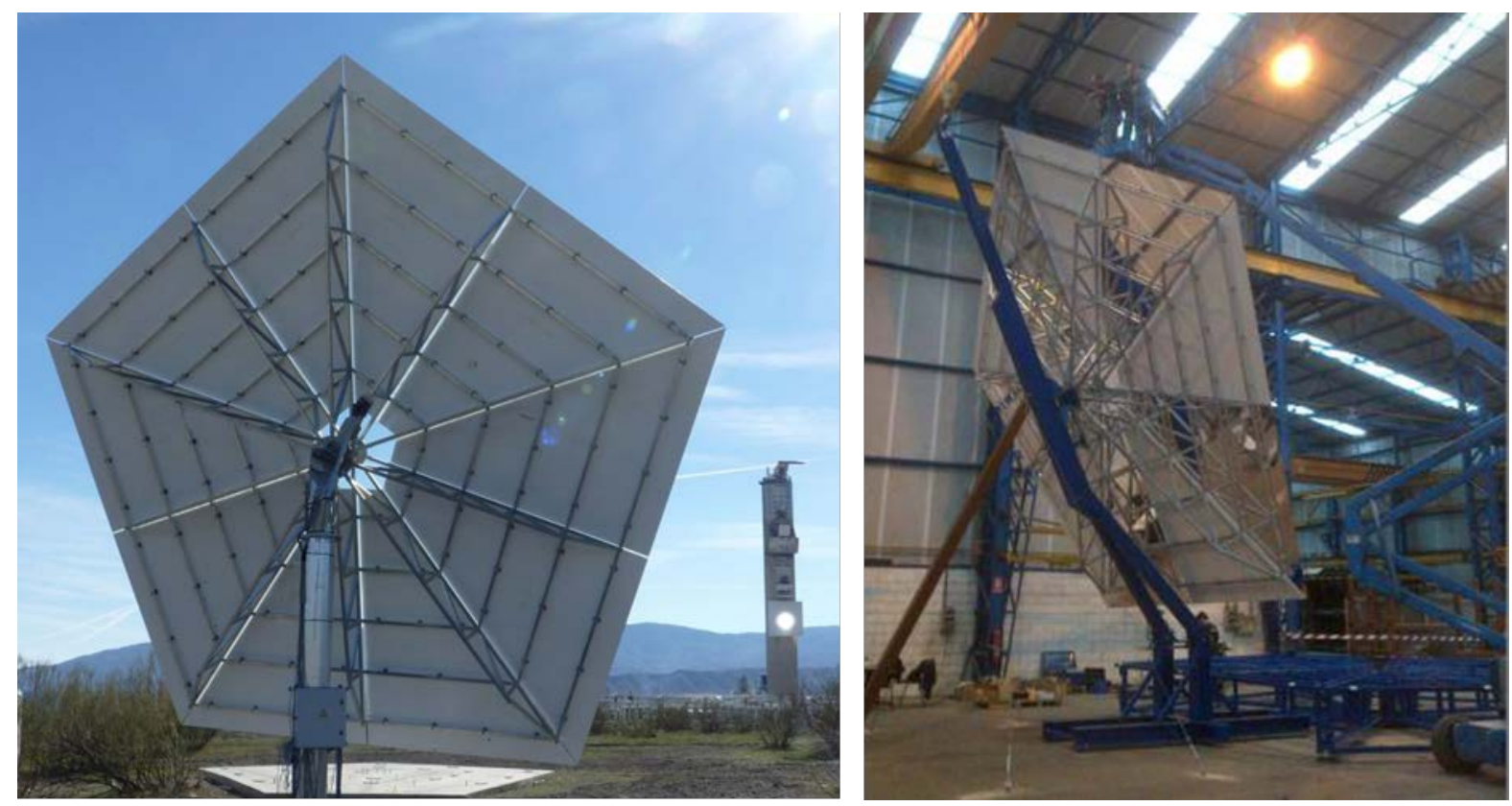

Fig. 31: 48m² heliostat „Stellio“ of schlaich bergermann partner at the Plataforma Solar de Almeria (sbp), (von Reeken et al., 2015) 
The Stellio concentrator is of low steel mass which is achieved by reducing the load path through the support structure. The support structure of the Stellio heliostat is evenly utilized, whereas a torque tube of conventional T-type heliostats is efficiently utilized only close to the drives, i.e. the centre, compare Fig. 32 (von Reeken et al., 2015). With the efficient Stellio design, a heliostat field cost of $\approx 100 \mathrm{USD} / \mathrm{m}^{2}$ is achieved (sbp, 2017).
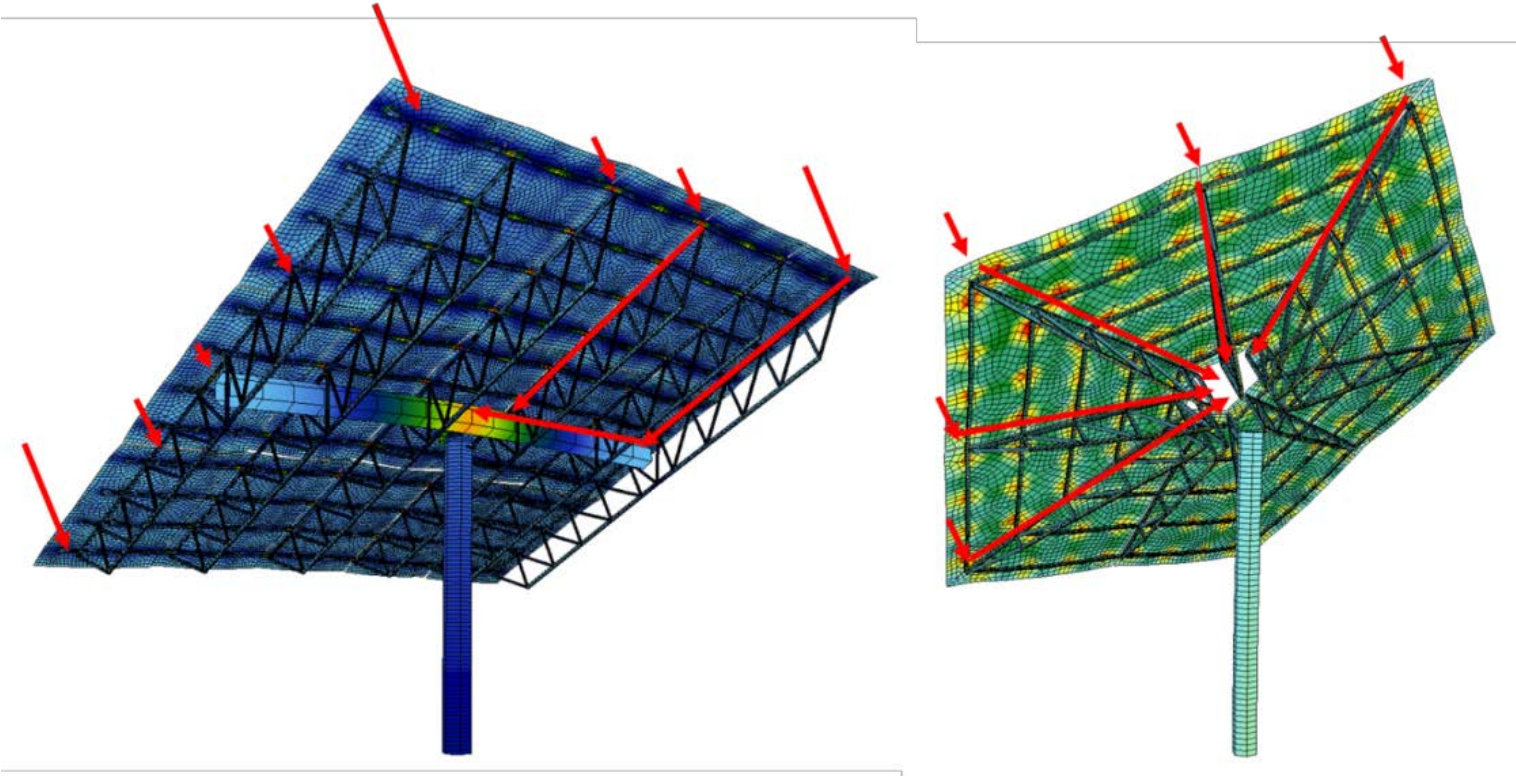

Fig. 32: Load path through the mirror support structure of a conventional T-type heliostat (left) and through the support structure of the Stellio heliostat (von Reeken et al., 2015)

\subsubsection{SENER}

The new heliostat of Sener is of $178 \mathrm{~m}^{2}$ size, uses hydraulic drives, and has stamped mirror facet support structures (\$4.2.2) and a concrete pylon (Fig. 33). Hydraulic drives are precise and cost effective especially for high loads and therefore for big heliostats. The hydraulic drive mechanism of Sener has three pistons for the azimuthal rotation (Abengoa's has only two, compare \$5.1.1). Extra pistons do not cause much extra cost compared to the hydraulic aggregate with pump and pressure reservoir. The advantage of three pistons is that the loads on the single pistons during rotation are more equal which reduces the maximum loads on the complete drive mechanism (Lecube Inchausti et al., 2016). 

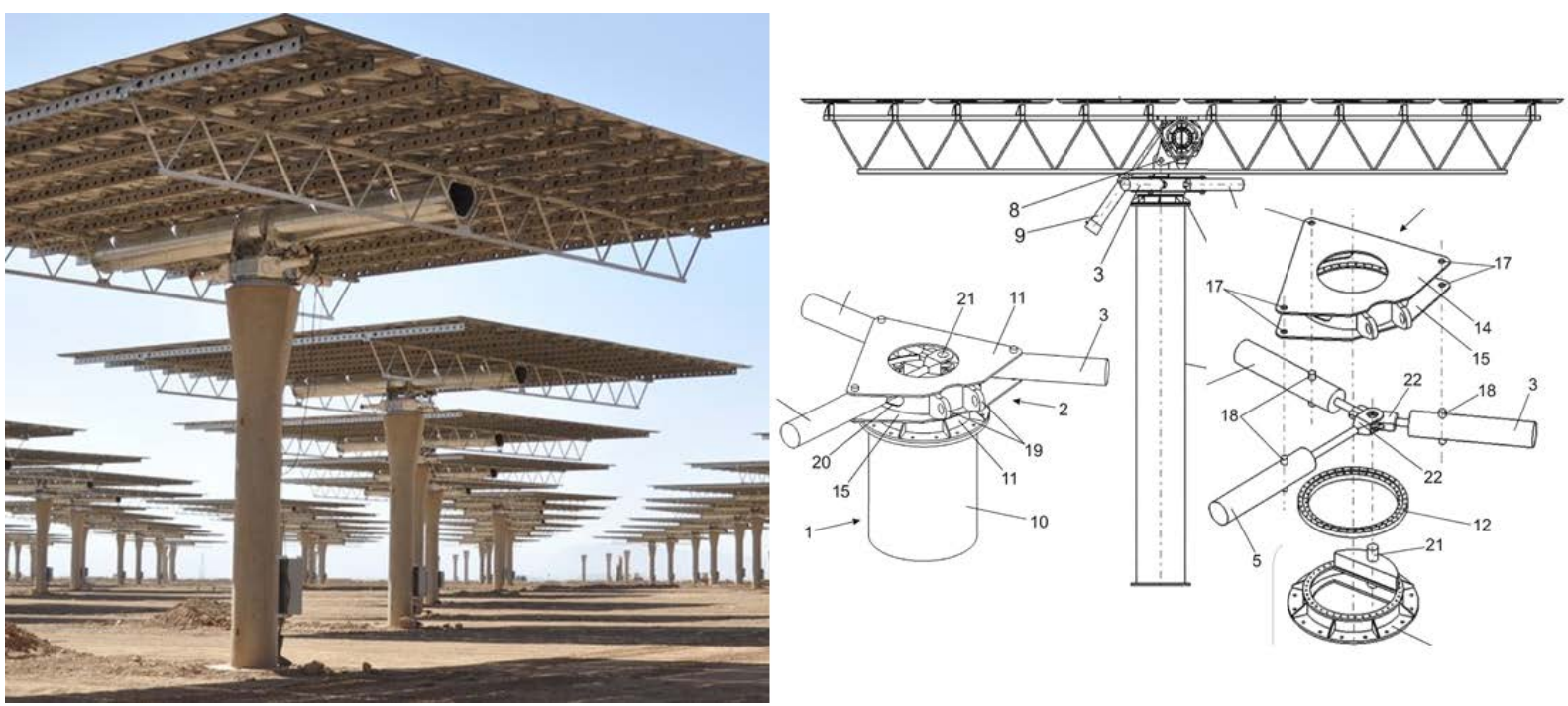

Fig. 33: Sener's $178 \mathrm{~m}^{2}$ heliostat with hydraulic drives and concrete pylon (Endres, 2017), (Lecube Inchausti et al., 2016)

\subsubsection{SolarReserve}

About the heliostat of SolarReserve not much information is available (SolarReserve, 2017). SolarReserve is continuing to find ways to take cost out of their large heliostat designs and is engaged in advanced R\&D activities to identify "step" reductions in collector field cost. These include innovative control, communication, powering, optical and mechanical elements (Deck, 2017).

\subsubsection{Titan Tracker (STD-150 HE and STD-264 HE)}

Titan Tracker offers carousel heliostats of $150 \mathrm{~m}^{2}$ and $264 \mathrm{~m}^{2}$ mirror area (Titan Tracker, 2017a). The concentrator is divided into two parts, enabling support of the elevation axis at the front of the panels, see Fig. 34 (Cabanillas Sandana, 2010). Framework structures are used to achieve high stiffness for relatively low mass. The heliostats are designed for $40 \mathrm{~m} / \mathrm{s}$ maximum wind speed for stow position and $23 \mathrm{~m} / \mathrm{s}$ for working positions.
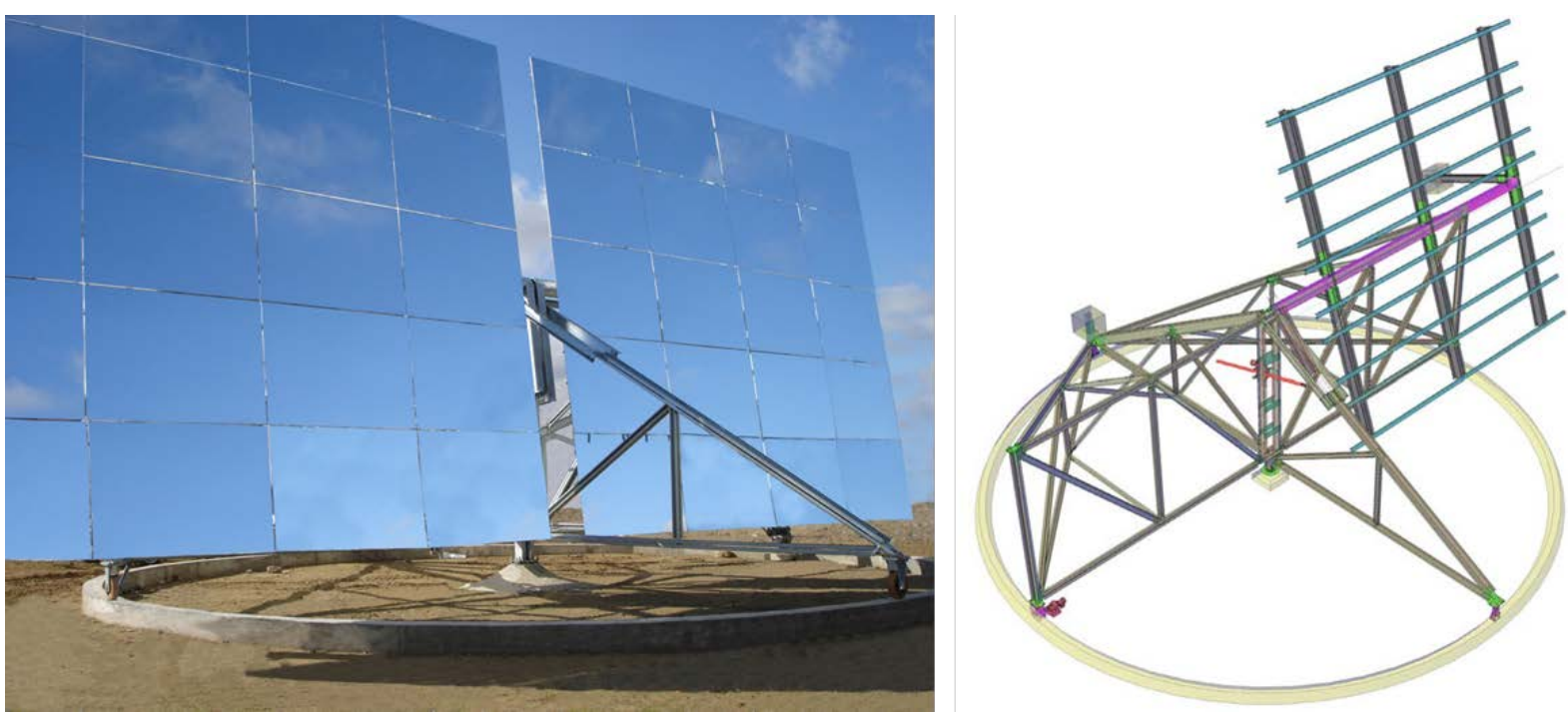

Fig. 34: Titan Tracker's heliostat of $150 \mathrm{~m}^{2}$ and $264 \mathrm{~m}^{2}$ size with carousel carriage and divided concentrator for frontal support of elevation axis (Titan Tracker, 2017a)

The tracker has a patented mechanism which allows for adaptations to possible irregularities in the race way. Tongue and groove joints at the pylon top, and hinges at the pylon base, 
allow the framework structure to rotate lowering its end and to keep the wheels in contact with the race way, see Fig. 35 (Cabanillas Sandana, 2010).

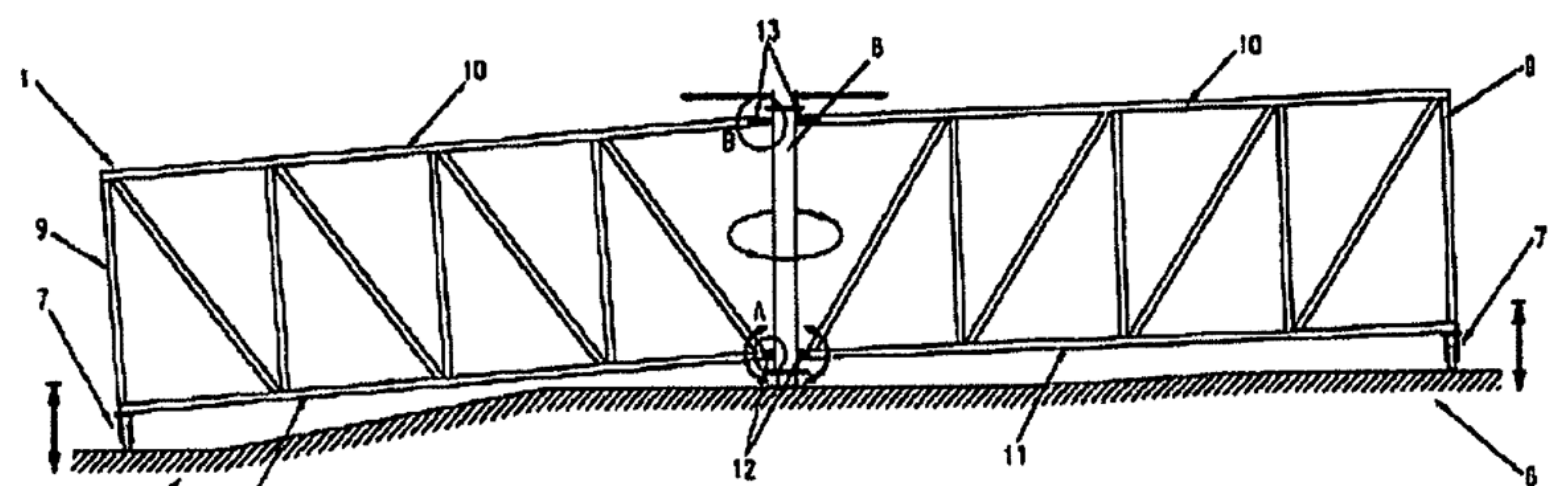

Fig. 35: Mechanism for adaptions of the framework structure to irregularities in the race way to keep the wheels in contact with the race way (Cabanillas Sandana, 2010)

For low precision applications (like PV trackers) formwork is not needed for the construction of the track. It does not require any ditches or excavation, and is constructed directly on the ground without moulds, see Fig. 36, left and middle (Titan Tracker, 2017b and 2017c). In combination with closed loop control (compare e.g. \$4.4.2) this low cost solution could be also be applicable for heliostats. For dish systems closed loop control is already realized (Titan Tracker 2017d). The long distance of the wheel drive to the centre of rotation and the additional chain gear (Fig. 36, right) allows the usage of comparably small and low cost gear motors (Fig. 35, middle).
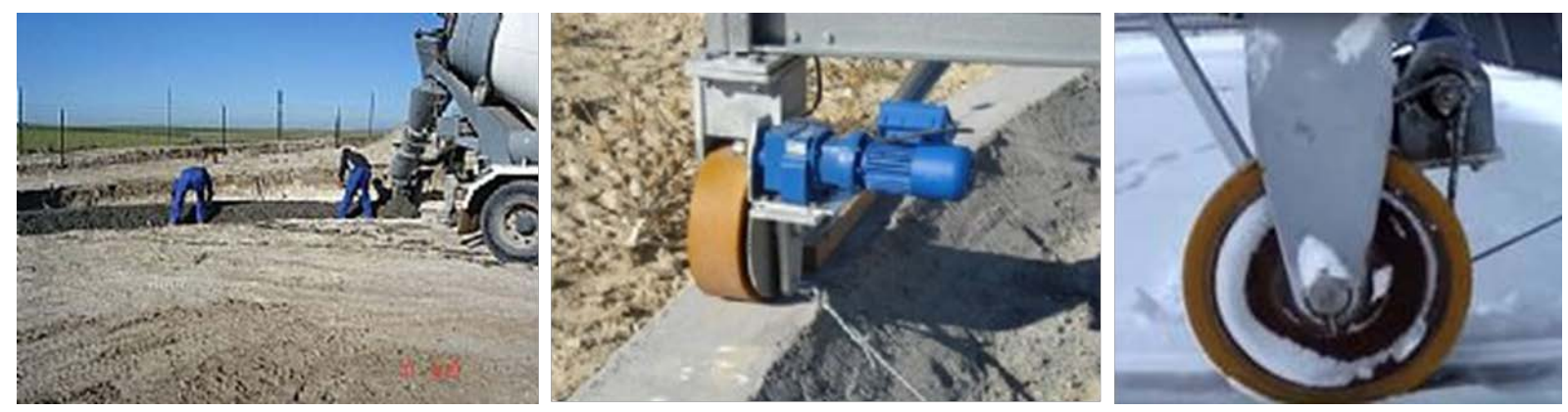

Fig. 36: Left and middle: Low cost race way of Titan Tracker for low precision applications (PV trackers) which is applicable also for high precision applications (CPV, dishes and heliostats) in combination with closed loop control; Middle and right: wheel drive with chain gear (Titan Tracker, 2017b, 2017c, 2017e)

\subsubsection{Greenway}

The $16 \mathrm{~m}^{2}$ heliostat of Greenway (Fig. 37, left) is tested for wind up to $44 \mathrm{~m} / \mathrm{s}$ for stow position and up to $12.5 \mathrm{~m} / \mathrm{s}$ for operation mode (Greenway, 2017). The central bearing support (Fig. 37 , right) is similar to that of BrightSource's LH 2.2 heliostat (compare §5.1.3). 

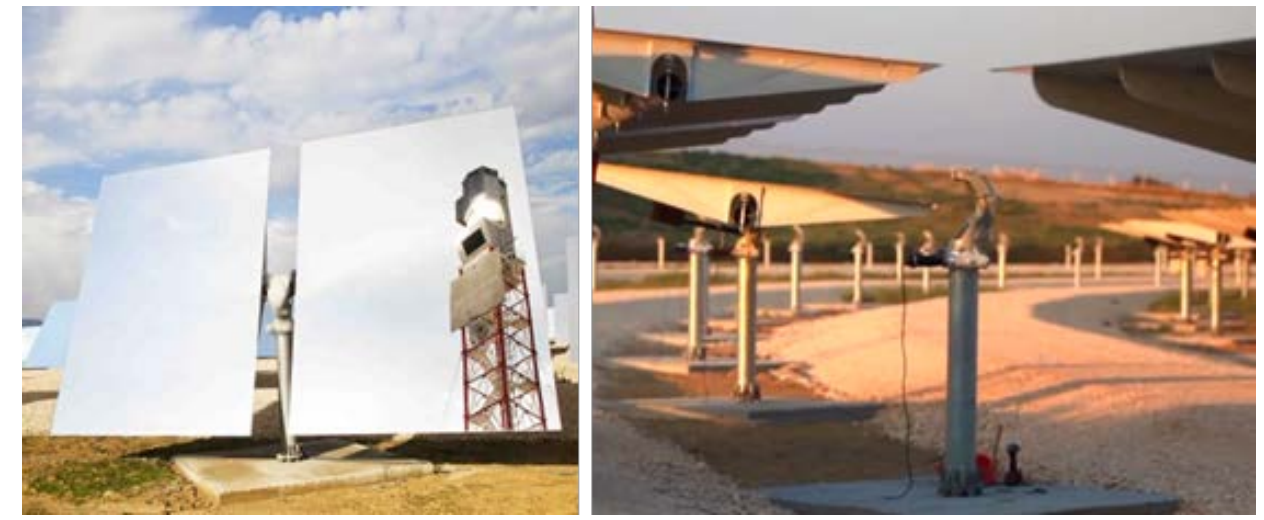

Fig. 37: Left: Greenway‘s 16m²; Right: central bearing support (Greenway, 2017 and 2014)

The cantilever arms of the mirror support structure are made from lightweight composite material (Fig. 38).

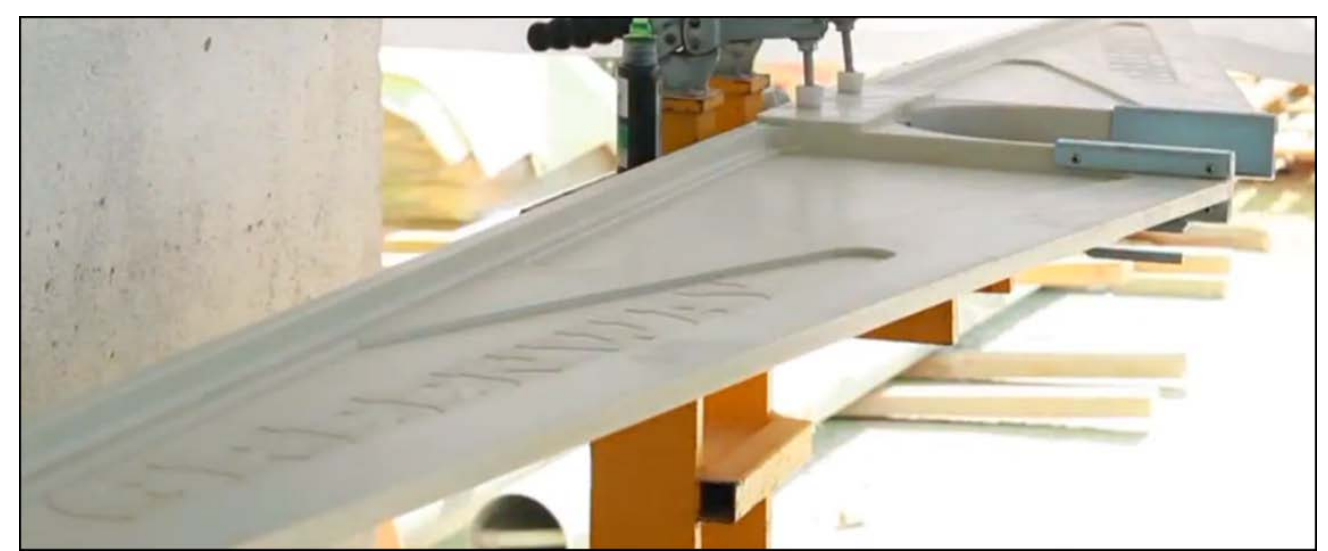

Fig. 38: Cantilever arms of mirror support structure made from lightweight composite material (Greenway, 2014)

\subsubsection{Solaflect Energy (Suspension Heliostat)}

Solaflect's suspension heliostat consists of 16 facets of $1 \mathrm{~m}^{2}$ size (Fig. 39). The support structure does not include a torque tube or truss supports which leads to low weight (Bender et al., 2011). Instead, the mirror facets are suspended by using poles and cables. The load capacity of the cables and poles is extraordinary high because the whole cross section of the material is loaded with the same tension or pressure respectively (in contrast to bending of beams), and hence the material is utilised completely to carry the load (compare (Ulmer, 1998)). A drawback of the design is that conventional cleaning of the mirrors is not possible. Cleaning robots might be a solution (Hardt et al., 2011). 


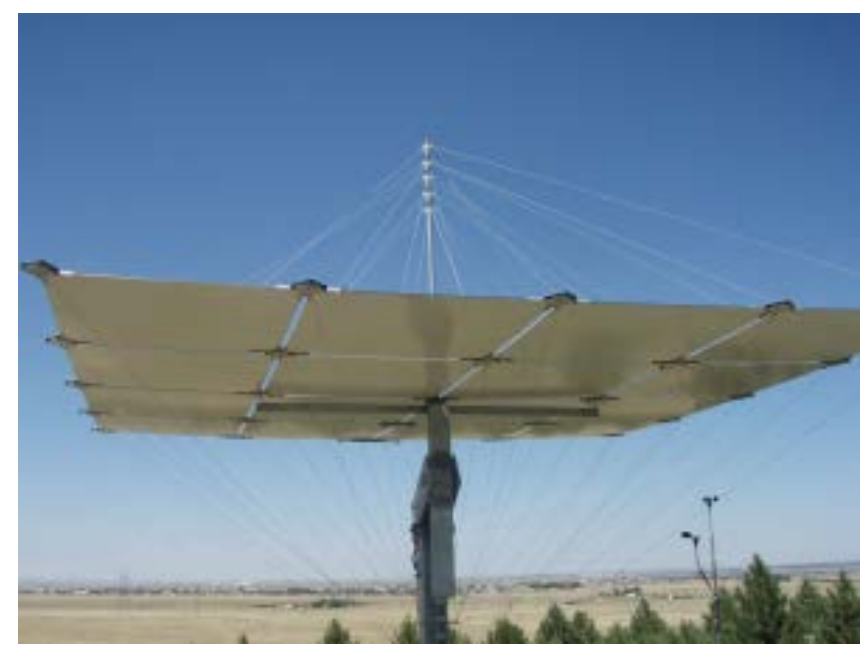

Fig. 39: Solaflect's suspension heliostat (photo: (Solarflect, 2017))

\subsubsection{Vast Solar}

Vast Solar's heliostats consist of a single $3.6 \mathrm{~m}^{2}$ mirror and an azimuth-elevation drive that are mounted on a pylon rammed directly into the ground (Vast Solar, 2016), (Fisher, 2015). The pylons are connected to each other by vertical bars or tubes (Fig. 40). The tubes have three main functions: 1 . They increase the stability of the pylons in direction of the tubes. 2 . The pylons are fixed by the tubes against rotation. Hence, no extra means at the lower end of the pylon against rotation is needed. 3. Cables for power supply and control can be connected to the tubes and don't have to be located below ground level which reduces installation cost. Vast Solar claims heliostat costs $<100 \mathrm{AUD} / \mathrm{m}^{2}\left(<77 \mathrm{USD} / \mathrm{m}^{2}\right)$ (Vast Solar, 2016).
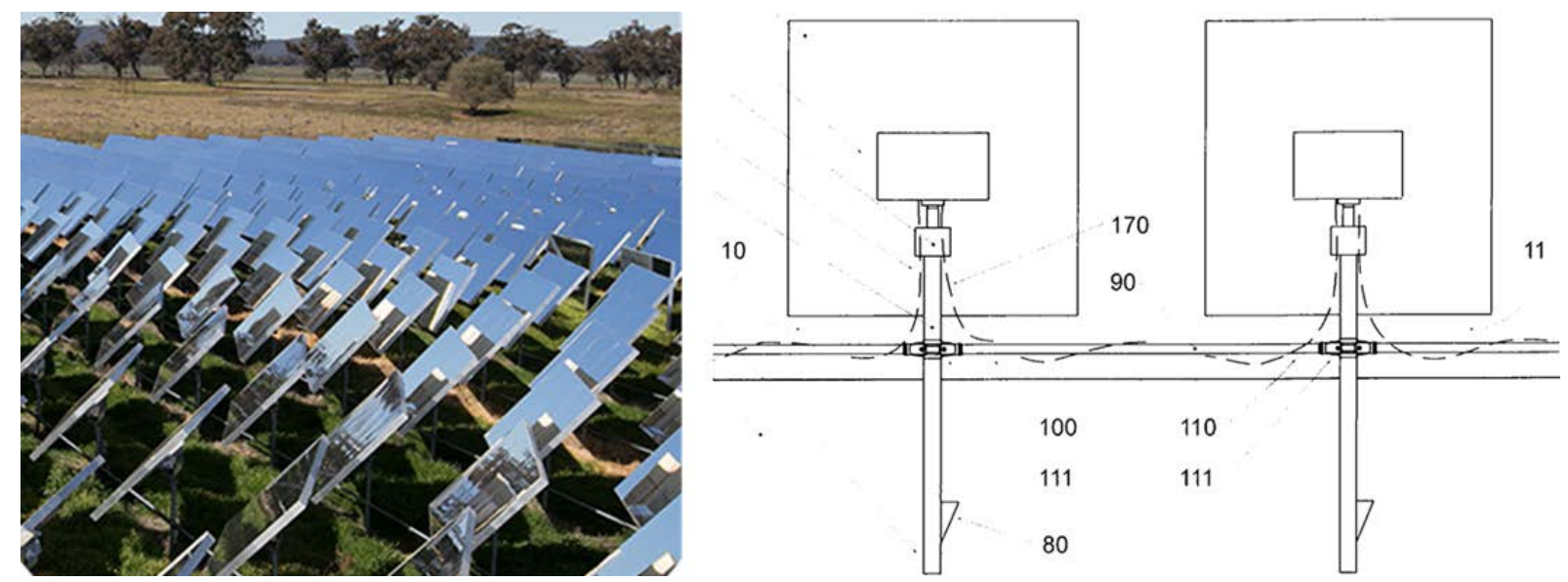

Fig. 40: Vast Solar's heliostats with ground anchor pylons connected to each other by tubes (Vast Solar, 2017), (Fisher, 2015)

\subsection{Possible next generation heliostats}

\subsubsection{Amrita University (pitch/roll heliostat)}

Freeman et al. (2016) developed a kinematic model of a pitch/roll heliostat and build a prototype (Fig. 41). The concentrator is connected to the pylon by a Hooke's joint and driven by two linear drives. The concentrator does not rotate about the azimuth axis as conventional heliostats. Therefore, the heliostats can be positioned closer to each other, which leads to higher heliostat field densities with higher field efficiencies. 

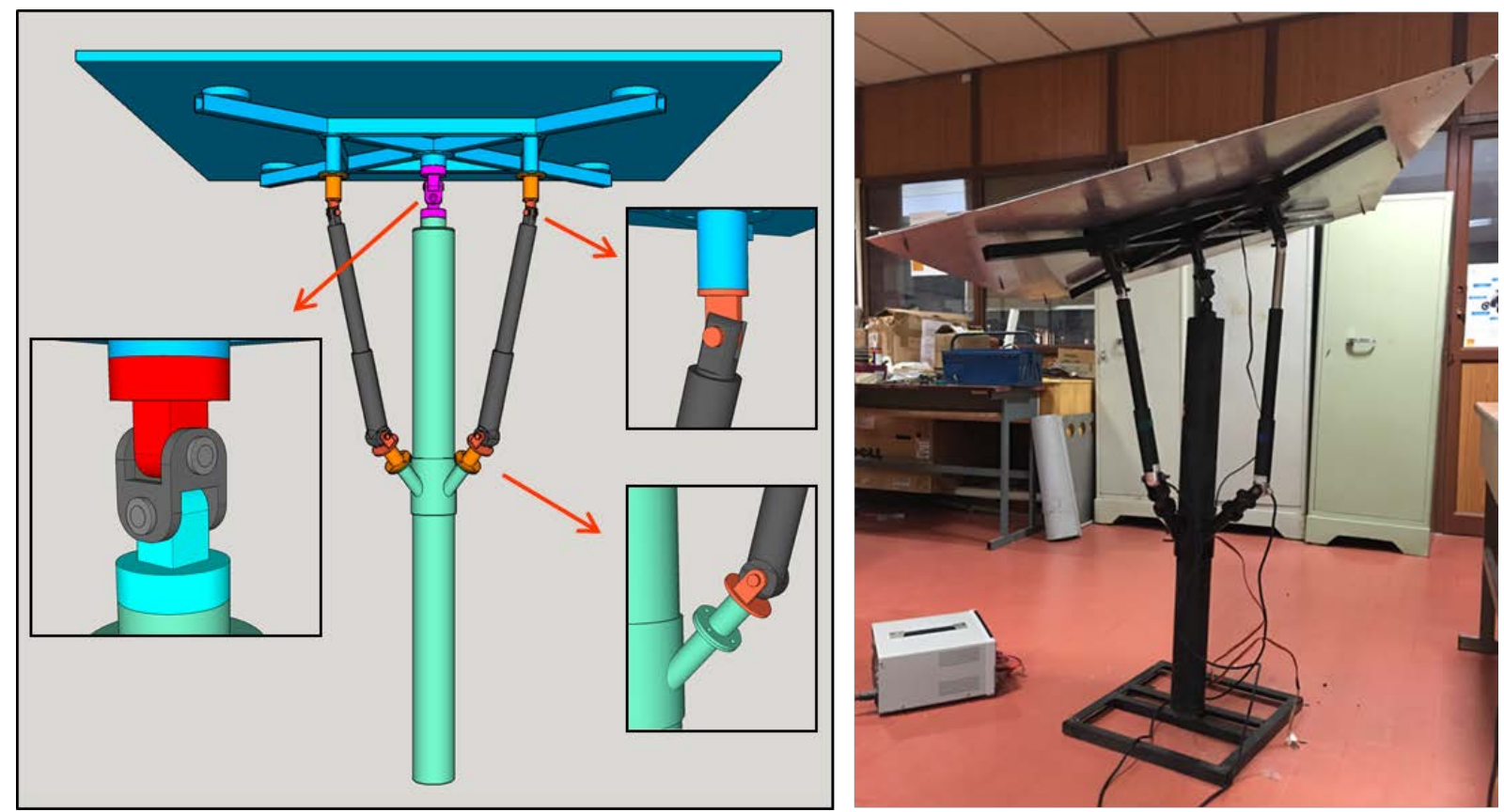

Fig. 41: Pitch/roll heliostat of Amrita University (Freeman et al., 2016)

A disadvantage of the approach is that for vertical mirror orientations the linear drives are almost parallel to the mirror panel which leads to a high loading of the drives and to low stiffness of the system.

\subsubsection{DLR (rim drive heliostat)}

A new kind of rim drive heliostat for target cost of $100 \mathrm{USD} / \mathrm{m}^{2}$ is under development of DLR (German Aerospace Center). At the Jülich power tower a second prototype with $9 \mathrm{~m}^{2}$ mirror area was installed (Fig. 42). Due to the rims, the loads on the drives are small and the backlash of the drives can be relatively high because of the long lever arms (distance between drives and centre of rotation), which enables the usage of low cost drives (Pfahl et al. 2013) (Pfahl et al., 2015). A further advantage of the rims is the additional rigidity they provide, which leads to higher resonance frequencies and thus to lower dynamic loads. The rims can be produced by simple roll bending machines. Hence, no mechanical precision components are needed which leads to a high local production share.
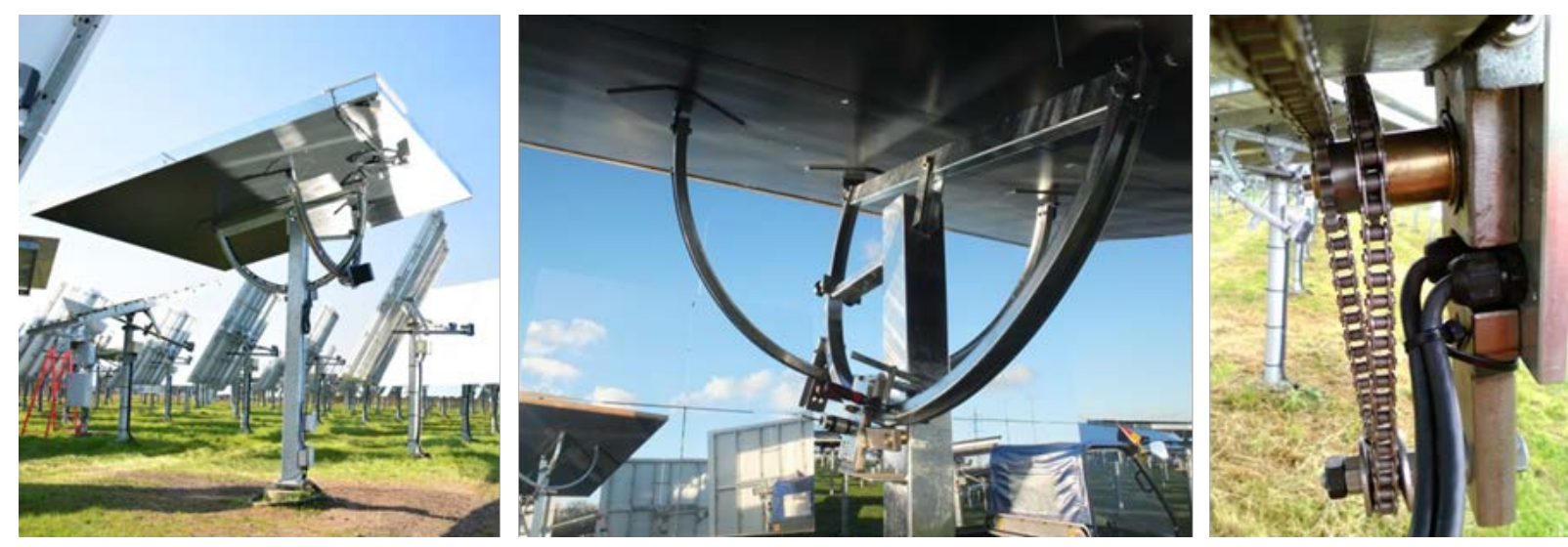

Fig. 42: DLR $9 \mathrm{~m}^{2}$ rim drive heliostat with chain gear avoiding fluctuating tension of the chain caused by the polygon effect (DLR)

The rims are driven by a chain gear with small sprockets for high gear ratio. Usually, small sprockets lead to fluctuating tension of the chain which reduces its lifetime (Liedke et al., 
2015). However, by a special arrangement of the sprockets (Fig. 42, right) the fluctuating tension is avoided.

The heliostat is equipped with a $9 \mathrm{~m}^{2}$ monolithic sandwich panel (Fig. 43) (Pfahl et al., 2016b). Using sandwich panels about 5\% higher efficiency is reached due to the higher reflectivity of the $1 \mathrm{~mm}$ thin glass mirror (compared to conventional $4 \mathrm{~mm}$ thick glass mirrors) and the higher slope accuracy (Holze et al., 2012).
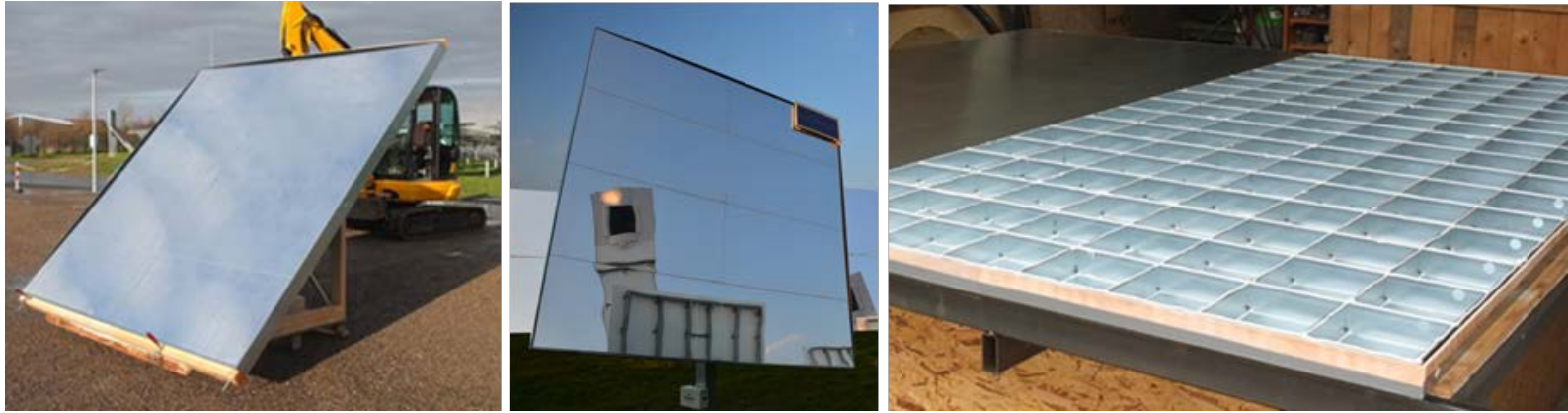

Fig. 43: DLR 9m² sandwich panel prototype (DLR)

The supporting structure for the mirrors consists of a sandwich board made from $0.5 \mathrm{~mm}$ thick galvanized steel sheets (Fig. 44). Front and back layers are glued on the core material. On the metal sandwich board, rigid foam plates are glued and shaped to achieve the required curvature. The thin glass mirrors are glued on the shaped plates (compare Fig. 43).

$1 \mathrm{~mm}$ thin glass mirrors

rigid foam plates

metal sheet sandwich

Fig. 44: Layers of mirror sandwich panel (DLR)

\subsubsection{DLR (carousel heliostat)}

To achieve heliostat field cost below $\approx 75 \mathrm{USD} / \mathrm{m}^{2}$ a new carousel heliostat (Fig. 45) is under development at DLR, which is designed to have very few components (Pfahl et al., 2016a). The main component is a monolithic sandwich reflector (compare §5.2.2). The complexity of canting is avoided by use of a single facet. The azimuth movement is realized by a simple carousel carriage and the elevation movement by a low cost linear drive connected to the panel's centre. Due to the usage of an optical sensor for control, the requirements on the accuracy of the mechanical components are reduced.

The azimuthal rotation is realized by a carousel carriage running on a simple track, which may consist of concrete plates stuck together (Fig. 45). The carriage is connected to the ground anchor which can be a pile driven into the ground. 


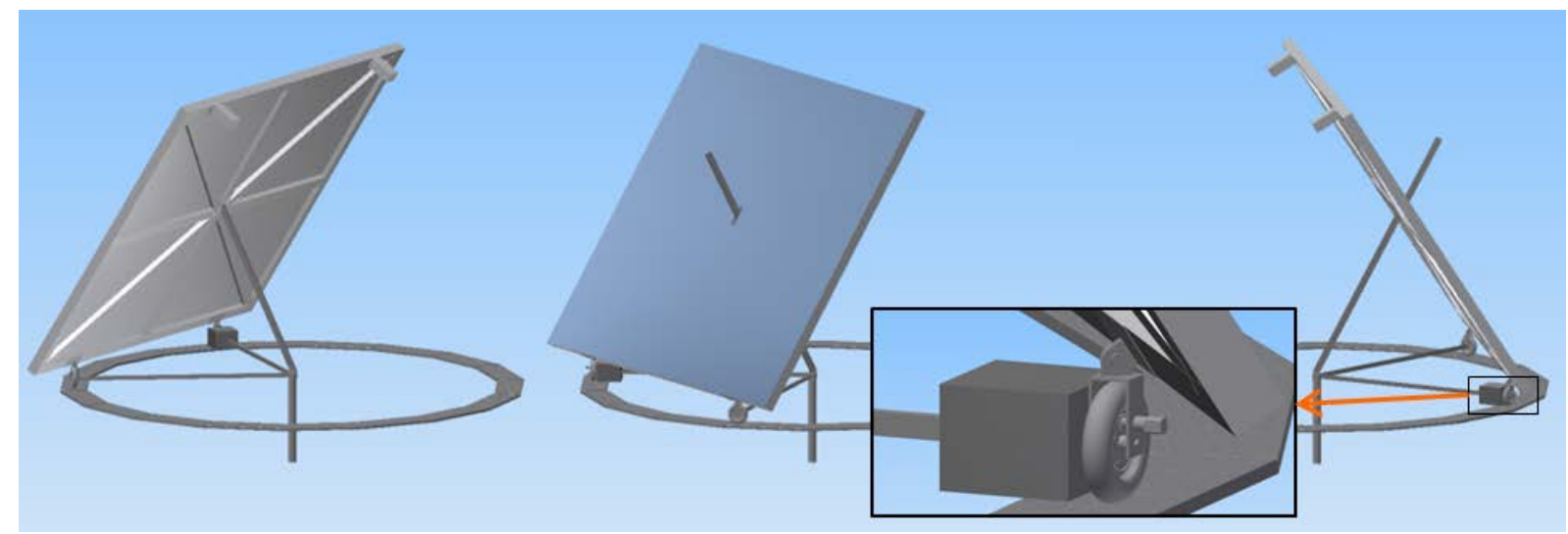

Fig. 45: Azimuthal rotation of a $50 \mathrm{~m}^{2}$ carousel type heliostat with wheel drive weighted against slippage (DLR)

The planarity accuracy of the track may be low because an optical sensor is used for the control of the orientation of the heliostat (\$4.4.2). One wheel of the carriage is directly driven (Fig. 45). Due to the long lever arm of the wheel to the centre of azimuthal rotation the load on the drive is low and the accuracy requirements as well. By weighting the wheel with a concrete block or a container filled with sand or stones, slippage during high wind loads is avoided. The size of the motor can be reduced by adding a chain gear (compare Fig. 36, right).

The elevation is realized by a spindle drive running through the centre of the panel (Fig. 46). During stow, the panel is pulled to the ground by the spindle and supported by the wheels and two extra supports. Thus, the panel is well protected under storm conditions. The reduced wind loads reduce the requirements and the costs of the sandwich panel.

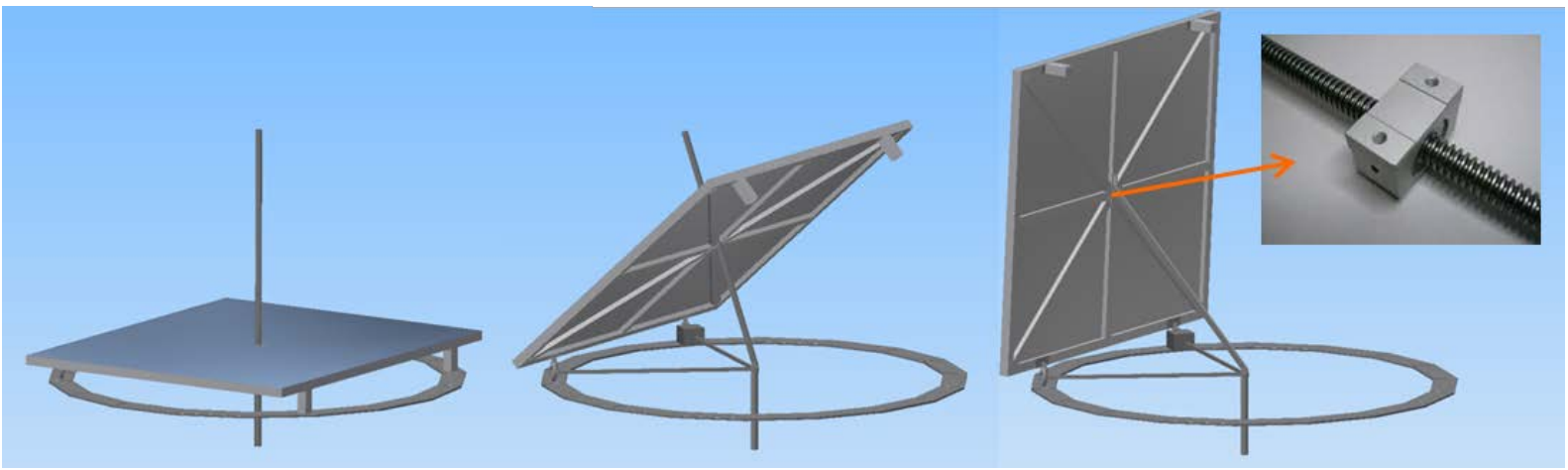

Fig. 46: Spindle elevation drive (DLR)

\subsubsection{HelioTower}

The key features of HelioTower's $36 \mathrm{~m}^{2}$ heliostat (Fig. 47) are: a horizontal first rotational axis, enabling the usage of linear actuators for both drives; a sheet metal fabricated pylon that is off-centric to allow the required range of tracking; and clipped reflector corners to reduce the required elevation axis height (Cordes et al., 2012), (Wieghardt et al., 2014). 

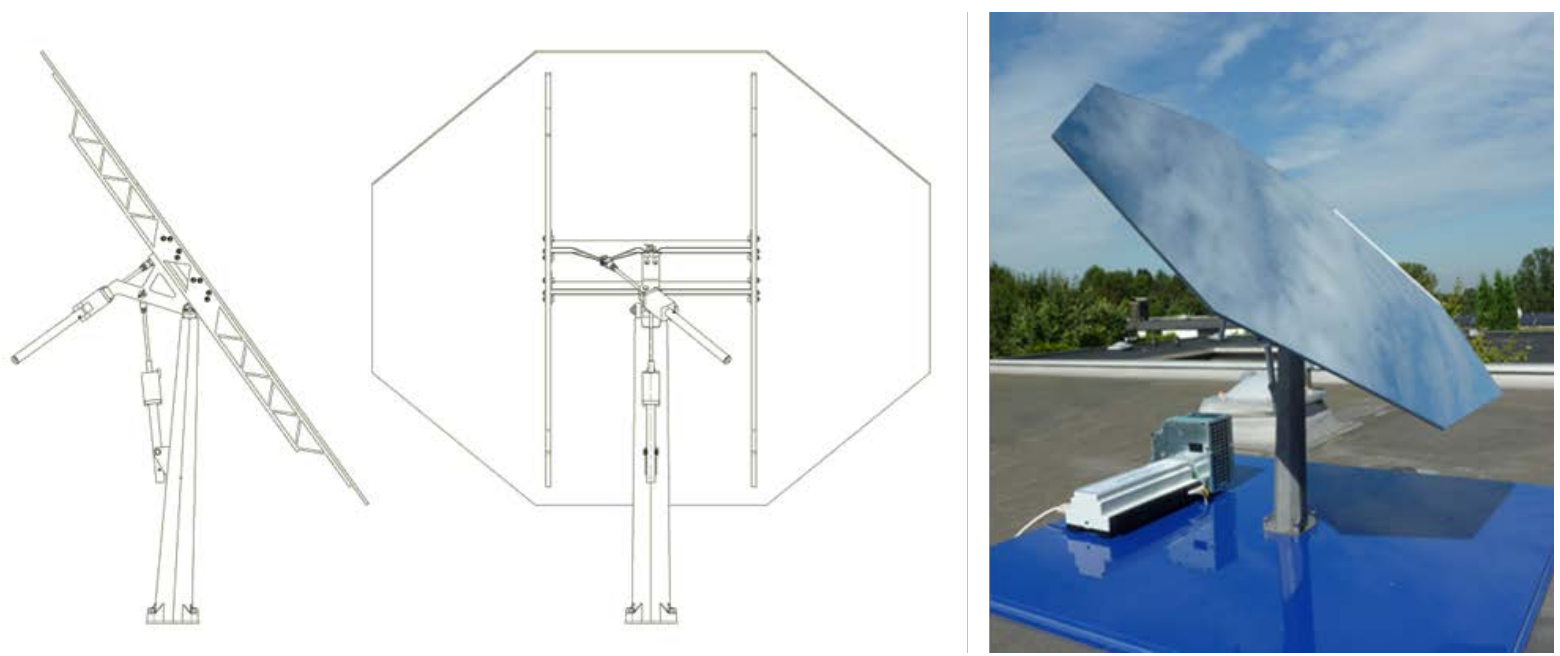

Fig. 47: HelioTower's heliostat with horizontal first axis, two linear drives and clipped mirror corners for lower elevation axis height; left: sketch (Cordes et al., 2012); right: functional model (HelioTower, 2017))

\subsubsection{IK4-TEKNIKER/CENER (EASY heliostat)}

IK4-TEKNIKER and CENER developed a small sized heliostat with a backlash free rim-cable drive system (Fig. 48) (Monreal et al., 2014), (Villasante et al., 2016) and an integrated fast calibration system (Burisch et al., 2016b). The calibration system enables calibration of complete heliostat fields of any size in few minutes, independent of the heliostat field size.
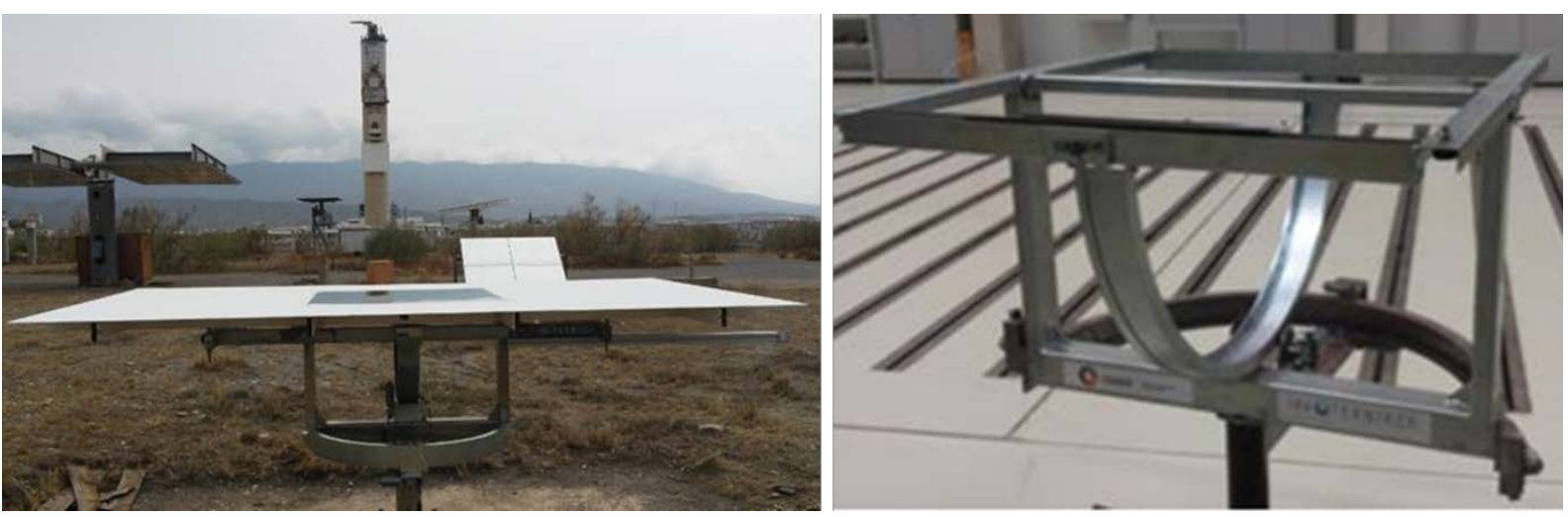

Fig. 48: IK4-TEKNIKER/CENER "EASY" heliostat with rim-cable drive system (Villasante et al., 2016), (IK4TEKNIKER)

\subsubsection{JPL, L'Garde, TentGuild Engineering, and TU Graz}

The NASA Jet Propulsion Laboratory (JPL), L'Garde, TentGuild Engineering Co., and the Technical University Graz developed a heliostat concept of $100 \mathrm{~m}^{2}$ size with sandwich panels using film reflectors, and with a cost target in the range of $100 \mathrm{USD} / \mathrm{m}^{2}$ (Buchroithner et al., 2016). The panels slide between rails which are supported by a three dimensional framework (Fig. 49). Spacers between the rails and the framework structure compensate for deformations caused by the welding of the framework. For both axes slew drives are used. 

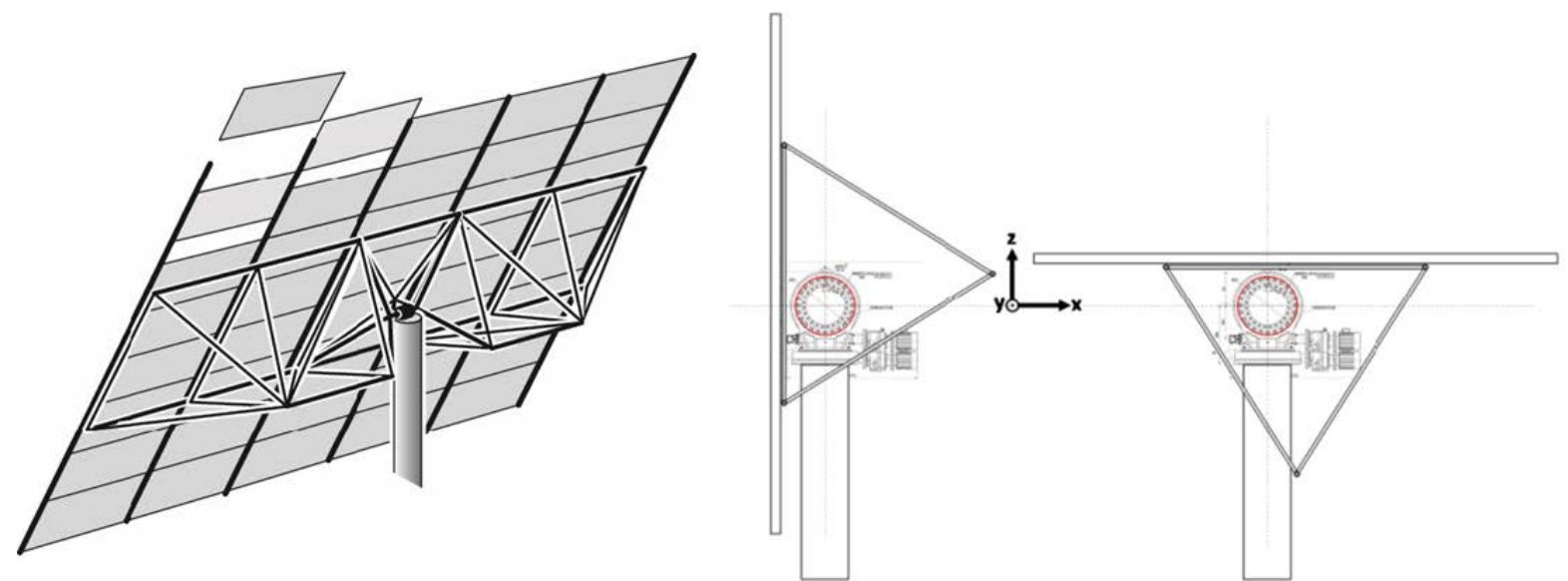

Fig. 49: $100 \mathrm{~m}^{2}$ heliostat concept developed by JPL, L'Garde, TentGuild Engineering, and TU Graz (Buchroithner et al., 2016)

The sandwich panels have a core of expanded polystyrene (EPS), stainless steel front layer and back layer, and a mirror film as the reflector (Fig. 50, left). A prototype of $6 \mathrm{~m}^{2}$ was built (Fig. 50, right).
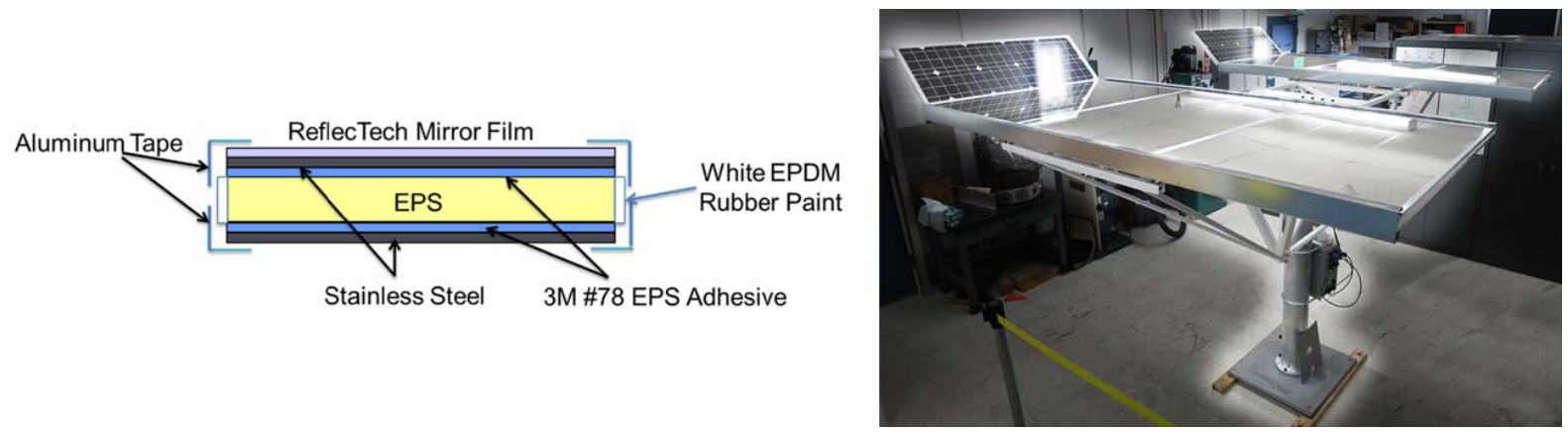

Fig. 50: Left: sandwich panel with expanded polystyrene core, stainless steel front layer and back layer, and thin film reflector; Right: $6 \mathrm{~m}^{2}$ prototype (Buchroithner et al., 2016)

\subsubsection{National Renewable Energy Laboratory}

In 2012, the US National Renewable Energy Laboratory (NREL) began pursuing a low-cost heliostat design to meet the SunShot cost target of $\$ 75 / \mathrm{m}^{2}$ while maintaining a total optical error of less than $2.5 \mathrm{mrad}$ in zero wind (Kutscher et al., 2013). The heliostat uses single facet flat concentrators of $6 \mathrm{~m}^{2}$ to negate the need for canting (Fig. 51). A glass integrated structural design for the back structure was developed to avoid complex manufacturing and field assembly processes. Additionally, a cable drive approach has been explored that reduces material while increasing mechanical advantage. This strategy requires lower torque, and therefore lower-cost actuators compared to traditional drive systems. Furthermore, NREL proposed development of a wireless network solution using locally powered (photovoltaic) control stations that used an RF transceiver for communication and a closed loop image based tracking system. 


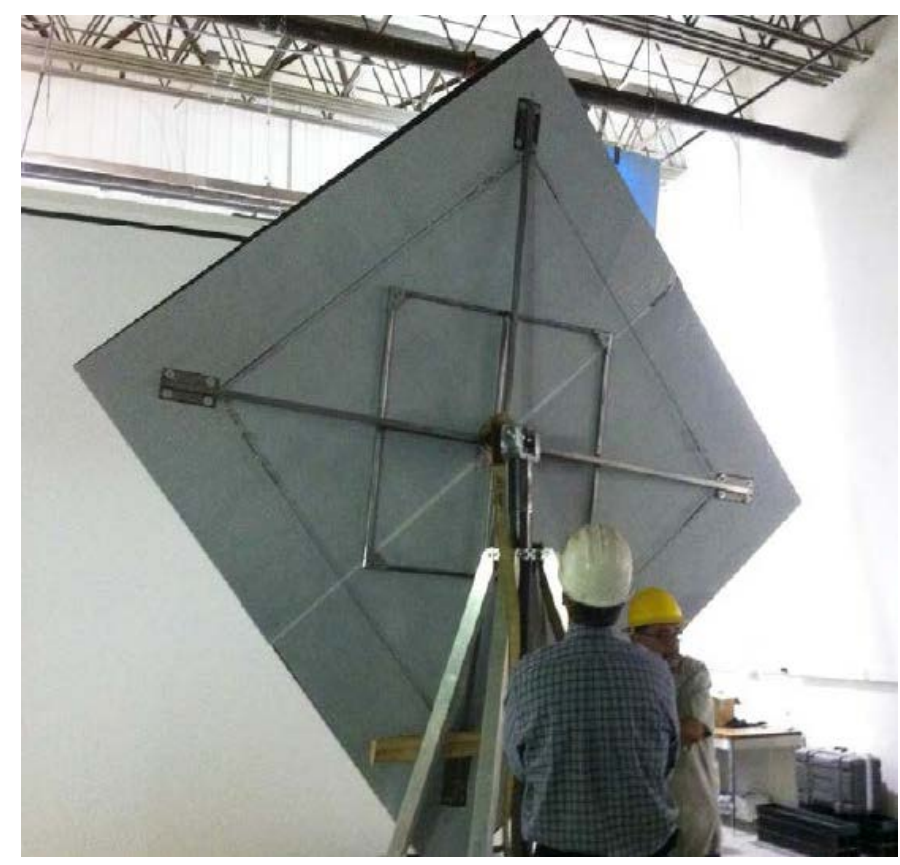

Fig. 51: NREL's $6 \mathrm{~m}^{2}$ heliostat prototype with cable drive (Coventry et al., 2016)

\subsubsection{STERG (HelioPOD)}

Stellenbosch University's Solar Thermal Energy Research Group (STERG) has developed $2.2 \mathrm{~m}^{2}$ heliostats with horizontal first axis and linear actuators for both axes (Landman et al., 2015). Six heliostats are connected to each other for higher stability and avoidance of earthwork or foundations, Fig. 52 (compare §5.1.5 and §5.1.14). It is estimated that for high production rates, a cost below $100 \mathrm{USD} / \mathrm{m}^{2}$ can be achieved (Larmuth et al., 2015).
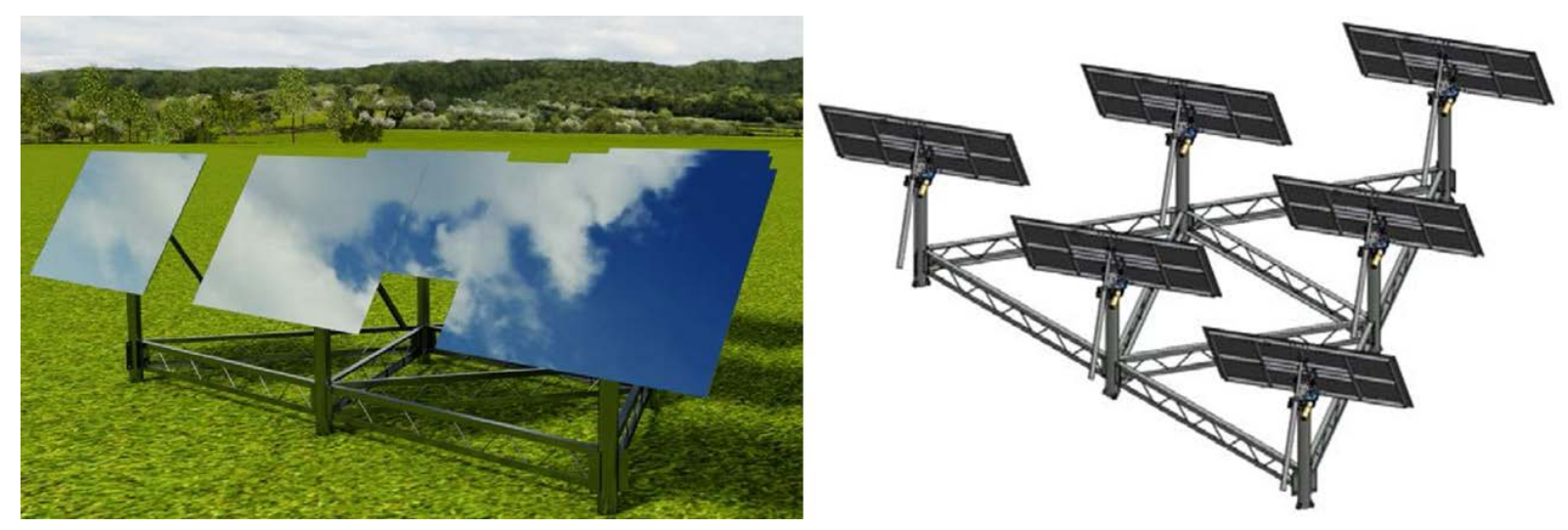

Fig. 52: STERG's HelioPOD heliostat system with six mirror facets of 2.23m² (Landman et al., 2015), (Delport and Craig, 2016)

The technology is demonstrated at a $100 \mathrm{~kW}_{\text {th }}$ pilot plant "Helio100" at Mariendahl in Stellenbosch, Fig. 53 (Larmuth et al., 2015). 

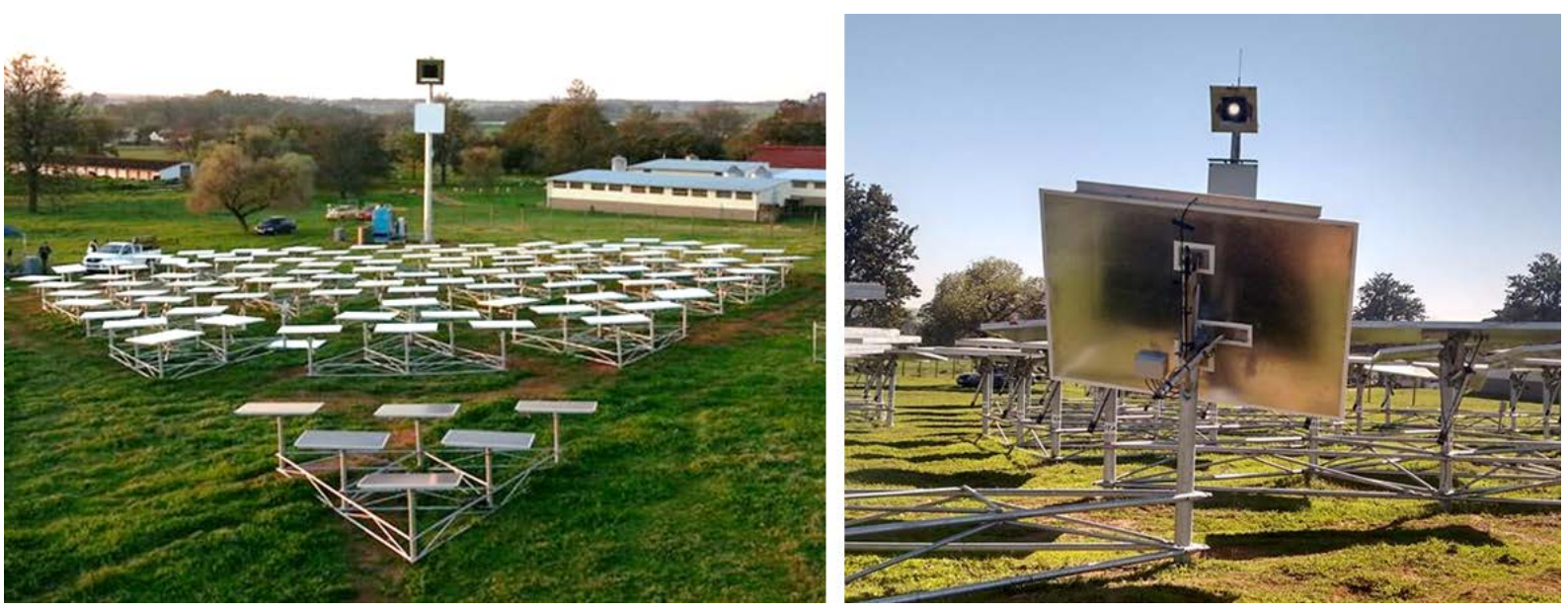

Fig. 53: Pilot and research facility Helio100 (Helio100, 2017)

\section{Canting}

Yellowhair and Ho (2010) reviewed several options for canting which are summarized in tabular form by Coventry et al. (2016, paragraph 13.4) along with some general information about canting. Téllez et al. (2014, paragraph 2.7) split the canting methods "into two broad categories, mechanical and optical. Mechanical methods (such as through the use of gauge blocks or inclinometers) involve pre-calculation of the facet canting angles required and manual measurement and adjustment of each facet to attain the desired angles. These processes are labour intensive, tedious, and prone to several sources of error, primarily due to structural gravity sag and local slope errors at the point of measurement. Optical methods (such as photogrammetry, fringe reflection or reflection of a known image) typically rely on applying a correction to the mirror facets such that a non-distorted reflection of a known image is obtained. Optical methods are not only able to correct facet canting, but also measure focal length errors, and in general provide higher accuracies."

\section{Heliostat manufacturing and assembly}

Usually, details about the manufacturing process are a well-kept secret of the companies and not much public information is available. An exception is the manufacturing of the heliostats for Ivanpah. A video of the assembly process is available online (BrightSource Energy, 2017). Additionally, some general information about heliostat manufacturing is given by Coventry et al. (2016, paragraph 7). They summarise: "It has been estimated that as much as $80 \%$ of the cost of product development and manufacture is determined by the decisions made in the initial stages of design. Concurrent engineering processes are essential for a quality, low-cost outcome for a new heliostat design, i.e. engineers across disciplines working together from the earliest stages of product design and through the design life-cycle. Make-buy decisions are important, and supplier capability is a key issue. The benefits of lowcost country sourcing cannot be overlooked."

\section{Heliostat qualification}

Heliostat testing and qualification, e.g. (Thalhammer, 1979), (King and Arvizu, 1981), (Mavis, 1988), (Strachan and Houser, 1993), (Weinrebe, et al., 1996), (Monterreal, 1997), has a long history in CSP, because it allows the designer to estimate and optimise performance. It is an integral part of heliostat design and development (phase 1), manufacturing (phase 2), commissioning (phase 3) and operating heliostat fields (phase 4). An overview of the four phases and their different measurement and qualification techniques 
is given in Table 1. For some specific heliostats, some phases may be combined, but usually, there is always a design/development phase and a manufacturing/commissioning phase.

Table 1: Overview of heliostat qualification in the different phases of from heliostat design to operation and the applied measurement techniques

\begin{tabular}{|c|c|c|c|c|}
\hline & $\begin{array}{l}\text { Prototype Evaluation } \\
\text { - Phase } 1\end{array}$ & $\begin{array}{c}\text { Assembly line } \\
\text { quality assurance } \\
\text { - Phase } 2\end{array}$ & $\begin{array}{c}\text { Techniques } \\
\text { during } \\
\text { commissioning } \\
\text { - Phase } 3\end{array}$ & $\begin{array}{c}\text { Qualification of } \\
\text { whole operating } \\
\text { heliostat fields } \\
\text { - Phase } 4\end{array}$ \\
\hline $\begin{array}{l}\text { Slope } \\
\text { deviation (§8.3) }\end{array}$ & DF / PG / LR & $\begin{array}{c}\text { DF / PG / MS / } \\
(\mathrm{LR})\end{array}$ & DF & DF \\
\hline $\begin{array}{l}\text { Shape deviation } \\
(\S 8.4)\end{array}$ & PG / LR / Sensors & PG / MS / (LR) & - & - \\
\hline Tracking (§8.5) & FDM / Inclinometer & - & see $§ 8.5$ & see $§ 8.5$ \\
\hline $\begin{array}{l}\text { Reflectance/ } \\
\text { Specularity } \\
(\S 8.6)\end{array}$ & $\begin{array}{c}\text { Reflectometer/ } \\
\text { Spectrophotometer }\end{array}$ & - & - & Reflectometer \\
\hline
\end{tabular}

DF: Deflectometry; PG: Photogrammetry, LR: Laser Radar, MS: Mechanical Sensing, FDM: Flux Density Measurement, Sensors: like accelerometers, inclinometers, strain gauges

Although the heliostat qualification has a long track record, new measurement techniques make it possible to more closely examine non-idealities in optical performance. Allowable error budgets for heliostats have been investigated in (Christian et al., 2015). Receiver size has a significant impact on the allowable heliostat error budgets.

For evaluation of heliostat prototypes (phase 1), a detailed measurement of the structural behaviour, e.g. the gravitational sag with heliostat elevation, is necessary. As the number of prototypes to be characterised is small, the measurement effort can be high and the time needed per heliostat can be larger.

In contrast, qualifying heliostats coming out of a manufacturing line (phase 2) needs an immediate measurement and direct feedback (minutes) to the production process. The number of heliostats is high and the measurement setup usually is limited to the confined space of a manufacturing hall. Normally, the quality control is restricted to the concentrator shape and pylon interfaces, but not to the final assembly of these parts.

The final assembly of pylon, drives and concentrator is usually done outside the manufacturing hall in the solar field. To commission a heliostat (phase 3), different techniques are used to align the tracking axes. Information about the remaining axes' misalignment and the drive offsets have to be gained to ensure the functionality of the tracking system. The heliostats are distributed according to the field design, their number is high, and the measurement has to be performed under outdoor conditions. The time and effort per heliostat for their qualification must be much lower compared to prototype evaluation.

During the last phase of commissioning or during operation (phase 4), evaluation of the heliostat quality is important for acceptance testing or maintenance issues, respectively. Either a subset or the whole field is measured. The same circumstances apply as for the measurements after final assembly in the field. However, additionally, the concentrator shape may be interest for acceptance testing, optimised aim point operation or for any readjustment after severe damage. 
Frequent measurement techniques used for shape measurements are photogrammetry, deflectometry, and laser scanning methods. Tracking is often tested by camera-target methods. The next sections give more details about current state of heliostat performance testing.

\subsection{SolarPACES Task III heliostat performance testing guideline}

Currently, a draft of the heliostat performance testing guideline (Röger et al., 2017a) using modern measurement methods is being discussed in the SolarPACES task III task group. The guideline consists of a list of parameters describing the performance of a heliostat. Furthermore, it contains information how these parameters can be measured or derived. According to the guideline, the most essential parameters (see Fig. 54, left column) are the total reflective area, the concentrator slope deviation, the concentrator shape deviation at different heliostat orientations, temperature and wind loads, the tracking characteristics and the reflectance and specularity of the reflective material. Furthermore, parameters regarding the durability, heliostat power consumption or emergency defocus time are among the essential parameters to describe heliostat performance.

These parameters do not depend on the position of the heliostat in a field, the aim point, sun position or specific meteorological conditions. They are independent of the operating conditions and hence are ideal to describe the performance of a heliostat in a general way.

Further parameters like the beam quality $\sigma_{B Q}$, the total beam dispersion $\sigma_{\text {tot }}$, flux profiles or integrated reflected power can be derived by raytracing simulations using the essential parameters and assuming specific boundary conditions for the positions of the heliostat and target, time and day of the year, direct normal irradiation, sunshape and atmospheric extinction coefficient (see Fig. 54, middle and right column).

The following sections describe the parameters according to Röger et al. (2017a) and the often used measurement techniques to derive them. 


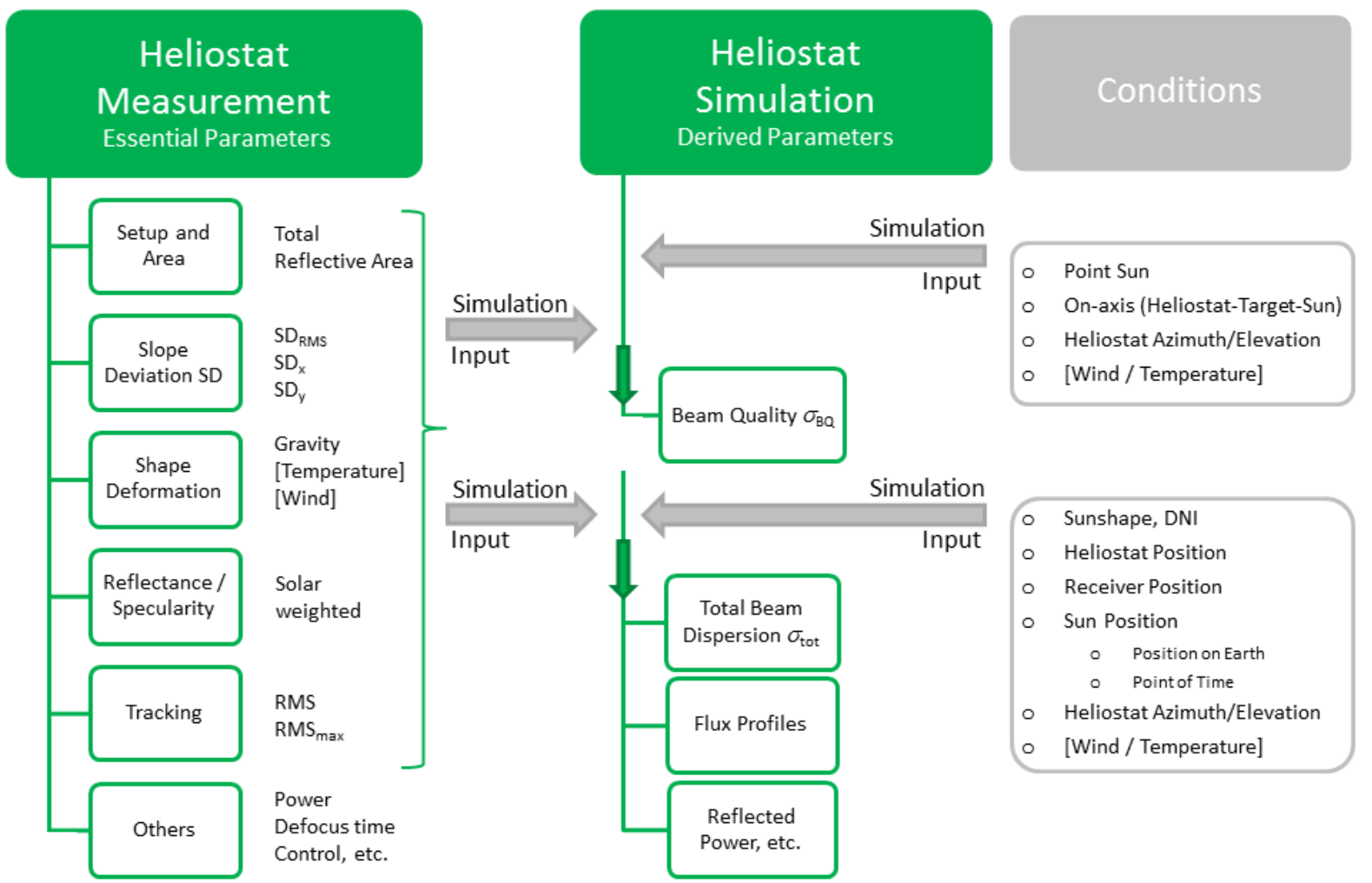

Fig. 54: Essential parameters for heliostat performance testing (left column) and derivation of further parameters using simulation (middle and right column), (Röger et al., 2017b)

\subsection{Total reflective area and heliostat setup}

The total reflective area is verified by measuring and summing up the sizes of the mirror panels. Additional to the reflective area, the general heliostat setup, like the axes alignment, the heliostat type and the number, size and location of mirror panels are frequently of interest.

\subsection{Concentrator slope deviation}

The slope of the mirror surface defines where the sun rays are reflected to. A nominal heliostat shape is defined prior to the calculation of concentrator shape deviations. Compared to this nominal shape, the slope deviation matrices SDx and SDy in horizontal and vertical direction describe the heliostat shape accuracy. These matrices are valid only for a given reference orientation of the heliostat unless the heliostat was totally rigid. According to Röger et al. (2017a) in order to fit nominal and measured shape, a least squares optimization is applied over the whole heliostat surface. The minimum recommend resolution is 100 data points $/ \mathrm{m}^{2}$. During measurements, the wind speed should be below the normal operation wind speed limit and there should be no excessive temperature gradients. Two slope deviation matrices are shown exemplarily in Fig. 55. The overall slope deviation of a concentrator surface can be described in one numerical value by calculating the RMS value between the measured and nominal slopes. 

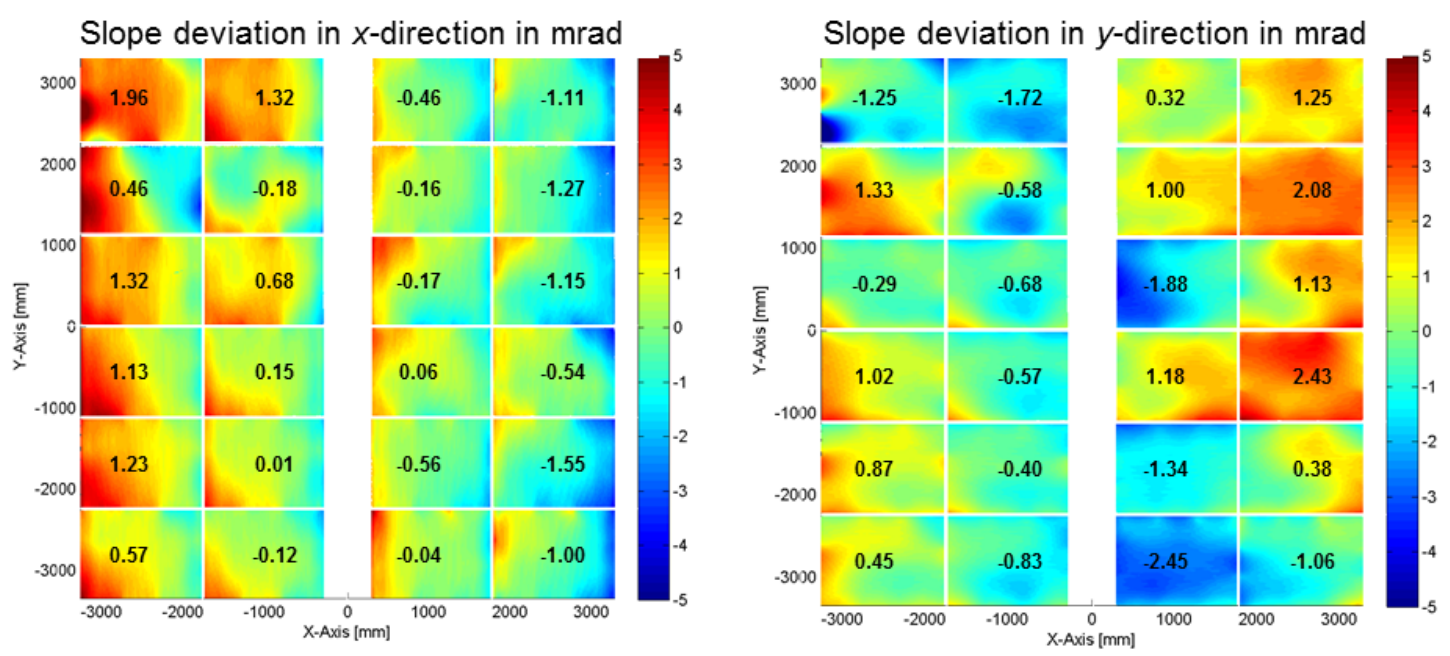

Fig. 55: Slope Deviation matrix in $x$ and $y$ direction (SDx and SDy) in mrad for a 40-m2 heliostat at the Plataforma Solar de Almería. The SD_RMS value is 2 mrad (Ulmer et al., 2011).

The slopes can be determined either directly by using deflectometric measurement techniques, e.g. (Ulmer et al., 2011), (Andraka et al., 2014), (Weber et al., 2014), (Arqueros et al., 2003) or by triangulation of a 3D point cloud and subsequent calculation of the normal vectors on each triangle. A 3D point cloud can be measured by photogrammetry, e.g. (Luhmann et al., 2006), (Shortis and Johnston, 1997), (Pottler et al., 2005), (FernándezReche and Valenzuela, 2012), laser scanning techniques, e.g. (Ulmer et al., 2012), (Monterreal et al., 2016) or mechanical sensing. These latter techniques are explained in $\S 8.4$.

Deflectometric techniques project known regular stripe patterns on a screen or target and take a digital photo of their reflection in the mirror surface. Deformations of the stripe pattern observed in the mirror give information about the normal vector or slopes of the mirror surface. The measurement procedure is fast and accurate and delivers spatially highly resolved results for the measured surface.

Ulmer et al. (2011) describe a measurement setup for a heliostat field during commissioning or in operation. A projector mounted in the field projects a series of horizontal and vertical stripe patterns with sinusoidal brightness variations on a screen or directly on the tower. The camera mounted on a pan-tilt-head on the tower top automatically takes pictures of one or several heliostats which have been oriented such that the camera sees the reflected pattern in the heliostats. If the distance between heliostat and target is very large, the target has to be quite large or the measurement has to be taken in various steps and the pictures have to be stitched together during the post-processing. Using this method, a large heliostat field can be automatically measured in a few nights with an accuracy of about $0.2 \mathrm{mrad}$.

For measurements of prototypes, a screen or wall has to be available and distances of at least several metres, better several tens of metres, between heliostat, camera and target are mandatory to apply deflectometry. The measurements should be done at night.

Another deflectometric method uses stars in the night sky to derive the slope deviation of heliostats (Arqueros et al., 2003). Image series with a CCD camera of the reflection of the star apparently traveling over the heliostat surface over time are taken. One scan takes about 8 minutes and several scans are needed to have sufficient lines on the heliostat. Measurement accuracy is reported to be around $1 \mathrm{mrad}$, although it may be improved. 
A further technique currently under development uses the sun, or more precise the sunshape as a natural target instead of a projection to evaluate heliostat slope errors (Coquand et al., 2016).

For the dynamic measurement of the wind influence on slope deviations in the solar field, first trials of dynamic deflectometry using colour-coded projection images and a camcorder have been applied to mirror facets (Wilbert, 2009).

Recently, the deflectometric setup has also been transferred to a manufacturing environment with a limited ceiling height and limited dimensions of the target. Several cameras have to be used and the evaluated results have to be stitched. It is shown that if the dimensions of the setup are calibrated well, the deflectometric principle delivers highly resolved results with good accuracy. The fast deflectometric measurement would allow for fast and individual canting of heliostats. The results will be published soon.

In the manufacturing environment, photogrammetric systems are used similar to the QFoto system used for parabolic troughs (Pottler et al., 2008), laser scanning techniques (laser radar) or tailor made mechanical systems.

For prototype evaluation or single operating heliostats, photogrammetry or laser scanning techniques (laser radar) can be used to derive 3D point clouds and calculate surface normal vectors.

\subsection{Concentrator shape deviation}

The shape as defined by the slope deviations and the nominal shape is not static. Structures deform with gravity (gravitational sag of the heliostat structure while moving the elevation axis), temperature and wind loads. Deformations can be expressed as local changes $\Delta S D x / y$ in the slope deviation entries of the matrices SDx/y. The resulting slope deviation matrices SDx,total and SDy,total are the sum of matrix in the reference position SDx/y and the changes due to gravity, temperature and wind influence, $\Delta \mathrm{SDx} / \mathrm{y}, \mathrm{grav}+\Delta \mathrm{SDx} / \mathrm{y}$,temp + $\Delta \mathrm{SDx} / \mathrm{y}$, wind.

The shape of a prototype heliostat under the different loads usually is measured with photogrammetry or laser scanning techniques (laser radar). Unless using natural markers like mirror edges like e.g. (Röger et al., 2012), retroreflective markers have to be attached to the heliostat while using photogrammetry. By taking several photographs from various angles of the heliostat, the 3D coordinates of the markers can be evaluated. Photogrammetry is usually used for deformation studies of a heliostat under different elevation angles to validate FEM predictions. The accuracy is in the sub-mm range.

In a manufacturing hall, the mirror bearing points of heliostat back structures can be automatically measured either by mechanical devices, photogrammetry (similar to parabolic troughs (Pottler et al., 2008)), or laser scanning techniques.

Laser scanning techniques like laser radars have been used for the measurement of large $3 \mathrm{D}$ objects. A laser ray directed by a rotational head and a tilting mirror on any direction is reflected on the mirror surface. A detector in the same casing measures the distance to the reflecting object. Prior to measurement, a specular reflecting mirror surface often has to be painted temporary with a diffuse reflecting paint. In recent years, the laser scanning method has been applied to CSP collectors. Laser scanning techniques can be used for prototype evaluation, manufacturing quality control or to measure single heliostats in a field. 
FEM simulation results are often used to study the influence of wind and temperature gradients on heliostat structure because measurement is more expensive and partly still challenging. Small-scale wind tunnel measurements are used to support the simulations, e.g. (Pfahl et al., 2011b), (Terrés-Nicoli et al., 2014).

Further dynamic properties are experimentally studied, e.g. by modal analyses (Ho et al., 2012), (Vásquez et al., 2015) using an impact hammer and accelerometers distributed over the heliostat frame. Furthermore, accelerometers, inclinometers, strain gauges and difference pressure gauges give information about the validity of simulations, e.g. (Pfahl et al., 2011a), (Ho et al., 2012), (Burisch et al., 2016a). DLR plans to study the deformation due to wind by using a stereophotogrammetry system. These systems usually use two cameras fixed on a bar and can measure the position and movement of markers fixed on a heliostat structure.

\subsection{Tracking accuracy}

Accurate tracking is crucial to minimising spillage losses and to have control over the flux distribution on the receiver. An analysis of the tracking error sources of the Solar Two plant is found in (Stone and Jones, 1999).

The tracking accuracy is frequently determined by a continuous position measurement of the beam centre on a white target using a CCD camera, e.g. (Thalhammer, 1979), (King and Arvizu, 1981), (Mavis, 1988), (Neumann and Monterreal, 1992), (Berenguel et al., 2004). According to Röger et al. (2017a), the measurement should be done during the course of a day for sun elevations over 10 degrees with a time resolution not less than 3 minutes between each reading for maximum wind speeds up to half of the normal wind speed limit. The tracking accuracy RMS is the root mean square of all deviations of the measured and the set aim point. Additional to the RMS value, the correlation between tracking and time which would lead to tracking offsets during the day, and the correlation between the tracking of the two axes, should be given.

The camera-target method is very accurate and appropriate for prototype evaluations. However, for commissioning of a total field, a rough pre-orientation with tachymeters or inclinometers is necessary. Another cost-effective and automatic technique for rough offset calibration uses a digital camera mounted on top of the tower and extracts the facet edges (Röger et al., 2012). By using the apparent side ratios and apparent angles of the heliostat facets, the rough orientation of the heliostat can be measured and the heliostats could be placed on a target.

Another approach uses one or more cameras looking down to the heliostat field. By artificial light sources of known positions being reflected in the mirrors (Zavodny et al., 2015) or by the sun being reflected in the mirrors (Coquand et al., 2016), or other markers, the heliostat orientation can be derived. With cheap cameras now available, concepts with cameras and microprocessor on each heliostat capturing artificial and natural markers are being developed to orient heliostats, e.g. (Burisch et al., 2016a).

A technique currently in development at DLR, without the need of fixed installed artificial light sources, markers, camera or the sun being at a specific position uses a flying quadrocopter with a small target and camera.

One system, designed to be used to enhance tracking accuracy while the receiver is under operation, uses various cameras located near the receiver facing down to the field (Kribus et al., 2004). It measures the actual radiation incident around the receiver's aperture. The aim 
point can be corrected using brightness differences seen by cameras mounted on different sides of the receiver.

Further systems under development mechanically excite the mirrors or the concentrators of the heliostat while they are focused on the receiver. Mechanical vibrations having small amplitudes and high frequencies $(\mathrm{kHz})$ can be introduced into the heliostat reflector surface using piezoelectric actuators (Convery, 2011). Alternatively, the whole concentrator can be excited with higher amplitudes and lower frequencies $(\mathrm{Hz})$ using the heliostat drives (Bern et al., 2016). Both concepts should allow identification of the light beams of the excited heliostat in the focus by its specific frequency.

\subsection{Reflectance, specularity, and durability}

Obviously, the performance of a heliostat is greatly influenced by the reflectance properties of the mirror surface. Different materials like metal sheets, glass mirrors or reflecting polymer films, besides of having different overall reflecting properties, have specific spectral properties and show a totally different beam spread of the reflected ray (Meyen et al., 2009), (Heimsath et al., 2015). Due to the large distances between reflector and receiver in power tower technology, the specularity of the reflection is of high importance. For this reason, the solar weighted spectral reflectance should be measured within $2.6 \mathrm{mrad}$ acceptance angle (Röger et al., 2017a). The reflectance is frequently determined by a portable reflectometer, based on the principle described in (Pettit et al., 1983a). The SolarPACES reflection guideline (Meyen et al., 2013) suggests measurements with a light incidence near normal (smaller than $15^{\circ}$ ). Additional to the portable reflectometer, a spectrophotometer is recommended to characterize reflecting materials. A recently developed spectral reflectometer permits the measurement of the solar weighted specular reflectance at different incidence and acceptance angles, thus providing all relevant reflectance data of solar mirrors (Sutter et al., 2016).

The durability of both reflector surfaces and other components such as actuators are also of high importance and currently under investigation.

\section{Methods and tools for heliostat field layout}

The layout of a solar tower plant, i.e. the definition of the number and positions of the heliostats and the size and position of the receiver on top of the tower, is a problem with almost indefinite degrees of freedom. That is why, since the early 1970s the development of the solar tower technology came along with the creation of numerical models and computer codes for heliostat field analysis and layout. These codes simulate the concentration of the sunlight by modelling the reflected image of the sun and taking into account the basic loss mechanisms that occur in the heliostat field, namely

- shadowing of mirror areas by neighbouring heliostats

- cosine loss, i.e. the reduction of effective mirror size due to off-axis-reflection

- blocking of reflected light by neighbouring heliostats

- attenuation of reflected light between heliostat and receiver due to absorption and scattering processes in the atmosphere

- reflected light reaching the receiver plane but not entering the aperture ("spillage") due to imperfect alignment of the heliostat and/or oversized reflection image 
Several methods and codes for heliostat field simulation have been described in literature since the early days. Good overviews of solar tower simulation tools can be found in (Ho, 2008), (García et al., 2008), (Bode and Gauché, 2012) and (Li et al., 2016). An important characteristic of these codes is the method to calculate the two-dimensional flux density of the reflected sunlight on a target.

The statistical method (also Monte-Carlo or ray tracing method) uses randomly chosen sun rays that are followed ("traced") from their origin on the sun disc to the reflection on the mirror and further to the intersection with the target plane. The distribution of the brightness on the sun disc, of the facet orientation and of the local mirror surface slope are described by statistical distribution functions. Alternatively, mirror surface slope information from deflectometry measurements can be used (§8). Ray numbers of several thousand rays per $\mathrm{m}^{2}$ mirror surface area are normally processed.

Alternatively, the convolution method is based on the mathematical description of the flux density distribution on the target as the convolution of the sun brightness distribution (sun shape) with the error distributions of the mirror (tracking and slope). It can be solved numerically by Fourier transformation and polynomial expansion, (Biggs and Vittitoe, 1979) and (Walzel et al., 1977). A very simple solution is possible when the sun shape is considered to be a circular Gaussian distribution, see (Pettit et al, 1983b) and (Schwarzbözl et al., 2009). This simple convolution method requires less computational effort than the other methods but is also of lower accuracy. The detailed convolution method was favored over the ray tracing method in the 1970s due to performance advantages regarding computation time. Today, the ray tracing method is clearly dominant because of the enormous advancement in computer technology regarding clock rate, multi-threading, parallel computing, e.g. see (Belhomme, et al. 2009).

Some developers try to attain additional progress in computational speed for the ray tracing method by shifting some or all of the core routines from the central processor (CPU) to the graphics processor unit (GPU, array of large numbers of parallel processors specialised in vector calculation), as it was done in the tool TieSol (Izygon et al. 2011).

In the following, the tools usable for field layout are discussed. They are grouped according to the methodology for the field layout process. Five main groups can be identified as presented in the overview of Table 2.

The Cellwise Method was probably one of the first coded field layout procedures. It was developed for the layout of large surround fields and is based on the subdivision of the field into cells of uniform density, with only one representative being calculated per cell.

In contrast, the Selection Method calculates every single heliostat of an oversized field, selecting the best performing ones to meet a certain design requirement. Obviously, a lot more of computational effort is necessary here compared to the Cellwise Method. However, the Selection Method allows the generic design of very individual fields depending on the receiver optical configuration (e.g. secondary reflectors, etc.). Most of the codes that are described in literature today are based on the Selection Method. 
Table 2: Overview of heliostat field layout tools

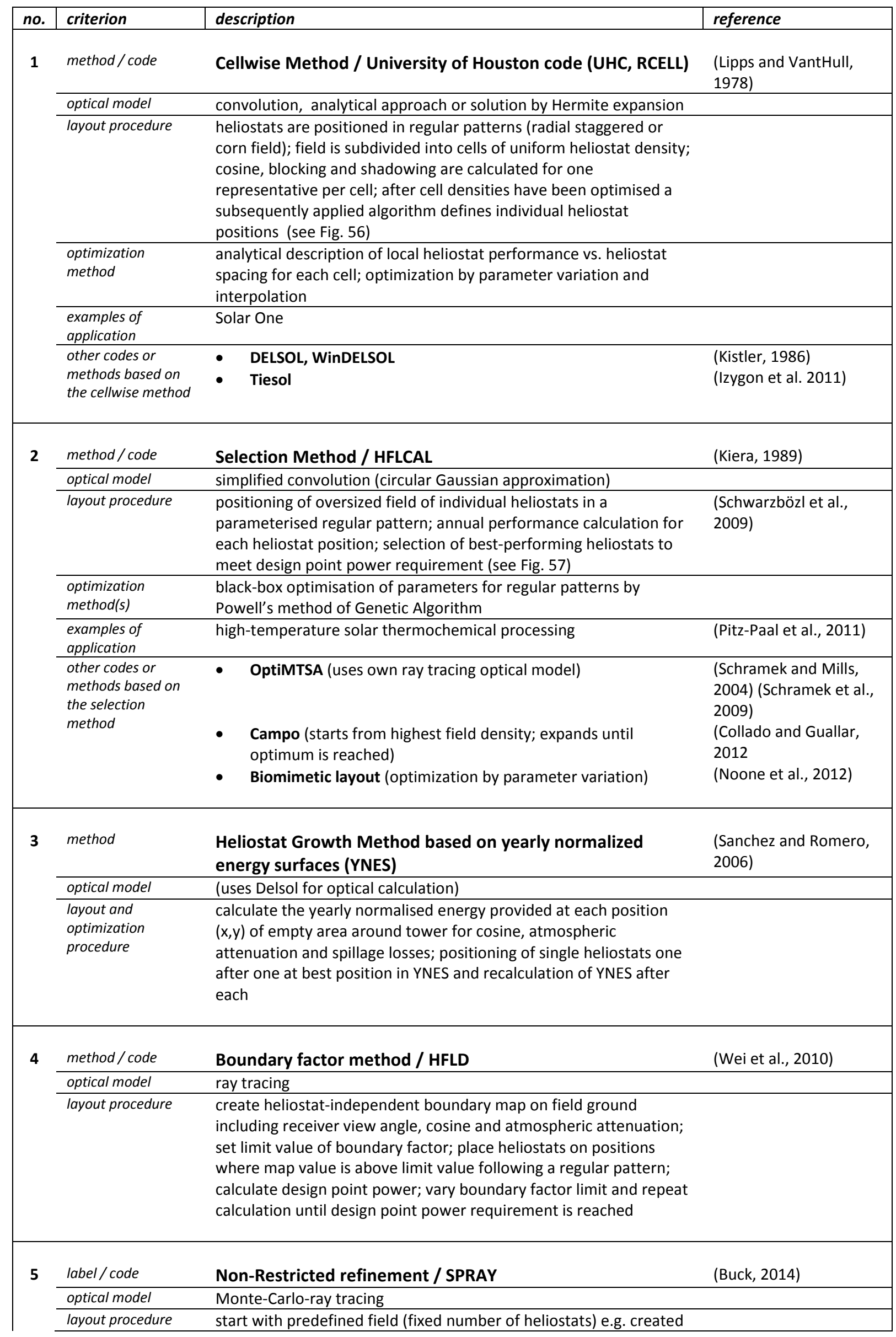




\begin{tabular}{|c|c|}
\hline & by another layout method; \\
\hline $\begin{array}{l}\text { optimization } \\
\text { method }\end{array}$ & $\begin{array}{l}\text { consider matrix of discrete alternative positions around each } \\
\text { heliostat position; assess alternative positions of a target heliostat } \\
\text { by calculation of the annual performance of the local subfield of } \\
\text { neighbouring heliostats; repeat for each heliostat in the field }\end{array}$ \\
\hline $\begin{array}{l}\text { other codes or } \\
\text { methods based on } \\
\text { the nonrestricted } \\
\text { refinement method }\end{array}$ & $\begin{array}{l}\text { improvement by using a local search metaheuristic (based on ray- } \quad \text { (Reinholz et al., 2016) } \\
\text { tracer STRAL) }\end{array}$ \\
\hline
\end{tabular}

A completely different approach was tried with the Heliostat Growth Method (YNES), where the field is built up one by one by setting each heliostat on the best available position. This method follows pure physics and is free from any predefined patterns but lacks from the fact that in the region close to the tower some compromise must be made (i.e. losses have to be taken into account) when a certain field size has to be reached to come to an overall optimum.

In the Boundary Factor Method the field is built up within physical boundaries following a regular pattern and the boundary is varied until the design point requirement is reached. This method is similar to the Selection Method but requires less computational effort as it avoids the calculation of "unused" heliostat positions.

The Non-Restricted Refinement Method obviously requires the largest amount of computational effort due to the enormous degree of freedom when single positions are varied. But, the problem is suitable for parallelisation and has still a lot of potential when the progress in computer technology and the development of efficient heuristic optimisation methods are considered.

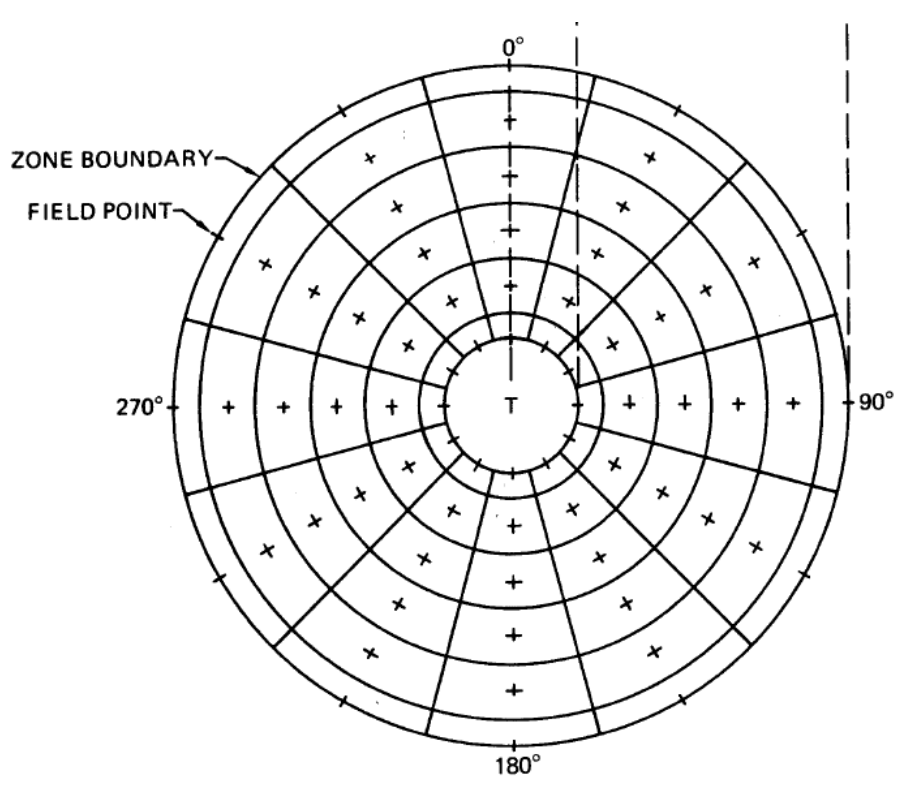

Fig. 56: Subdivision of surround field into zones and indication of field points, where representative heliostats are calculated (Kistler, 1986) 


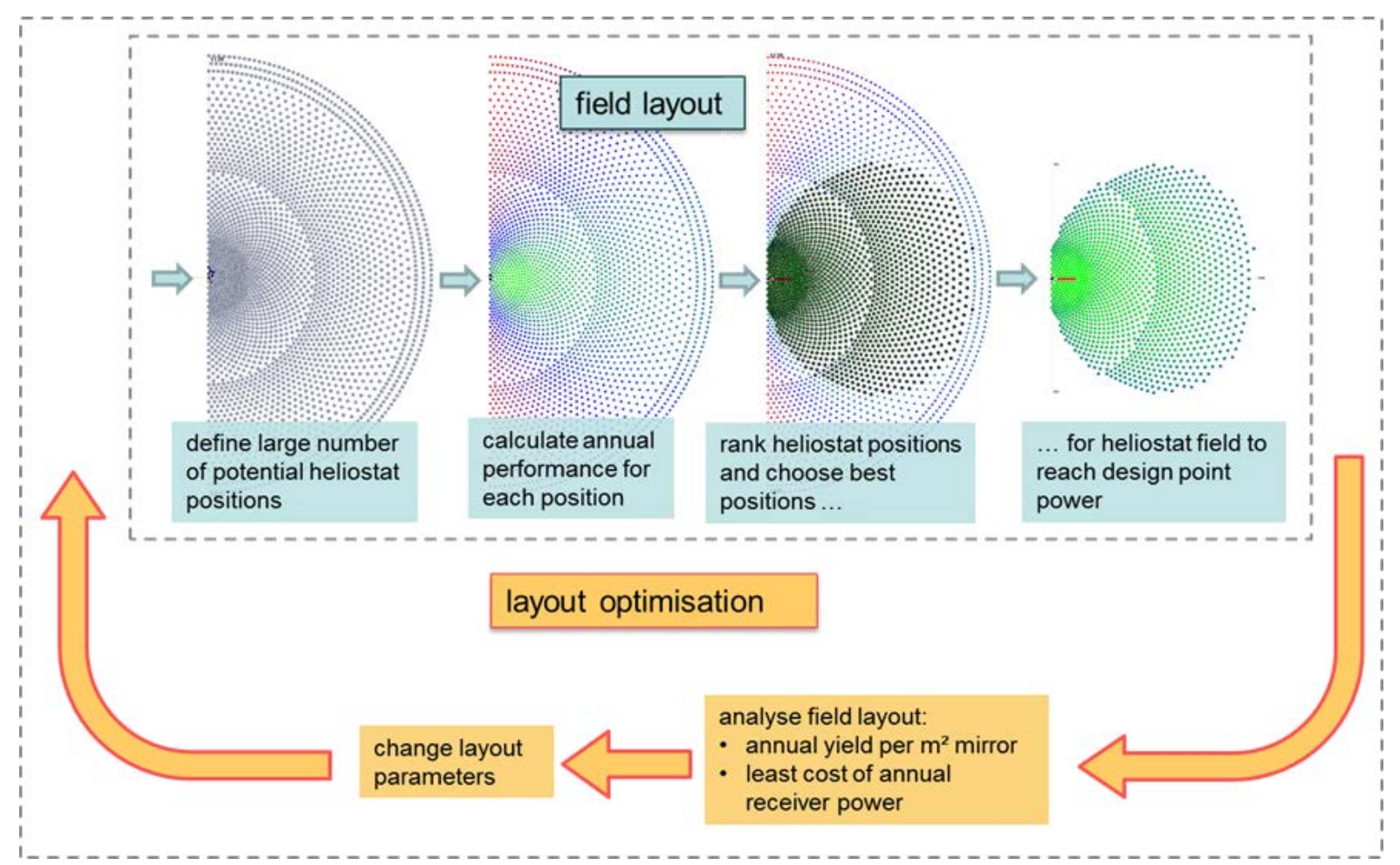

Fig. 57: Visualization of the selection method as implemented in the software code HFLCAL (DLR)

\section{Mirror cleaning}

The efficiency of CSP plants depends on the reflectance of the concentrating mirrors. Their reflectivity can be greatly reduced by soiling - the reversible process of particle and dust adhesion to surfaces. The parameter to quantify soiling-induced reflectance loss is called cleanliness $(\xi)$. It is defined as the ratio of the reflectivity $(\rho)$ of a solar reflector relative to its reflectivity in the clean state $\left(\rho_{\mathrm{cl}}\right)$ :

$\xi(\mathrm{t})=\frac{\rho(\mathrm{t})}{\rho_{\mathrm{cl}}}$

$\xi$ changes due to time and site dependent on influences such as dust deposition, rain and mirror cleaning.

A reduction in cleanliness corresponds to the same reduction of the overall optical efficiency of the heliostat. Cleanliness is often determined with handheld reflectometers by comparing the reflectance of the soiled mirror to that of a clean one (Crawford et al., 2012). In measurement campaigns for soiling research, reflector samples are exposed to the environment and $\xi$ is measured regularly.

In a solar field, mirror cleaning can restore initial reflectivity $\rho_{\mathrm{cl}}$. It requires man power, water, fuel, and maintenance as well as initial investment for the cleaning vehicles. Cleaning vehicles clean between 10,000 and $30,000 \mathrm{~m}^{2}$ of mirror surface per $8 \mathrm{~h}$ shift and require one to two persons for operation (Kaiser, 2011). Furthermore, if cleaning is performed during daytime, the heliostats being cleaned have to be defocused which results in a temporal reduction of solar field availability. Power plant operators thus face a trade-off between keeping cleaning costs low and solar field efficiency high.

There are a variety of automatic and semi-automatic cleaning vehicles available on the market as described e.g. in (Schell, 2011), (Alon et al., 2014), (Ecilimp Termosolar, 2017). Some prototypes are currently under development such as a gravity driven cleaning lip system at DLR. 
Several studies compare the efficiency of different cleaning technologies such as pressurised water, rotating brushes, cleaning agents and combinations thereof (Fernández-García, 2014).

Cleaning might be required less frequently on a site with low dust pollution than on a site with heavy dust load. The water demand for cleaning is also dependent on the power plant configuration and the applied cleaning technology. The water requirements shown in Table 3 are taken from DLR internal calculations based on cleaning truck testing and soiling rate measurements (to be published in (Wolfertstetter, 2017)). In the literature, values in the range of $0.034-0.26 \mathrm{~m}^{3} / \mathrm{MWh}_{\mathrm{e}}$ (corresponds to approximately $10-76 \mathrm{~L} / \mathrm{m}^{2} /$ annum) can be found. An exceptionally low water consumption is achieved by cleaning robots for Fresnel collectors $\left(0.002 \mathrm{~m}^{3} / \mathrm{MWh}_{\mathrm{e}}\right.$, calculation based on (Frenell, 2017)) and PV panels (Sarver et al., 2013). The latter could in principle be applied to heliostats.

Dust settlement to the mirror facets can be reduced by stowing the heliostats in face-down position during night-time and in face-up position when significant rainfall is expected. Other dust avoiding technologies include anti-soiling mirror surface coatings (Schwarberg and Schiller, 2012) and the application of active dust repellent technologies such as application of alternating electrostatic fields or surface vibrations (Berg, 1978), (Williams et al., 2007). The active dust mitigation methods result in higher investment and operation costs that should be compared to the increase in revenues in a yield analysis study before installation.

Table 3: Typical water consumption per MWhe for cleaning at different soiling rates

\begin{tabular}{ll} 
CSP mirror cleaning & $\begin{array}{l}\text { quality: demineralised water (efficiency } \\
\text { increases with demineralisation grade) }\end{array}$ \\
Soiling rate in 1/day & cleaning water consumption $\mathbf{~ m}^{3} / \mathrm{MWhe}$ \\
\hline 0.005 (e.g. PSA) & 0.054 \\
0.01 & 0.11 \\
0.02 (e.g. UAE) & 0.24
\end{tabular}

Regardless of the cleaning method applied, a cleaning schedule must be defined for operation and the kind and number of cleaning vehicles has to be selected. To this end, the parameter soiling-rate (SR) is often determined (Deffenbaugh et al., 1986), (Biryukov et al., 1999). It is defined as the change of cleanliness with time according to

$\operatorname{SR}(\mathrm{t})=\frac{\mathrm{d} \xi(\mathrm{t})}{\mathrm{dt}} \approx \frac{\xi(\mathrm{t}+\Delta \mathrm{t})-\xi(\mathrm{t})}{\Delta \mathrm{t}}$.

where $\Delta t$ is the time difference between measurements. SR is independent of the cleaning schedule applied during measurement. Long term SR measurements for various sites have been reported (Deffenbaugh et al., 1986), (Pettit et al., 1981), (Arantzasu, 2012), (Griffith et al., 2014), (Tahboub et al., 2011), (Vivar et al., 2011). They show high intra-annual variation of SR which is mostly not bound to seasons. There is a strong dependence on the site of measurement and the conditions of exposure such as inclination angle and orientation of samples. The mean SR or cleanliness values determined in these studies are shown in Table 4. 
Table 4: Overview on existing soiling-rate measurement campaigns from literature. Multiple SR values correspond to multiple orientations given in the same order in the column "orientation".

\begin{tabular}{|c|c|c|c|}
\hline Source & Location & Orientation & SR \\
\hline (Pettit et al., 1981) & Albuquerque, NM, USA & $\begin{array}{l}0^{\circ}, 45^{\circ}, 90^{\circ}, 180^{\circ} \\
\text { South }\end{array}$ & $\begin{array}{l}0.0055 \text { /day, } \\
0.0048 \text { /day, } \\
0.0019 \text { /day, } \\
0.0006 \text { /day, }\end{array}$ \\
\hline (Roth and Pettit, 1980) & Albuquerque, NM, USA & $\begin{array}{l}45^{\circ} \text { South ca. } 1,5 \mathrm{~m} \\
\text { height }\end{array}$ & $0.0012-0.0144$ /day \\
\hline $\begin{array}{l}\text { (Deffenbaugh et al., } \\
\text { 1986) }\end{array}$ & $\begin{array}{l}7 \text { industrial sites in the } \\
\text { USA }\end{array}$ & Not specified & $0.0017-0.0055$ /day \\
\hline $\begin{array}{l}\text { (Fernandez-Garcia, } \\
\text { 2012) }\end{array}$ & $\begin{array}{l}\text { Plataforma Solar de } \\
\text { Almeria, Spain }\end{array}$ & trough & $0.001-0.007$ /day \\
\hline (Griffith et al., 2014) & $\begin{array}{ll}27.7^{\circ} \mathrm{S} & 23.05^{\circ} \mathrm{E} \\
\text { (Australia) }\end{array}$ & $\begin{array}{l}0^{\circ} \mathrm{W}, 45^{\circ} \mathrm{W}, 45^{\circ} \mathrm{E}, 2 \mathrm{~m} \\
\text { height }\end{array}$ & $\begin{array}{l}0.0038 \text { /day, } \\
0.0070 \text { /day, } \\
0.0037 \text { /day }\end{array}$ \\
\hline (Tahboub et al., 2011) & $\begin{array}{l}23.6^{\circ} \mathrm{N} 55.2^{\circ} \mathrm{E} \text { (site1) } \\
24.2^{\circ} \mathrm{N} 55.8^{\circ} \mathrm{E} \text { (site 2) } \\
\text { both sites in Abu Dhabi }\end{array}$ & $0^{\circ}, 45^{\circ}, 90^{\circ}, 1 \mathrm{~m}$ height & $\begin{array}{l}0.024 \text { /day (mean value } \\
\text { for all mirrors exposed } \\
\text { at site 1), } 0.021 \text { /day } \\
\text { (site 2) }\end{array}$ \\
\hline (Wolfertstetter, 2017) & $\begin{array}{l}\text { Plataforma Solar de } \\
\text { Almeria, Spain (PSA) } \\
\text { Missour, } \quad \text { Morocco } \\
\text { (MOR) }\end{array}$ & $\begin{array}{l}\text { Tracked mirror } \\
\text { TraCS instrument }\end{array}$ & $\begin{array}{l}1.5 \text { year average } \\
\text { soiling rates: } \\
0.0052 \text { /day (PSA) } \\
0.0063 \text { /day (MOR) }\end{array}$ \\
\hline
\end{tabular}

There exist only few studies investigating the impact of SR and cleaning action on the financial yield of concentrating solar power (CSP) plants. Kattke and Vant-Hull, (2012) assume a constant yearly SR in order to determine an optimal target cleanliness value for solar tower plants that shall not be underrun during operation. The cost for one complete solar field cleaning is taken from (Cohen et al. 1999) and the solar field size is one of the adjusted variables. They conclude that the optimal results are obtained with a target cleanliness of $0.97-0.98$ and a solar field that is $3-4 \%$ larger than if cleanliness were assumed as 1.

Heimsath et al. (2010) and Crawford et al. (2012) determined an optimal cleaning frequency for parabolic trough plants with only a few assumptions regarding cleaning costs and financial loss due to reduced reflectivity. They used different constant SR to show that the resulting cleaning frequency is highly dependent on SR. They concluded that constant monitoring of the average solar field cleanliness $\left(\xi_{\text {field }}\right)$ is necessary for the best operation of a CSP plant.

However, the application of a constant SR can cause errors because high DNI days might actually coincide with below average $\xi_{\text {field }}$. On a day with high DNI, a low cleanliness can reduce power plant output more (in absolute values) than on a cloudy day. Time resolved SR data can be acquired in a time efficient manner with the TraCs instrument that compares the directly measured direct normal irradiance (DNI) to the irradiance measured after reflection on a sample mirror (Wolfertstetter et al., 2012), (Wolfertstetter et al., 2014).

In a recent study (Wolfertstetter, 2017) based on time resolved SR data acquired with TraCS in southern Spain cleaning strategies, i.e. cleaning parameters such as the number of cleaning units and the frequency of cleaning have been compared by the financial benefit. It could be shown that the assumption of a constant SR as well as constant cleanliness values leads to substantial errors up to $9 \%$ of the total net profit of the project. The selection of the best cleaning strategies can improve the profits of a CSP project by up to $2.6 \%$ compared to constant cleaning strategies with a previously fixed number of vehicles. 
The histograms of two one-year datasets of daily soiling rates measured with TraCS at two different sites are shown in Fig. 58. They show different distributions of SR. The Moroccan site shows significantly more occurrences of high SR $<-0.02$ /day than the PSA site. This shows the different soiling characteristics and thus cleaning needs of the two sites although the average SR differs by only 0.001 /day (see Table 4). These results emphasize the importance of a detailed soiling and cleaning analysis in both project development and operation phases.

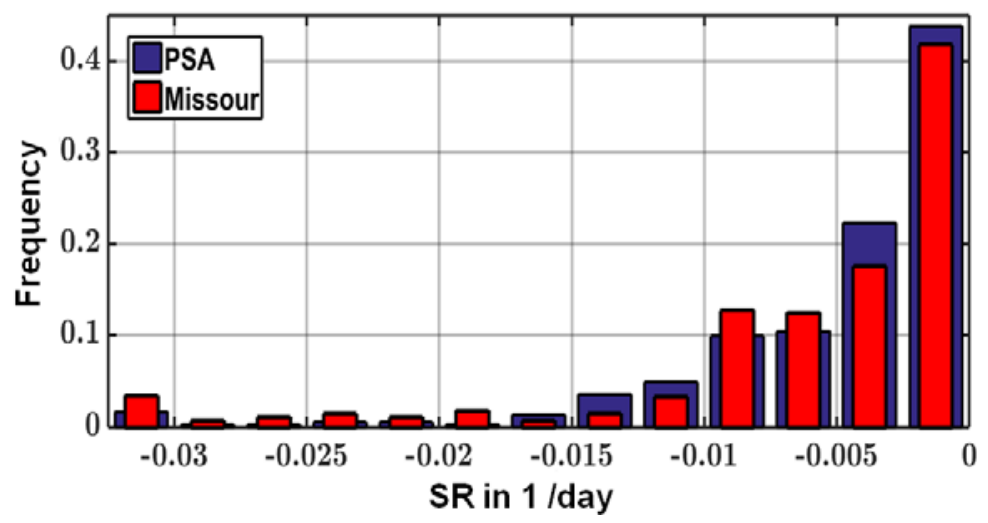

Fig. 58: Histogram of daily soiling rate measurements during 1 year at Plataforma Solar de Almeria in southern Spain (PSA) and Missour, Morocco acquired with the TraCS instrument.

\section{Heliostat cost}

In a review of costs in 2013, Coventry et al. (2016, paragraph 16) summarised the results of several heliostat cost studies. The cost of heliostats for high production rates at that time were estimated to be in the range of $150-200 \mathrm{USD} / \mathrm{m}^{2}$. Although there is little published about current heliostat costs, there is evidence both anecdotally and based on significantly lowered LCOE bid prices (e.g. SolarReserve's Copiapo plant in Chile in August 2016 at 63/MWh), that heliostat costs have been reduced significantly since 2013. This is supported by claims from some commercial heliostat developers of costs at or below $100 \mathrm{USD} / \mathrm{m}^{2}$ (Stellio $\$ 5.1 .8$, Vast Solar \$5.1.14). With the new approaches target cost of $75 \$ / \mathrm{m}^{2}$ (which sounded utopian when first demanded by the SunShot initiative) seem to be realistic

\section{Summary and outlook}

The amount and variety of creative ideas to drive heliostat field cost down is impressive. 21 heliostat designs based on many different approaches for cost reduction were presented. For the heliostat field layout, canting, control, qualification, and cleaning a huge amount of literature is available with smart solutions. Significant advances have been made in recent years to the understanding of wind loads, the impact of turbulence, and dynamic wind loading impact on heliostats. It is clear from the continued evolution of commercial heliostat designs that strong progress is being achieved with manufacturing methods, although details about new manufacturing strategies are often kept secret. Nonetheless, commercial suppliers of heliostat technologies are now claiming costs around $100 \mathrm{USD} / \mathrm{m}^{2}$ or even around $75 \mathrm{USD} / \mathrm{m}^{2}$ for one supplier and for some new approaches, which represents an encouraging downward over the past few years.

\section{Acknowledgment}

We acknowledge Gregory Kolb for his valuable comments for improvement of the paper. 


\section{References}

Abengoa, http://www.abengoa.com/htmlsites/boletines/en/junio2012/produccion/, accessed January 2017.

Alon, L., Ravikovich, G., Mandelbrod, M., Eilat, U., Schop, Z., Tamari, D., 2014, Computer-Based Management of Mirror-Washing in Utility-Scale Solar Thermal Plants. ASME. Energy Sustainability, Volume 1; doi: 10.1115 / ES2014-6562.

Andraka, C.E., 2008, Cost/Performance Tradeoffs for Reflectors Used in Solar Concentrating Dish Systems. In: ASME 2nd International Conference on Energy Sustainability, Jacksonville, Florida

Andraka, C. E., et al., 2014, Rapid reflective facet characterization using fringe reflection techniques, Journal of Solar Energy Engineering, 136, No. 1. 011002.

AORA, 2017a, http://aora-solar.com/active-sites/\#!prettyPhoto/5/, accessed January 2017.

AORA, 2017b, http://aora-solar.com/news/?download\&uri=http://aora-solar.com/wp-content/uploads/ 2012/11/PSA51.jpg, accessed January 2017.

Arantzasu, F.-G., 2012, Estudio De La Reflectancia Especular En Plantas De Captadores Solares Cilindroparabolicos, PhD Thesis.

Arqueros, F.; Jimenez, A.; Valverde, A., 2003. A novel procedure for the optical characterization of solar concentrators. Solar Energy, 75, 135-142.

Balz, M., Göcke, V., Keck, T., von Reeken, F., Weinrebe, G., Wöhrbach, M., 2015, Stellio Development, Construction and Testing of a Smart Heliostat, SolarPACES 2015 conference, Cape Town, South Africa.

Banks D., 2011, Measuring peak wind loads on solar power assemblies. The 13th. International Conference on Wind Engineering, Amsterdam, Netherlands.

Belhomme, B., Pitz-Paal, R., Schwarzbözl, P., Ulmer, S., 2009, A New Fast Ray Tracing Tool for HighPrecision Simulation of Heliostat Fields. Journal of Solar Energy Engineering.

Bender, B., Chalifoux, B., Schneider, D., 2011, Suspension Heliostat Material Efficiency, Proc. SolarPACES 2011 conference, Granada.

Berenguel, M., Rubio, F.R., Valverde, A., Lara, P.J., Arahal, M.R., Camacho, E.F., López, M., 2004, "An Artificial Vision-Based Control System for Automatic Heliostat Positioning Offset Correction in a Central Receiver Solar Power Plant", Solar Energy 76, pp. 563-575.

Berg, R.S., 1978, Heliostat Dust Buildup And Cleaning Studies, Sandia laboratory report 78-0510; March, 1978). p. 1-34.

Bern, G., Schöttl, P., Heimsath, A., Nitz, P., 2016, Novel Imaging Closed Loop Control Strategy for Heliostats, SolarPACES 2016, Abu Dhabi, UAE.

Biggs, F., Vittitoe, C. N., 1979, Helios Model for the Optical Behavior of Reflecting Solar Concentrators. Albuquerque, NM. SANDIA report No. SAND-76-0347.

Biryukov, S., Faiman, D., Goldfeld, A., 1999, An Optical System for the Quantitative Study of Particulate Contamination on Solar Collector Surfaces, Solar Energy 66, no. 5: 371-78.

Bode, S.-J., Gauché, P., 2012, Review of Optical Software for use in Concentrating Solar Power Systems, in SASEC (South African Solar Energy Conference) 2012, Stellenboch, South Africa, 2012.

BrightSource Energy, 2010, http://www.brightsourceenergy.com/image-downloads, accessed June, 2010.

BrightSource Energy, 2012, http://www.brightsourceenergy.com/image-downloads, accessed June, 2012.

BrightSource Energy, 2015, http://www.brightsourceenergy.com/, accessed December 2015. 
BrightSource Energy, 2016, BrightSource Launches Next Generation Solar Field Technolgies, http://www.brightsourceenergy.com/stuff/contentmgr/files/0/752fe6e5bb0f68491caf055e3aaf2d85/pdf/ brightsource_energy_solar_field_technology_advances_final_032116.pdf.

Buchroithner, A., Ganapathi, G., Palisoc, A., Greschik, G., 2016, Solarstrom für 6 Cent/kWh: Entwicklung eines low-cost Heliostaten mit Dünnfilmreflektor am Nasa Jet Propulsion Laboratory, 14. Symposium Energieinnovation, 10.-12.02.2016, Graz/Austria.

Buck, R., 2014, Heliostat field layout improvement by nonrestricted refinement. Journal of Solar Energy Engineering, 136(2), 021014.

Buck, R., Teufel, E., 2009, Comparison and Optimization of Heliostat Canting Methods. Journal of Solar Energy Engineering, 131(1), doi:10.1115/1.3027500.

Burisch, M., Gomez, L., Olasolo, D., Villasante, C., 2016a, Heliostat kinematic system calibration using uncalibrated cameras, SolarPACES 2016, Abu Dhabi, UAE.

Burisch, M., Sanchez, M., Olarra, A., Villasante, C., 2016b, Heliostat Calibration Using Attached Cameras and Artificial Targets. In V. Rajpaul, \& C. Richter (Eds.), AIP Conference Proceedings (Vol. 1734, No. 1, p. 130005). AlP Publishing.

Cabanillas Saldana, J.P., 2010, Dual-Axis Solar Tracker, US patent US 2010/0024861 A1.

Ceron Garcia, F.J., 2013, Solar Tracker Including an Azimuth Rotation Mechanism, international patent, WO2013178850A1.

Christian, J., Moya, A., Ho, C., Andraka, C., \& Yuan, J., 2015, Probabilistic Analysis to Quantify Optical Performance and Error Budgets for Next Generation Heliostats, Journal of Solar Energy Engineering, 137(3), 031014.

Cohen, G. E., Kearny, D., Kolb, G.J., 1999, Final Report on the Operation and Maintenance Improvement Program for Concentrating Solar Power Plants, Technical Report, SAND99-1290, Sandia National Laboratories.

Collado, F. J., Guallar, J., 2012. Campo: Generation of Regular Heliostat Fields. Renewable Energy, 46, 49-59.

Collins, M., 2016, "Design and Simulation of a Sensor for Heliostat Field closed loop control", SolarPACES.

Convery, M.R., 2011, Closed-loop control for power tower heliostats, Proc. SPIE 8108, High and Low Concentrator Systems for Solar Electric Applications VI, 81080M; doi:10.1117/12.898564; http://dx.doi.org/10.1117/12.898564.

Cook, N. J., 1985, The Designer's Guide to Wind Loading of Building Structures. Part 1: Background, Damage, Wind Data and Structural Classification. Butterworths, London.

Coquand, M., Caliot, C., Hénault, F., 2016, Backward-gazing method for heliostats shape Measurement and calibration, SolarPACES 2016, Abu Dhabi, UAE.

Cordes, S., Prosinečki, T.C., Wieghardt, K., 2012, An approach to competitive heliostat fields. In: 18th annual SolarPACES symposium. 2012. Marrakesh.

Coventry, J., Pye, J., 2013, "Heliostat cost reduction - where to now ?", Energy Procedia, SolarPACES 2013, Las Vegas, Arizona, USA.

Coventry, J., Campbell, J., Xue, Y.P., Hall, C., Kim, J.S., Pye, J., Burgess, G., Lewis, D., Nathan, G., Arjomandi, M., Stein, W., Blanco, M, Barry, J., Doolan, M., Lipinski, W., Beath, A., 2016, "Heliostat Cost Down Scoping Study - Final Report", ANU document reference: STG-3261 Rev 01, ASTRI, Australia. 
Crawford, J., Stewart, J., and J. Pérez-Ullivarri, J., 2012, A Comparison of Three Portable Reflectometers for Use in Operations and Maintenance of CSP Plants, Proceedings of SolarPACES conference 2012, Marrakech, Morocco.

CSIRO, 2012, http://www.scienceimage.csiro.au/mediarelease/mr10-124.html, accessed June 2012.

CSP Today 2013a, CSP Solar Tower Report.

CSP today, 2013b, CSP Today Industrial Applications Guide: Desalination and Enhanced Oil Recovery, http://csptoday.com/csp/pdf/CSP-Desalination0813_Sevilla_EN.pdf, accessed February, 2015.

Deck, M., 2017, SolarReserve, personal communication.

Deffenbaugh, D.M., Green S.T., Svedeman S.J., 1986, The Effect of Dust Accumulation on LineFocus Parabolic Trough Solar Collector Performance, Solar Energy 36, no. 2: 139-46.

Delport, G.W., Craig, K.J., 2016, Structural analysis of dynamic response of HelioPOD under wind loading, 4th Southern African Solar Energy Conference (SASEC 2016), Stellenbosch, South Africa.

Diver, R.B., Grossman, J.W., 1998, Sandwich Construction Solar Structural Facets, Report number SAND98-2845C.

Dyrbye, C., Hansen, S.O., 1997. Wind Loads on Structures. Wiley \& Sons, Chichester, England, p. 186.

Ecilimp Termosolar, http://termosolar.ecilimp.com/ecilimp_termosolar.html, accessed January 2017.

Emes, M.J., Arjomandi, M., Nathan, G.J., 2015. Effect of Heliostat Design Wind Speed on the Levelised Cost of Electricity from Concentrating Solar Thermal Power Tower Plants, Solar Energy 115, 441-451.

Endres, A., 2017, http://www.zeit.de/wirtschaft/2016-11/ouarzazate-solarthermie-marokkoenergiewende, accessed January 2017.

Fernandez-Garcia, A., 2012, Estudio de la Reflectancia Especular en Plantas de Captadores Solares Cilindroparabolicos. Coleccion documentos, CIEMAT.

Fernández-García, A., Álvarez-Rodrigo, L., Martínez-Arcos, L., Aguiar, R., Márquez-Payés, J.M., 2014, Study of Different Cleaning Methods for Solar Reflectors Used in CSP Plants, Energy Procedia, Volume 49, Pages 80-89, ISSN 1876-6102

Fernández-Reche, J.; Valenzuela, L., 2012, Geometrical assessment of solar concentrators using close-range photogrammetry, Energy Procedia, 30. Jg., S. 84-90.

Fisher, J., 2015, Apparatus and Method for Heliostat Support, international patent, WO 2015/143494 A1.

Freeman, J., Shankar, B., Sundaram, G., 2016, Inverse Kinematics of a Dual Linear Actuator Pitch/Roll Heliostat, SolarPACES 2016 conference, Abu Dhabi, UAE.

Frenell, 2017, http://www.frenell.de/core-technologies/\#collapse-3, accessed February 2017.

Garcia, P., Ferriere, A., Bezian, J.-J. 2008. Codes for Solar Flux Calculation Dedicated to Central Receiver System Applications: A Comparative Review. Solar Energy, 82(3), 189-197.

Gary, J., Turchi, C., Sieger, N., 2011. CSP and the DOE Sunshot Initiative, Proc. SolarPACES 2011 conference, Granada, Spain.

Ghanadi, F., Yu, J., Emes, M., Arjomandi, M., Kelso, R., 2016, Numerical Investigation of Wind Loads on an Operating Heliostat, SolarPACES 2016 conference, in press.

Gong, B., Li, Z., Wang, Z., Wang, Y., 2012, Wind Induced Dynamic Response of Heliostat, Renewable Energy, 38 (1), pp. 206-213. 
Gong, B., Wang, Z., Li, Z., Zang, C., Wu, Z., 2013. Fluctuating Wind Pressure Characteristics of Heliostats, Renewable Energy, 50, pp. 307-316.

Gonzáles, R.S., Flamant, G., 2014. Technical and Economic Feasibility Analysis of Using Concentrated Solar Thermal Technology in the Cement Production Process: Hybrid Approach-A Case Study, Journal of Solar Energy Engineering 136.

Greenway, 2014, http://www.greenwaycsp.com/en/home.aspx, accessed January 2014.

Greenway, 2017, http://www.greenwaycsp.com/en/technology/intelligent-heliostats.aspx, accessed January 2017.

Griffith, D.T., Moya, A.C., Ho, C., Hunter, P.S., 2011, Structural dynamics testing and analysis for design evaluation and monitoring of heliostats. In Proc. of the 5th Int. Conference on Energy Sustainability, ES2011-54222, pp. 567-576, ASME, Washington, DC, Aug. 7-10 2011.

Griffith, D.,L., Vhengani, and M. Maliage, M., 2014, Measurements of Mirror Soiling at a Candidate Csp Site, Energy Procedia 49: 1371-78.

Gross, F., et al., 2016, "A Universal Heliostat Control System", SolarPACES 2016 conference, in press.

Haberstroh, H., Keck, T., Weinrebe, G., Wöhrbach, M., Husenbeth, C., von Reeken, F., Balz, M., 2012, Optimization of Heliostat Axes Orientations to Reduce Annual Angular Ranges, in SolarPACES 2012, AIP, Marrakesh, Morocco.

Hardt, M., Martínez, D., González, A., Garrido, C., Aladren, S., Villa, J.R., Saenz, J., 2011, HECTOR Heliostat Cleaning Team-Oriented Robot, Proc. SolarPACES 2011 conference, Granada.

Harper, P.J., et al. Use of Mems and Optical Sensors for Closed Loop Heliostat Control, 2016, http://aip.scitation.org/doi/abs/10.1063/1.4949162.

Heimsath, A., Heck, M., Morin, G., Kiewitt, W., Platzer, W., 2010, Soiling of Aluminum and Glass Mirrors under Different Climatic Conditions and Techno-Economic Optimization of Cleaning Intervals, SolarPACES 2010 conference, Perpignan, France.

Heimsath, A., Schmid, T., Nitz, P., 2015, Angle resolved specular reflectance measured with VLABS, Energy Procedia 69, 1895 - 1903.

Helio100, 2017, http://helio100.sun.ac.za/?page_id=349, accessed January 2017.

HelioTower, 2017, http://heliotower.com/heliostat.html, accessed January 2017.

Ho, C.K., 2008. Software and Codes for Analysis of Concentrating Solar Power Technologies. SANDIA Report. Albuquerque, New Mexico, Sandia National Laboratories. SAND2008-8053.

Ho, C., Griffith, D. T., Sment, J., Moya, A. C., Christian, J. M., Yuan, J. K., \& Hunter, P. S., 2012, Dynamic testing and analysis of heliostats to evaluate impacts of wind on optical performance and structural fatigue, Proceedings of Solar Power and Chemical Energy Systems (SolarPACES) 2012 Conference, Marrakech, Morocco.

Holze, C., Brüggen, H., Misseeuw, R., Cosijns, B., Albers, R., Isaza, D., Buck, R., Pfahl, A., 2012, Laminated Solar Thin Glass Mirror Solution for Cost Effective CSP Systems, SolarPACES 2012 Conference, Marrakesh, Morocco, September 11-14.

Huss, S., Traeger, Y. D., Shvetz, Z., Rojansky, M., Stoyanov, S. and Garber, J., 2011, Evaluating effects of wind loads in heliostat design. In Proc. of the 17th SolarPACES Int. Conference, Granada, Spain, Sept. 20-23 2011.

Izygon, M., Armstrong, P., Nilsson, C., \& Vu, N., 2011, TieSOL-a GPU-based suite of software for central receiver solar power plants. Proceedings of SolarPACES.

Kaimal, J., Wyngaard, J., Izumi, Y. and Cote, O., 1972, Spectral characteristics of surface-layer turbulence. J. Royal Meteorol. Soc., 96, pp. 563-589. 
Kaiser, A., 2011, Reflektivitätsmessungen und Waschfahrzeugauswahl in einem ParabolrinnenKraftwerk. Bachelor thesis, University of Applied Sciences Munich.

Kattke, K., Vant-Hull, L., 2012, Optimum Target Reflectivity for Heliostat Washing." In SolarPACES conference Marrakech, Morocco.

Kiera, M., 1989, Heliostat Field: computer codes, requirements, comparison of methods. In: Becker, M., Böhmer, M. (Eds.): GAST - The Gas-Cooled Solar Tower Technology Program. Proceedings of the Final Presentation. Springer Verlag, Berlin.

King, D.L.; Arvizu, D.E., 1981. Heliostat characterization at the central receiver test facility. J. Sol. Energy Eng. 103, 82-88.

Kistler, B.L., 1986, A user's manual for DELSOL3: a computer code for calculating the optical performance and optimal system design for solar thermal central receiver plants. Sandia National Laboratories, Sandia Report No. SAND86-8018.

Kolb, G.J., Jones, S.A., Donnelly, M.W., Gorman, D., Thomas, R., Davenport, R., Lumia, R., 2007. Heliostat Cost Reduction Study, SANDIA Report SAND2007-3293, Albuquerque, New Mexico, USA.

Kolb, G.J., 2017, personal communication.

Kribus, A., Vishnevetsky, I., Yogev, A., Rubinov, T., 2004, Closed loop control of heliostats, Energy 29, 905-913.

Kubisch, S., Randt. M., Buck, R., Pfahl, A., Unterschütz, S., 2011, Wireless Heliostat and Control System for Large Self-Powered Heliostat Fields", SolarPACES conference 2011, Granada, Spain.

Kutscher, C., 2013, Low-Cost Heliostat for Modular Systems. In: Sunshot CSP program review. 2013. Phoenix, Arizona

Landman, W.A., Gauché, P., Malan, K., Larmuth, J.N., Bode, S.J., Mouzouris, M., Dreijer, J., Kotze, J.P., 2015, On the Development of a Local Heliostat Technology for the Concentrating Solar Power Industry, POWER-GEN Africa 2015.

Larmuth, J.N., Landman, W.A., Gauché, P., 2015, A Top-down Approach to Heliostat Cost Reduction, SolarPACES 2015 conference.

Lata, J., Alcalde, S., Fernandez, D., Lekube, X. 2010, First Surrounding Field of Heliostats in the World for Commercial Solar Power Plants - Gemasolar. In: Proc. of 16th International SolarPACES Symposium 2010, Perpignan.

Lata Pérez, J.M., 2010, Heliostat Facet, US Patent US020100265602A1.

Lecube Inchausti, X., Villar-Roel Pinedo, E., Lata Pérez, J.M., 2016, Azimuthal Rotation Mechanism for Solar Trackers, international patent WO 2016/000895 A1.

Lehmann, A., 2017, Jan., personal communication.

Lehmann A, Allenspach, P. 2012, Toroidal Heliostat, international patent, WO 2012/139169 A1.

Lehmann, A, Shirvington, T, Allenspach, P. 2012, Development and Validation of the Passive Adjustment Toroidal Heliostat (PATH). In: 50th annual Australian Solar Coucil (AuSES) conference, Melbourne.

Li, L., Coventry, J., Bader, R., Pye, J., Lipiński, W., 2016, Optics of Solar Central Receiver Systems: A Review. Optics express, 24(14).

Liedke, P, Lewandowski, A., Pfahl, A., Hölle, E., 2015, Precise Low Cost Chain Gears for Heliostats, SolarPaces 2015.

Lipps, F. W., Vant-Hull, L. L., 1978. A Cellwise Method for the Optimization of Large Central Receiver Systems, Solar Energy, Vol. 20, pp. 505-516. 
Lovegrove, K., Stein, W., 2012. Concentrating Solar Power Technology - Principles, Developments and Applications, Woodhead Publishing Series in Energy: Number 21, Oxford, Cambridge, Philadelphia, New Delhi.

Luhmann, T., Robson, S., Kyle, S., 2006, Close Range Photogrammetry: Principles, Techniques and Applications, Whittles Publishing, Caithness, Scotland.

Lumley, J. and Panofsky, H., 1964, The Structure of Atmospheric Turbulence. Interscience Publishers, New York.

Mancini, T.R., Heller, P., Jones, S., Romero, M., 2000. Catalog of Solar Heliostats, SolarPACES report No. III-1/00.

Mavis, C.L., 1988, 10 MWe Solar Thermal Central Receiver Pilot Plant Heliostat and Beam Characterization System Evaluation, November 1981-December 1986, SAND 87-8003, Sandia National Laboratories, Livermore, CA.

Meyen, S., et al, 2013, Parameters and method to evaluate the solar reflectance properties of reflector materials for concentrating solar power technology, SolarPACES Guideline version 2.5, June 2013, http://www.solarpaces.org/images/pdfs/201306_SolarPACES-Reflectance-Guidelines-V2_5.pdf.

Meyen, S., Lüpfert, E., Pernpeintner, J., Fend, T., 2009, "Optical characterisation of reflector materials for concentrating solar power technology", 15th International SolarPACES Symposium 15.-18. Sept. 2009, Berlin, Germany.

Monreal, A., et al. EASY, 2014, An Innovative Design for Cost Effective Heliostats/Solar Fields, Energy Procedia 49, 174-183.

Monterreal, R., Enrique, R., Fernández-Reche, J., 2016, An Improved Methodology for Heliostat Testing and Evaluation at the Plataforma Solar de Almería, SolarPACES 2016, Abu Dhabi, UAE.

Monterreal R., Garcia G., Romero M., Barrera G., 1997, Development and Testing of a $100 \mathrm{~m}^{2}$ GlassMetal Heliostat with a new Local Control System. Solar engineering, Washington, DC, p. 251-260.

Neumann, A., Monterreal, R., 1992, Measurement of concentrated solar radiation with the HERMES II System at the PSA," 6th International Symposium on Solar Thermal Concentrating Technologies, Mojacar, Spain, Sept. 28-Oct. 2.

Noone, C.J., Torrilhon, M., Mitsos, A., 2012, Heliostat field optimization: A new computationally efficient model and biomimetic layout. Solar Energy, 86(2), 792-803.

NREL. Web Page, 2017, http://www.nrel.gov/csp/solarpaces/power_tower.cfm, accessed February 2017.

O'Neill, Mark, 3M, 16 Sept. 2014, personal communication.

Padmanathan, P., head of ACWA Power, http://reneweconomy.com.au/2015/saudi-power-giant-seessolar-taking-on-base-load-fossil-fuels-57218, accessed February 28, 2015.

Peterka, J.A., Derickson, R.G., 1992, Wind Load Design Methods for Ground-Based Heliostats and Parabolic Dish Collectors. Tech. Rep. SAND92-7009, Sandia National Laboratories, Albuquerque, NM.

Peterka, J., Tan, Z., Cermak, J. and Bienkiewicz, N., 1989, Mean and peak wind loads on heliostats. Journal of Solar Energy Engineering, 111(2), pp. 158-164, 1989.

Pettit, R.B., Freese, J.M., Mahoney, A.R., 1983a, The development of a portable specular reflectometer for monitoring solar mirror materials, SPIE, Vol. 428.

Pettit, R., Vittitoe, C., Biggs, F. ,1983b, Simplified Calculational Procedure for Determining the Amount of Intercepted Sunlight in an Imaging Solar Concentrator. ASME, Transactions, Journal of Solar Energy Engineering, 105, 101-107. 
Pettit, R., Freese, J., Roth, E., 1981, Studies of Dust Accumulation on Solar-Mirror Materials, Sandia National Labs., Albuquerque, NM (USA), SAND-81-0075C; CONF-810137-1.

Pfahl, A., 2014. Survey of Heliostat Concepts for Cost Reduction, Solar Energy Engineering, 136.

Pfahl, A., Brucks, A., Holze, C., 2014. Wind Load Reduction for Light-Weight Heliostats. Energy Procedia 49, 193-200.

Pfahl, A., Buck, R., Gross, F., 2016b, Solarvorrichtung, Verfahren zur Herstellung eines Formteils und Verfahren zur Herstellung eines Formgebungselements, German patent application 102016210569.8.

Pfahl, A., Buck, R., Liedke, P., Gross, F., 2016a, Solar Device, international patent WO 2016202941 A2.

Pfahl, A., Buck, R., Rehschuh, K., 2008, Method for Controlling the Orientation of a Heliostat on a Receiver, Heliostat Apparatus and Solar Power Plant, WO2008/058866A1.

Pfahl, A., Buselmeier, M., Zaschke, M, 2011a. "Wind Loads on Heliostats and Photovoltaic Trackers of Various Aspect Ratios". Solar Energy 85, 2185-2201.

Pfahl, A., Buselmeier, M., Zaschke, M., 2011b. Determination of Wind Loads on Heliostats, Proc. SolarPACES 2011 conference, Granada, Spain.

Pfahl, A., Randt, M., Holze, C., Unterschütz, S., 2013, Autonomous Light-Weight Heliostat With Rim Drives, Solar Energy, 92, pp 230-240.

Pfahl, A., Randt, M., Meier, F., Zaschke, M., Geurts, C.P.W., Buselmeier, M., 2015, A Holistic Approach for low Cost Heliostat Fields. Energy Procedia.

Pfahl, A., Zaschke, M., Geurts, C.P.W., Buselmeier, M., 2017, Impact of Turbulent Energy Spectra Characteristics on Wind Loading of Heliostats and PV Trackers in Stow. Journal of Wind Engineering and Industrial Aerodynamics, in preparation.

Pidaparthi, A.S., Hoffmann, J.E., 2016, Effect of Heliostat Size on the Levelized Cost of Electricity for Power Towers, SolarPACES 2016 conference, Abu Dhabi, UAE.

Pitz-Paal, R., Botero, N. B., Steinfeld, A., 2011, Heliostat field layout optimization for high-temperature solar thermochemical processing. Solar Energy, 85(2), 334-343.

Pottler, K, Lüpfert, E., Johnston, G., Shortis, M., 2005, "Photogrammetry: A powerful tool for geometric analysis of solar concentrators and their components." Journal of Solar Energy Engineering, 127, 1, 94-101.

Pottler, K.; Röger, M.; Lüpfert, E.; Schiel, W., 2008, Automatic Noncontact Quality Inspection System for Industrial Parabolic Trough Assembly. J. Sol. Energy Eng., Vol. 130, No. 1.

von Reeken, F., Weinrebe, G., Keck, T. Balz, M., 2015. Heliostat Cost Optimization Study, SolarPACES 2015 conference.

von Reeken, F., Weinrebe, G., Balz, M., 2016, Special Stiffness Requirements of Heliostats for Regions With High Operational Wind Speeds, SolarPACES 2016 conference, Abu Dhabi, UAE.

Reinholz, A., Husenbeth, C., Schwarzboezl, P., Buck, R., 2016, Optimizing heliostat positions with Local Search Metaheuristics using a ray tracing optical model, in SolarPACES 2016, Abu Dhabi, 2016.

Ricklin, P., Slack, M., Rogers, D., Huibregtse, R., 2014, Commercial Readiness of eSolar Next Generation Heliostat, Energy Procedia 49.

Röger, M., Prahl, C., Ulmer, S., 2012, Heliostat Shape and Orientation by Edge Detection. J. Sol. Energy Eng., Vol. 132, No. 2.

Röger, M., et al., 2017a, Guideline for heliostat performance testing, SolarPACES Task III Guideline, http://www.solarpaces.org/tasks/, publication planned in Solar Energy 2017. 
Röger, M, Prahl, C., Pernpeintner, J., Sutter, F., 2017b, New methods and instruments for performance and durability assessment In: Heller, P. (Ed.), The Performance of Concentrating Solar Power Systems: Modelling, Measurement and Assessment, Woodhead Publishing, 2017 (in press).

Roth, E. P. and Pettit, R. B., 1980, The Effect of Soiling on Solar Mirrors and Techniques Used to Maintain High Reflectivity. Technical report.

Sanchez, M., \& Romero, M., 2006, Methodology for generation of heliostat field layout in central receiver systems based on yearly normalized energy surfaces. Solar Energy, 80(7), 861-874.

Sarver, T., Al-Qaraghuli, A., Kazmerski, L.L., 2013, A comprehensive review of the impact of dust on the use of solar energy: History, investigations, results, literature, and mitigation approaches. Renewable and Sustainable Energy Reviews, 22(0), pp.698-733.

sbp, 2017, http://www.sbp.de/themenwelt/stellio-heliostat-the-state-of-the-art-concentrating-solarpower-csp/, accessed January 2017.

Schell, S, 2011, Design and evaluation of esolar's heliostat fields, Solar Energy, Volume 85, Issue 4, April 2011, Pages 614-619, ISSN 0038-092X.

Schramek, P., Mills, D.R., 2004, Heliostats for maximum ground coverage. Energy, 29(5), 701-713.

Schramek, P., Mills, D. R., Stein, W., Le Lièvre, P., 2009, Design of the heliostat field of the CSIRO solar tower. Journal of Solar Energy Engineering, 131(2), 024505.

Schramek, P., Tanner, A., Lievre, P., 2008, Solar Energy Collector Heliostat, International Patent WO2008/092194A1.

Schwarberg, F., Schiller, M., 2012, Enhanced Solar Mirrors With Anti-Soiling Coating, proceedings of the SolarPACES conference 2012, Marrakech, Morocco.

Schwarzbözl, P., Pitz-Paal, R., Schmitz, M., 2009, Visual HFLCAL - A Software Tool for Layout and Optimisation of Heliostat Fields, presented at the SolarPACES 2009, Berlin.

Shortis, M., Johnston, G., 1997, Photogrammetry: an available surface characterization tool for solar concentrators, part II: assessment of surfaces, Journal of Solar Energy Engineering, 119. Jg., No. 4, S. 286-291.

Silva, J, 2017, New York Times, https://www.nytimes.com/2016/11/14/world/africa/south-africaenergy-solar-wind-nuclear.html?_r=1, accessed January 2017.

Solaflect, 2017, http://www.solaflect.com/solar-solutions/suspension-heliostat/design/, accessed Jan. 2017.

SolarReserve, 2017, http://www.solarreserve.com/en/technology/heliostats-and-collector-field-controls, accessed January 2017.

Stone, K.W.; Jones, S.A., 1999. Analysis of Solar Two tracking error sources. Sandia National Laboratories, SAND99-0239C.

Strachan, J.W., Houser, R.M., 1993, Testing and Evaluation of Large-Area Heliostats for Solar Thermal Applications, Sandia National Laboratories, Albuquerque, NM, SAND92-1381, UC-235.

Sutter, F., Meyen, S., Fernandez-Garcia, A., Heller, P., 2016, Spectral characterization of specular reflectance of solar mirrors. Solar Energy Materials and Solar Cells, 145, pp. 248-254. DOI: 10.1016/j.solmat.2015.10.030.

Tahboub, Z., Dahleh, B., Goebel, O. 2011, Solar Mirrors Soiling Campaign Abu Dhabi, SolarPACES 2011 conference. Granada, Spain.

Téllez, F., Burisch, M., Villasante, C., Sánchez, M., Sansom, C., Kirby, P., Turner, P., Caliot, C., Ferriere, A., Bonanos, C.A., Papanicolas, C., Montenon, A., Monterreal, R., Fernández, J., 2014, "State of the Art in Heliostats and Definition of Specifications - Survey for a low cost heliostat development", STAGE-STE EERA EU project, deliverable 12.1. 
Terrés-Nícoli, J.M., Mans, C.,King, J.P.C., 2014, Dynamic Effects of a Heliostat to Wind Loading, Energy Procedia 49, 1728-1736.

Teufel, E., Buck, R., Pfahl, A., Böing, G., Kunert, J., 2008, "Dimensioning of Heliostat Components Under Wind and Gravity Load: the Map Approach", Proc. SolarPACES 2008 conference, Las Vegas, Nevada.

Thalhammer, E., 1979, Heliostat Beam Characterization System - Update, I.S.A. Reprint 79-692, ISA79 National Conference and Exhibit, Chicago Illinois.

Titan Tracker, 2017a, http://www.titantracker.es/v_portal/apartados/apartado.asp?te=699, accessed January 2017.

Titan Tracker, 2017b, http://www.titantracker.es/v_portal/apartados/apartado.asp?te=704, accessed January 2017.

Titan Tracker, 2017c, http://www.titantracker.es/v_portal/apartados/apartado.asp?te=633, accessed January 2017.

Titan Tracker, 2017d, http://www.titantracker.es/v_portal/apartados/apartado.asp?te=700, accessed January 2017.

Titan Tracker, 2017e, https://www.youtube.com/watch?v=FOp7LXAQqMw, accessed January 2017.

Torresol Energy, 2017, http://www.torresolenergy.com/TORRESOL/imagelibrary/en?initdate=\&enddate=\&categoria=cw4e4122c7d262d, accessed January 2017.

Ulmer, S., 1998, "Influences of Cost Reduction Measures on the Beam Quality of a Large-Area Heliostat", Diploma thesis, IER, University Stuttgart, Stuttgart, Germany.

Ulmer, S., März, T., Prahl, C., Reinalter, W., Belhomme, B., 2011, Automated high resolution measurement of heliostat slope errors, Solar Energy, 85, No. 4, 681-687.

Ulmer, S., Weber, C., Koch, H., Schramm, M., Pflüger, H., Climent, P., Yildiz, H., 2012, HighResolution Measurement System for Parabolic Trough Concentrator Modules in Series Production. SolarPACES 2012. Marrakech, Morocco.

Vásquez-Arango, J.F., 2016, Dynamic Wind Loads on Heliostats. PhD Thesis, RWTH Aachen University.

Vásquez-Arango, J.F., Buck, R., Pitz-Paal, R., 2015, Dynamic Properties of a Heliostat Structure Determined by Numerical and Experimental Modal Analysis. Journal of Solar Energy Engineering, 137 (5), 051001-051001. DOI: 10.1115/1.4030846 ISSN 0199-6231.

Vast Solar, 2016, Presentation at ASTRI Annual Workshop Public Symposium 2016, http://www.astri.org.au/wp-content/uploads/2016/04/ASTRI-20160502-1450-James_Fisher-

Vast_Solar.pdf, accessed January 2017.

Vast Solar, 2017, http://www.vastsolar.com/, accessed January 2017.

Villasante, C., Olasolo, D., Burisch, M., Santana, I., 2016, EASY - Low-cost cable driven heliostat: setup and characterization, SolarPACES 2016 conference, Abu Dhabi, UAE.

Vivar, M., Herrero, R., Antón, I., Martínez-Moreno, F., Moretón, R., Sala, G., Blakers, A.W., Smeltink, J., 2010, Effect of Soiling in Cpv Systems, Solar Energy 84, no. 7: 1327-35.

Walzel, M. D., Lipps, F. W., Vant-Hull, L. L., 1977, A Solar Flux Density Calculation for a Solar Tower Concentrator Using a two-Dimensional Hermite Function Expansion, Solar Energy, Vol. 19, pp. 239253.

Weber, C.; Ulmer, S.; Koch, H., 2104, Enhancements in high-resolution slope deviation measurement of solar concentrator mirrors, Energy Procedia, 49, 2231-2240. 
Wei, X., Lu, Z., Wang, Z., Yu, W., Zhang, H., Yao, Z., 2010, A new Method for the Design of the Heliostat Field Layout for Solar Tower Power Plant. Renewable Energy, 35(9), 1970-1975.

Weinrebe, G., Schmitz-Goeb, M., Schiel, W., 1996, On the performance of the ASM 150 stressed membrane heliostat, American Society of Mechanical Engineers international solar energy conference, San Antonio, TX (US), 31 Mar - 3 Apr 1996, CONF-9603117, ISBN 0-7918-1765-2. ASME, New York, NY (US).

Wieghardt, K., Cordes, S., Langenberg, G., Prosinecki, T., 2014, Solar Thermal Heliostat, international patent, WO 2014/041000 A3.

Wilbert, S., 2009, Weiterentwicklung eines optischen Messsystems zur Bestimmung der Formabweichungen von Konzentrationen solarthermischer Kraftwerke unter dynamischem Windeinfluss. Diplomarbeit (in German language), Rheinische Friedrich-Wilhelms-Universität, Bonn, Germany, DLR, Tabernas.

Williams, R.B., Tanimoto, R., Simonyan, A., et al., 2007, Vibration Characterization Of Self-Cleaning Solar Panels With Piezoceramic Actuation. Collection Of Technical Papers. In: Proceedings of the 48th AIAA/ASME/ASCE/AHS/ASC structures, structural dynamics, and materials conference; 2007. p. 512-20.

Wolfertstetter, F., 2017, Auswirkungen von Verschmutzung auf Konzentrierende Solarthermische Kraftwerke, PhD thesis, RWTH Aachen.

Wolfertstetter, F., Pottler, K., Alami, A., Mezrhab, A., Pitz-Paal, R., 2012, A Novel Method for Automatic Real-Time Monitoring of Mirror Soiling Rates, SolarPACES 2012, Marrakech, Morocco.

Wolfertstetter, F., Pottler, K., Geuder, N., Affolter, R., Merrouni, A., Mezrhab, A., Pitz-Paal, R., 2014, Monitoring of Mirror and Sensor Soiling with Tracs for Improved Quality of Ground Based Irradiance Measurements." Energy Procedia 49: 2422-32).

Yellowhair, J., Andraka, C.E., 2013, Evaluation of advanced heliostat reflective facets on cost and performance. In: 19th annual SolarPACES symposium, Las Vegas.

Yellowhair, J., Ho, C.K., 2010, Heliostat Canting and Focusing Methods: An Overview and Comparison. In: 4th International Conference on Energy Sustainability, Phoenix, Arizona.

Zaibel, R., Dagan, E., Karni, J., Ries, H., 1995, An Astigmatism Corrected Target-Aligned Heliostat for High Concentration, Solar Energy Materials and Solar Cells, 37(2), pp. 191-202.

Zavodny, M., Slack, M., Huibregtse, R., Sonn, A., 2015, "Tower-Based CSP Artificial Light Calibration System", Energy Procedia 69 (2015) 1488-1497; SolarPACES 2014.

Zavoico, A., 2001, Solar Power Tower - Design Basis Document, Sandia SAND2001-2100 2001, http://prod.sandia.gov/techlib/access-control.cgi/2001/012100.pdf. 